\title{
El desmán ibérico Galemys pyrenaicus (É. Geoffroy Saint-Hilaire, 1811) en los Pirineos meridionales
}

\author{
Iberian Desman Galemys pyrenaicus \\ (É. Geoffroy Saint-Hilaire, 1811) in the Southern Pyrenees \\ Galemys pyrenaicus muturluzea \\ (É. Geoffroy Saint-Hilaire, 1811) hego Pirinioetan
}

\author{
Pere Aymerich $^{1 *}$, Joaquim Gosálbez ${ }^{1}$ \\ ${ }^{1}$ Departament de Biologia Animal. Universitat de Barcelona. \\ *Corresponding author: pere_aymerich@yahoo.es
}

\section{RESUMEN}

Se presentan sintéticamente los resultados del conjunto de trabajos sobre el desmán ibérico Galemys pyrenaicus (É. Geoffroy Saint-Hilaire, 1811) realizados en el periodo 2000-2009 en los Pirineos meridionales. Estos trabajos han consistido en el estudio de la distribución y el hábitat (prospección de excrementos en más de 800 tramos fluviales), actividad y uso del espacio (57 individuos marcados con chip de identificación y 33 con radioemisores), y prosiguen con trabajos sobre demografía y genética. Como resultados más interesantes o innovadores para el conocimiento de la especie destacamos los siguientes: 1) El desmán está ausente de gran parte de la vertiente meridional de los Pirineos (Aragón), seguramente por la existencia de barreras biogeográficas que han impedido una recolonización postglacial; es probable que ausencias a gran escala por causas similares se produzcan también en otras zonas geográficas. 2) Dentro del área de distribución se detectan discontinuidades frecuentes a escala local, atribuibles también a causas naturales y no a perturbaciones antrópicas, y además hay indicios de fluctuaciones temporales en la presencia de la especie. 3) Nuestros resultados sobre uso del espacio y actividad invalidan gran parte de lo que se ha publicado previamente sobre estas cuestiones; el desmán se muestra como un animal menos rutinario y de comportamiento más complejo de lo que se suponía. 4) Se han obtenido evidencias de que no es una especie altamente agresiva ni territorial. 5) Los refugios ("nidos") en las riberas son estructuras persistentes y de uso colectivo, seguramente de gran importancia para la conservación de la especie.

PALABRAS CLAVE: Comportamiento, distribución, Galemys pyrenaicus, hábitat, seguimiento.

We present a synthesis of the results obtained from the studies on the desman Galemys pyrenaicus (É. Geoffroy Saint-Hilaire, 1811) in the southern Pyrenees during the period 2000-2009. Distribution, habitat, activity and space use were studied based on the data obtained from faeces prospection in more than 800 river sections, 57 individuals marked with transponders, and 33 radiotracked individuals. Besides, studies on population demography and genetics were also carried out and are currently ongoing. Most intresting results were: 1) The desman is absent from most of the southern slope of the central Pyrenees (aragonese Pyrenees). This is probably due to biogeographical barriers that did not allow a postglacial recolonization of the species. In fact it is likely that large scale absences occur for similar reasons in other geographical areas. 2) Within its distribution range there were frequent discontinuities at local scale probably also due to natural causes and not to human disturbance. Evidences of temporal fluctuations on species presence were also found at local scale. 3) Our results on activity and space use invalidate most of what has been previously published on these aspects; the behaviour of the desman seems to be more complex and not to follow a standard routine. 4) Evidences on a not highly aggressive and territorial behaviour were found. 5) Riverside shelters ("nests") were persistent structures of collective use, and probably of great importance for the conservation of the desman.
\end{abstract}

KEY WORDS: Behaviour, distribution, Galemys pyrenaicus, habitat, monitoring

\section{LABURPENA}

Labur aurkeztuko ditugu hemen 2000-2009 aldian hego-Pirinioetan Galemys pyrenaicus muturluzeari (É. Geoffroy Saint-Hilaire, 1811) buruz egindako lanen emaitzak. Lan horietan aztertu ditugu banaketa eta habitata (gorotzen azterketa 800 ibai-tarte baino gehiagotan), jarduerak eta espazioaren erabilera (57 ale markatu ditugu identifikazio-txip bidez eta 33 irrati-igorgailu bidez) eta jarraitzen dugu espeziearen demografiari eta genetikari buruzko lanak ere egiten. Espeziea ezagutzeko bidean, honako hauek dira lortu ditugun emaitza interesgarri edo berritzaileenak: 1) Ez dago muturluzerik Pirinioen hegoaldeko isurialdearen zatirik handienean (Aragoi), seguru asko oztopo biogeografikoek birkolonizazio postglaziarra eragotzi dutelako. Litekeena da beste eremu geografiko batzuetan ere antzeko arrazoiengatik muturluzeen eskala handiko desagertzeak izatea. 2) Banaketa-eremuaren barruan ohikoak dira etenak tokiko eskalan eta horiek ere arrazoi naturalei egozteko modukoak dira eta ez asaldura antropikoei. Gainera, badira espeziearen presentziak aldi baterako gorabeherak izan dituela dioten zantzuak ere. 3) Espazioaren erabilerari eta jarduerari buruz lortu ditugun emaitzek baliogabetu egiten dute lehendik gai horiei buruz argitaratutakoa. Muturluzearen portaera uste baino neurri txikiagoan da errutinazkoa eta uste baino jokabide konplexuagoa du. 4) Ez dela oso espezie erasokorra eta lurraldekoia esateko ebidentziak lortu ditugu. 5) Ibaiertzetako babeslekuak ("habiak") egitura iraunkorrak eta erabilera kolektibokoak dira eta seguru asko, garrantzi handia izango dute espeziearen kontserbaziorako. 


\section{INTRODUCCIÓN}

El desmán ibérico Galemys pyrenaicus (É. Geoffroy Saint-Hilaire, 1811) es un mamífero insectívoro semiacuático endémico del norte de la Península lbérica y singular por ser uno de los dos únicos representantes actuales junto con el desmán ruso Desmana moschata (Linnaeus, 1758)- del grupo relicto de los Desmaninos, una subfamilia de los Tálpidos. Hasta la década de 1980 esta especie fue estudiada fundamentalmente en los Pirineos franceses, con el resultado de trabajos que son referencias básicas sobre los aspectos más diversos: anatomía y biología (Trutat, 1891; Peyre, 1961; Richard, 1985), actividad, uso del espacio y organización social (Stone, 1985, 1987a, 1987b) y estudio de la distribución (Bertrand, 1994). En el resto del área de distribución de la especie el estudio del desmán fue muy esporádico hasta la última década del siglo XX, pero en los últimos tiempos se ha generado una cantidad notable de trabajos, que han tenido como objetivos conocer la distribución (Castién \& Gosálbez, 1992; Nores et al., 1992; Queiroz et al., 1998; Agirre-Mendi, 2004; Nores, 2007) o el estudio de varios aspectos de su biología y ecología (por ejemplo: Castién \& Gosálbez (1995), GonzálezEsteban et al., (2002), Nores et al., (1998).

En el año 2000 iniciamos una serie de trabajos en los Pirineos meridionales, que tuvieron como primeros objetivos el estudio de la distribución y los hábitats, prosiguieron con la actividad y el uso del espacio, y actualmente se centran en la obtención de datos sobre la organización socioespacial, la demografía y la genética. Una pequeña parte de la información obtenida se ha publicado en forma de artículos sobre aspectos concretos (Aymerich et al., 2001; Aymerich \& Gosálbez, 2002; Aymerich, 2004) o de artículos divulgativos muy sintéticos (Aymerich \& Gosálbez, 2009) y otra parte se trata en artículos científicos actualmente en elaboración, pero existen datos que sólo están disponibles en informes internos de acceso complejo. Transcurrida una década desde el inicio de los trabajos ya disponemos de una visión bastante completa sobre varios aspectos (distribución, hábitat, actividad, uso del espacio a pequeña escala), mientras que la información sobre otras cuestiones aún es parcial (organización social, demografía, genética). Si bien el trabajo aún no está finalizado, el objetivo de esta publicación es hacer una síntesis de los conocimientos generados con estos estudios y ponerlos así a disposición del público interesado en el desmán.

En los apartados siguientes se expone en una u otra medida casi toda la información obtenida hasta ahora, para ofrecer una visión de conjunto del estado de los conocimientos, aunque el tratamiento de los diversos aspectos es desigual. Se desarrollan con mayor atención las cuestiones que no se han publicado ya en artículos de detalle o que está previsto publicar próximamente. Para los aspectos que son tratados en artículos específicos, este trabajo se limita a ofrecer una información sintética, y el lector podrá completar la información consultando las publicaciones ya disponibles o las nuevas publicaciones en preparación cuando estas aparezcan. Estos contenidos se desarrollan en cuatro bloques temáticos:
1) Distribución: metodologías para el estudio de la distribución, interpretación de los datos disponibles y distribución conocida en los Pirineos meridionales.

2) Hábitat: factores que condicionan la presencia del desmán (a escala grande y media, de origen natural y antrópico).

3) Actividad y uso del espacio: información obtenida hasta la actualidad con el seguimiento de individuos de desmán marcados en los Pirineos.

4) Discusión-conclusiones: aspectos a mejorar en el conocimiento del desmán.

\section{DISTRIBUCIÓN \\ Aspectos metodológicos}

Los métodos utilizados para conocer la distribución del desmán son básicamente cuatro: la recopilación de citas seguras de individuos, las encuestas, el trampeo y la prospección de excrementos. Todos estos métodos presentan limitaciones, que condicionan la fiabilidad de los resultados y su aplicación en determinadas escalas espaciales. Hasta ahora, la prospección de excrementos ha demostrado ser el método más efectivo, y el único fiable para establecer de modo sistemático y aceptablemente preciso la distribución del desmán en un momento dado en el conjunto de una cuenca fluvial.

\section{$\underline{\text { Recopilación de citas seguras de individuos }}$}

Este fue el primer método que se usó para establecer la distribución del desmán, y se mantuvo como el principal hasta hace unas tres décadas. Consiste en recopilar todos los datos seguros referentes a individuos de desmán, en general ejemplares conservados en colecciones zoológicas, restos de individuos depredados, observaciones confirmadas por fotografías y capturas (con nasa o pesca eléctrica) realizadas por personas que identifican bien la especie.

Se trata de un método con muchas limitaciones para establecer la distribución real del desmán, ya que los datos suelen ser escasos y muy fragmentarios. La obtención de citas, además, está bastante condicionada por la intensidad en la aplicación territorial de la pesca eléctrica o la pesca con nasas, prácticas que suelen proporcionar capturas esporádicas. Como consecuencia de la escasez de datos obtenidos con este sistema se ha tendido a subestimar la distribución y la frecuencia del desmán, favoreciendo la percepción general de que se trata de una especie muy rara y amenazada. Resulta muy ilustrativo de las limitaciones del método el cambio experimentado en el conocimiento de la distribución en los Pirineos catalanes: hasta hace un cuarto de siglo (Gosàlbez, 1987) no se había confirmado su presencia, que no fue constatada hasta finales de los años 1980 gracias a capturas accidentales (Marsol \& Castells, 1989), y sólo una década después (Aymerich et al., 2001) se verificó mediante prospección de excrementos que estaba extendido por varias cuencas fluviales y que era relativamente frecuente. 
Desde el inicio de nuestros trabajos en el Pirineo catalán en el año 2000 hemos hallado miles de excrementos de desmán y capturado medio centenar de individuos, pero tan sólo ha sido posible obtener 7 nuevas citas seguras por otras fuentes (tres por pesca eléctrica, dos por muerte accidental, una por fotografía y una por filmación)

Este método presenta otras limitaciones notables, que en general causan una sobreestimación del área actualmente ocupada por el desmán, y que hay que tener en cuenta cuando se interpretan los datos: 1) Las citas, además de escasas, son asincrónicas y suelen referirse a períodos temporales muy prolongados, a menudo de varias décadas o de un siglo. Pero es probable que parte de estos datos provengan de zonas donde la especie ya se ha extinguido debido a cambios drásticos en la calidad del hábitat, por lo que la distribución que reflejan algunos mapas obtenidos mediante acumulación de citas históricas estaría sobreestimada. Esta problemática se ha reflejado en el Libro Rojo de los mamíferos de España (Nores, 2007) en relación con la distribución histórica en el Sistema Central y es posible que sea extrapolable a otras zonas como Galicia o partes de la franja cantábrica. 2) Una parte de las citas seguras pueden corresponder a individuos extraviados, que son capturados o hallados muertos muy lejos de las zonas habitualmente ocupadas por la especie. En relación con esta posibilidad, Bertrand (1994) indica que varias citas a muy baja altitud en los ríos Adour y Tec -en los dos extremos de los Pirineos- parecen atribuibles a individuos que fueron arrastrados río abajo por la crecida del caudal a causa del deshielo en las montañas (abril-mayo). 3) En algunas ocasiones hay incertidumbre sobre el origen real de los ejemplares conservados en colecciones, por lo que existe el riesgo de introducir errores en la distribución supuesta, que se pueden prolongar durante décadas. Es el caso de una cita histórica de un ejemplar supuestamente procedente de la sierra prepirenaica de Guara (Cabrera, 1914), en Aragón, área sin citas posteriores de desmán y con hábitats muy poco adecuados; actualmente se considera que lo más probable es que esa cita derive de una confusión en la procedencia del ejemplar, pero se mantuvo como válida hasta hace poco. Otro caso de procedencia dudosa es también de Aragón y se refiere a un ejemplar hallado muerto en una calle de Jaca, lejos del río, y que se conserva en el Instituto Pirenaico de Ecología; la prospección sistemática de la cuenca del río Aragón en 2003, en la cual se sitúa Jaca, no permitió confirmar ningún indicio de la especie (Aymerich \& Gosálbez, 2004a), por lo que no se descarta que el ejemplar conservado procediera de cautividad

La recopilación de citas, pues, se puede considerar útil para tener información anecdótica sobre la distribución del desmán, o como máximo sobre la presencia a escala de grandes zonas geográficas. Sin embargo no es válida para conocer con un mínimo detalle la distribución a escala regional (cuenca fluvial o río particular), ni tampoco sirve para conocer la distribución del desmán en un período temporal corto, de unos pocos años, ya que la obtención de datos es demasiado lenta.

\section{Encuestas}

Las encuestas han sido utilizadas habitualmente, de forma sistemática o irregular, como complemento a la recolección de citas seguras y al trampeo, con el objetivo de establecer la distribución del desmán sobre grandes territorios. Los mapas de referencia sobre la distribución en España (Nores et al., 1992; Nores, 2007) y Francia (Bertrand, 1993, 1994) incluyen una proporción considerable de citas obtenidas mediante encuestas, mayor en el caso español (se trata de un mapa obtenido por acumulación de datos muy heterogéneos) que en el francés (realizado de un modo más sistemático, y con mucha información aportada gracias a la prospección de excrementos).

El gran problema de este método es que tiene una fiabilidad muy baja, porque muchos de los informadores no son capaces de identificar el desmán y lo confunden con otras especies. Estas confusiones se dan con alta frecuencia incluso con personas que en principio pueden ser consideradas altamente fiables, como pueden ser naturalistas, pescadores, guardas de caza o pesca. Nuestra experiencia es que estos presuntos "informadores fiables" confunden muy a menudo el desmán con otras especies (es suficiente comentar que alguno estaba convencido de haber visto desmanes en las copas de los árboles). La mayor parte de los errores de identificación son atribuibles a confusiones con musarañas acuáticas (Neomys sp.) o rata de agua Arvicola sapidus Miller, 1908, y son relativamente comprensibles porque muchas personas desconocen la presencia de estos micromamíferos semiacuáticos en los ríos de montaña, por lo que tienden a creer que cualquier observación fugaz de un pequeño mamífero dentro del agua es de un desmán. En cualquier caso, el problema no es tanto la fiabilidad de los informadores como la aceptación como válidas de muchas observaciones en las obras de referencia sobre distribución, que en ocasiones aplican un filtrado deficiente de los datos. Este problema resulta patente, por ejemplo, en el primer trabajo global sobre distribución del desmán en España (Nores et al., 1992), que con seguridad incluye un número significativo de citas erróneas, algunas de las cuales (cuenca del Llobregat en Cataluña, varias del Pirineo aragonés) se han perpetuado hasta los mapas de referencia más recientes (Nores, 2007). El resultado de nuestros trabajos en los Pirineos permite asegurar que muchas supuestas citas de desmán de varias cuencas fluviales (Llobregat, Noguera Ribagorçana, Cinca,...) son debidas a confusiones con musarañas de agua -abundantes o frecuentes en casi todos los ríos con supuestas citas de desmán (ver, por ejemplo, Tabla 4) o, más raramente, rata de agua. En zonas extrapirenaicas también se pueden descartar las presuntas citas del macizo del Moncayo (Sistema Ibérico), donde la prospección sistemática de todos los ríos ha permitido constatar una alta frecuencia de Neomys anomalus Cabrera, 1907, pero ningún indicio de desmán (Aymerich \& Gosálbez, 2004a). Desconocemos cual es la proporción de citas erróneas en otras áreas geográficas, pero hay motivos para suponer que puede ser apreciable y que han incidido significativamente en la delimitación de los "mapas históricos" del desmán, que sería conveniente revisar. 
Considerando el alto riesgo de introducir datos erróneos, las encuestas son un método que no tiene un nivel de fiabilidad aceptable, y que se debe excluir como fuente de información directa sobre la distribución del desmán. Como máximo, debería ser utilizado para obtener datos previos sobre zonas de presencia probable, que posteriormente tienen que ser confirmados mediante captura o localización de excrementos. Pero en ningún caso se puede aceptar una cita verbal aparentemente fiable como único dato para establecer la presencia de desmán en un determinado río.

\section{Trampeo}

El trampeo es un método desarrollado a mediados del siglo XX en el Pirineo francés, consistente en la captura de desmanes con nasas semisumergidas, derivadas de las usadas tradicionalmente para la pesca (Fig 1). El objetivo principal es obtener desmanes para su estudio, pero también permite conocer la distribución. Mediante redes se cierra transversalmente el paso de los ríos, de forma total o parcial, y los desmanes entran en las nasas en sus desplazamientos, sin necesidad de cebo alimentario. Si resulta viable cerrar de modo completo el río y existen desmanes en ese tramo, la probabilidad de captura es del 100\%. Si no se puede cerrar el río de modo completo la probabilidad es también alta, y se acerca al 100\% si se mantienen varias trampas durante dos o más noches consecutivas. Este método ha sido usado especialmente para confirmar la presencia del desmán en un determinado río o tramo de río, en lugares donde ya existían informaciones previas de observaciones probables. En los trabajos sobre distribucion a gran escala se ha utilizado como complemento de las encuestas (Peyre, 1956; Richard, 1976; Nores et al., 1992) o de la prospección de excrementos (Bertrand, 1994).

La fiabilidad del trampeo es alta pero resulta poco eficiente, ya que requiere un gran esfuerzo para la instalación de las trampas (el tiempo necesario es de unos 30-60 minutos por trampa para 2 personas experimentadas) y para su control (si se quiere evitar la muerte por inanición de los desmanes es necesario revisar las trampas cada 3-4 horas). El rendimiento o eficiencia del trampeo, expresado como captura por trampa y noche (número desmanes capturados/número de trampas $x$ número de noches) es muy variable, en función de la abundancia de desmanes, de las características del río y de la habilidad en la instalación de las trampas. Existe poca información publicada sobre el rendimiento, y en general es anecdótica, puesto que no se re-

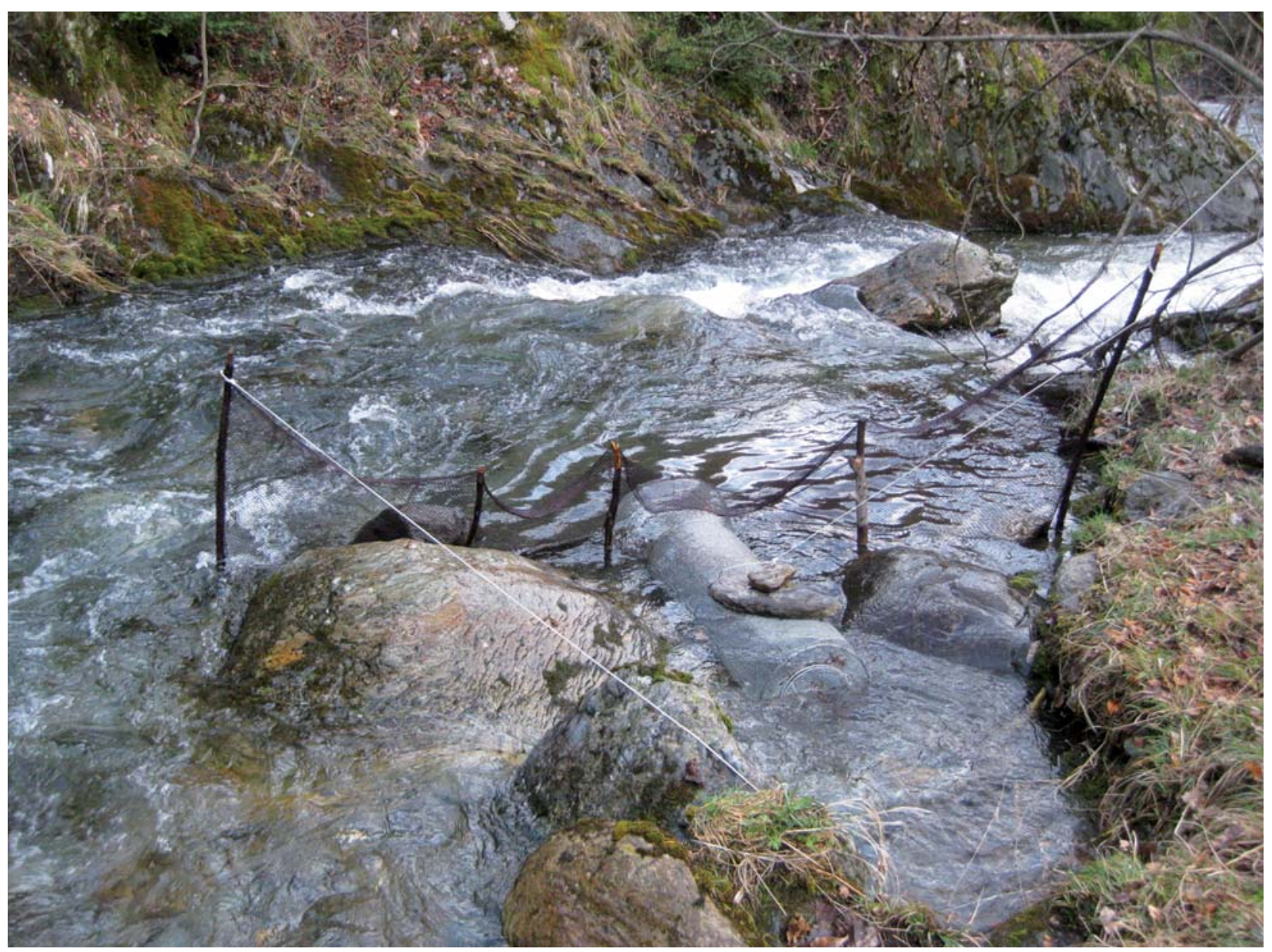

Fig. 1. - Nasa para la captura de desmanes. (Autor: Joaquim Gosàlbez)

Fig. 1. - Basket trap for Iberian desman capture. (Author: Joaquim Gosàlbez) 
laciona el esfuerzo con la longitud de río prospectada. Por ejemplo, Bertrand (1994), con 5 trampas y 112 noches capturó 32 individuos, esto es una eficiencia de 0,06. González-Esteban et al. (2003), en 16 campañas de 3 noches consecutivas para tramos de 800-3700 m obtienen un rendimiento desde 0 hasta 0,27 . Nuestra experiencia personal es diversa, con eficiencias máximas de 1,5 para 2 trampas y 2 noches o 0,7 para 7 trampas y 2 noches, y con eficiencias mínimas de 0 para 16 trampas y 2 noches, siempre en ríos donde la presencia (continua o irregular) de desmán ha sido confirmada mediante la prospección de excrementos.

Más interesante resulta conocer la eficiencia estandarizada, considerando los resultados obtenidos con un esfuerzo constante sobre tramos de una longitud determinada. La Tabla 1 muestra los resultados obtenidos con campañas de 2 noches y 7-8 trampas $/ \mathrm{km}$ realizadas en tres años consecutivos y en todas las estaciones del año en cuatro tramos fluviales de $1 \mathrm{~km}$ del Pirineo catalán (cuenca del Noguera Pallaresa, afluente del Ebro). Las eficiencias medias se situaron entre 0,01 y 0,12 capturas/trampanoche, según tramos, y con notables variaciones para un mismo tramo en diferentes campañas. La irregularidad en la eficiencia fue mucho más elevada en el río Noguera de Vallferrera, un curso fluvial con presencia de desmán aparentemente fluctuante (tan sólo se capturó en el $60 \%$ de campañas, $n=10$, sumando los dos tramos) y de dimensiones medias (anchura media de unos $10 \mathrm{~m}$ ) que en el río Tor, un afluente del anterior con presencia permanente de desmán (en todas las campañas se han efectuado capturas) y de dimensiones menores (anchura media 4-5 m).

No existe correlación significativa entre el esfuerzo de trampeo y la eficiencia o el número de capturas. A partir del análisis de los resultados de 12 campañas en el río Tor no se observa relación significativa entre el esfuerzo y la eficiencia (test de Kruskal-Wallis, $P=0,165$ ) ni entre el efuerzo y el número de individuos capturados por km (test de Kruskal-Wallis, $P=0,488$ ). Tampoco se observa relación entre el número de noches consecutivas de trampeo y la eficiencia (test $W$ de Mann-Whitney: $W=25,5, P=$ 0,257 ) o el número de capturas/km (test W de Mann-Whitney: $W=29,0 ; P=0,086$ ).

\begin{tabular}{|l|l|l|l|l|}
\hline Río (River) & Tor-1 & Tor-2 & $\begin{array}{l}\text { Noguera de } \\
\text { Vallferrera -1 }\end{array}$ & $\begin{array}{l}\text { Noguera de } \\
\text { Vallferrera -2 }\end{array}$ \\
$\begin{array}{l}\text { Campañas (n) } \\
\text { Campaigns ( } n \text { ) }\end{array}$ & 6 & 6 & 5 & 5 \\
\hline $\begin{array}{l}\text { Esfuerzo } \\
\text { (noches } x \text { trampa) } \\
\text { Effort (nights } x \text { trap) }\end{array}$ & 92 & 92 & 76 & 72 \\
\hline $\begin{array}{l}\text { Eficiencia } \\
\text { (capturas/esfuerzo) } \\
\text { Efficiency } \\
\text { (captures/effort) }\end{array}$ & 0,12 & 0,08 & 0,04 & 0,01 \\
$(0,0,19)$ & $(0,06-0,12)$ & $(0-0,14)$ & $(0-0,06)$ \\
\hline $\begin{array}{l}\text { Individuos / } \mathrm{km} \\
\text { Individuals } / \mathrm{km}\end{array}$ & $1,8(0-3)$ & $1,2(1-2)$ & $0,6(0-2)$ & $0,1(0-1)$ \\
\hline
\end{tabular}

Tabla 1. - Resultados de las campañas de trampeo sucesivas en los mismos tramos de $1 \mathrm{~km}$ (periodo 2006-2010).

Table 1. Results of successive trapping campaigns in the same river sections of $1 \mathrm{~km}$ (period 2006-2010).
Según nuestra experiencia, dos noches consecutivas de trampeo con un esfuerzo de unas 4 trampas $/ \mathrm{km}$ parecen suficientes para confirmar la presencia de desmán y para obtener una estimación aproximada de su densidad en ese tramo y época, ya que en 8 campañas de 5-6 noches consecutivas siempre se han capturado individuos en las dos primeras noches, mientras que a partir de la segunda noche las nuevas capturas son muy raras y generalmente sólo hay recapturas. Esta concentración de las capturas en las dos primeras noches también ha sido observada por González-Esteban et al. (2003).

Como conclusión se puede afirmar que el trampeo es un método efectivo, ya que permite establecer con seguridad la presencia de desmán, pero poco eficiente, puesto que el esfuerzo mínimo estimado es de 2 noches para muestrear tramos fluviales de pocos km. Esta limitación hace que sea un método inadecuado para estudios sobre distribución del desmán sobre grandes territorios. Además siempre comporta un cierto riesgo de mortalidad, si no se revisan las trampas con una frecuencia adecuada, que aumenta notablemente si hay una manipulación posterior de los individuos capturados. Obviamente, este riesgo no afecta a la obtención de datos sobre distribución, pero parece poco ético asumirlo si existen métodos alternativos no peligrosos para el animal. En nuestra opinión, las capturas deben reservarse para situaciones excepcionales en las que las características del río hagan imposible la aplicación de otros métodos. En cambio, es un método insustituible cuando es necesario realizar marcajes de individuos.

\section{Prospección de excrementos}

Este método fue desarrollado hace tres décadas por Bertrand (1986). Tiene una base muy similar a los muestreos sistemáticos de excrementos que se aplican de forma rutinaria para detectar la presencia de Lutra lutra (Linnaeus, 1758) (Mason \& McDonald, 1987), consistentes en recorrer tramos de río de una longitud determinada y buscar heces de la especie. Sin embargo, el muestreo de desmán es más laborioso, debido a que los excrementos son pequeños (en general 10-15 x 3-7 mm), suelen estar escondidos en cavidades entre rocas $(74,7 \%$ de una muestra de 162) y plantean un cierto riesgo de confusión con otras especies (Fig 2). El mismo método se ha demostrado que es también muy eficiente para detectar la presencia de Neomys spp. (Aymerich \& Gosálbez, 2004b).

La introducción de la prospección de excrementos representó un salto trascendental en el conocimiento de la distribución del desmán, ya que por primera vez era viable aplicar un método de estudio sistemático sobre grandes territorios y sin necesidad de un esfuerzo descomunal. El primer resultado fue la actualización de la distribución en Francia (Bertrand, 1993, 1994), seguido por el establecimiento de la distribución en Portugal (Queiroz et al., 1998) y en los Pirineos de Cataluña, Andorra y Aragón (Aymerich et al., 2001; Aymerich, 2004; Aymerich \& Gosálbez, 2004a). De forma muy limitada el método también se ha utilizado en otras zonas (e.g. Nores et al., 1992; Agirre-Mendi, 2004). 


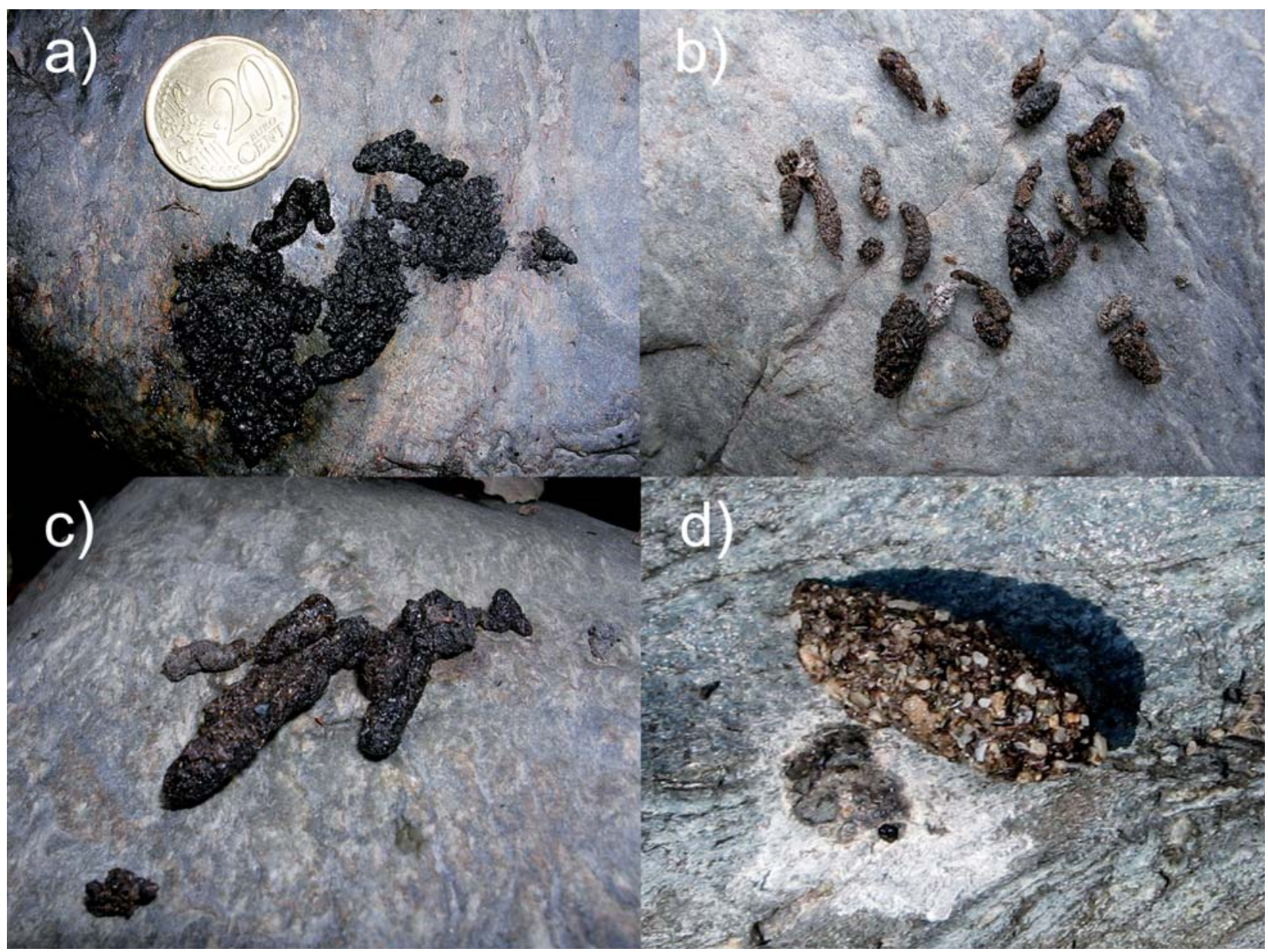

Fig. 2. - a) Letrina de desmán, en la que se mezclan excrementos recientes de morfología típica con excrementos antiguos amorfos; b) Muestra de excrementos de Neomys sp. de aspecto y tamaño diverso, pero todos claramente atribuibles a mugaños; c) Excrementos de aspecto intermedio entre Galemys y Neomys, de identificación incierta en el campo, pero que corresponden a desmán; d) Egagrópila típica de mirlo acuático (Cinclus cinclus). (Autor: Pere Aymerich)

Fig. 2. - a) Iberian desman latrine with fresh droppings with typical morphology together with old and formless excrements; b) Neomys sp. excrements of different shape and size, but all clearly attributable to water-shrews; c) Intermediate size droppings between Galemys and Neomys of uncertain identification in the field, but that correspond to Galemys pirenaicus. d) Dipper (Cinclus cinclus) pellet. (Author: Pere Aymerich)

Como todos los métodos, presenta algunas limitaciones, pero en conjunto es altamente fiable y eficiente. La idoneidad de la prospección de excrementos como método de aplicación general para el estudio de la distribución del desmán se ha discutido en algunos trabajos (González-Esteban et al., 2003) y, en general, ha sido objeto de un debate recurrente y bastante estéril, que aún sigue vivo en algunos ámbitos. Aunque en algunos casos deben haber influído el diseño de la prospección o las condiciones físicas de los tramos explorados, parece que la mayor parte de los resultados poco satisfactorios con este método tienen más relación con la falta de pericia personal en el muestreo que con unas improbables condiciones especiales de determinadas zonas geográficas o ríos. En cualquier caso, no hay razones lógicas para que un método que se ha aplicado con éxito en todos los ríos de Portugal y de los Pirineos no sea generalizable al conjunto del área de distribución de la especie. Los principales factores limitantes del método son dos: las condiciones del muestreo y el riesgo de confusión con rastros de otras especies. Habría que añadir otro, la experiencia o la habilidad de las personas que realizan el muestreo, que sin duda condiciona mucho los resultados, pero es obvio que un equipo que emprenda un estudio de distribución sistemático del desmán debe garantizar un buen conocimiento del método.

Por lo que se refiere a las condiciones del muestreo, es necesario realizar una selección previa de los tramos y de los días. Los tramos escogidos para realizar el muestreo deben disponer de un número mínimo de soportes adecuados para encontrar heces de desmán, que son piedras u otros objetos semisumergidos (troncos, sustratos artificiales) en contacto directo con el agua, y preferentemente rodeados por agua $(63,6 \%$ de una muestra de 162). Estos sustratos están presentes en mayor o menor medida en todos los ríos, pero hay tramos que casi no tienen ninguno, por lo que deben ser descartados de la prospección. En cuanto a la selección del día, hay que evitar los 2-3 días siguientes a lluvias torrenciales o a crecidas del caudal, poque habrán lavado la mayor parte de excrementos. Tampoco es recomendable prospectar en época de deshielo ni en días de invierno con nieve o fuer- 
tes heladas, pues la probabilidad de encontrar excrementos disminuye y hay que incrementar la longitud del tramo a prospectar. Estas precauciones resultan suficientes. No parecen existir épocas del año más desfavorables para localizar excrementos, y las lluvias no torrenciales tampoco impiden su detección.

La problemática de la confusión con otras especies resulta más compleja (Fig 2). Con algo de experiencia sólo existe riesgo de confusión con algunos excrementos de musaraña acuática (Neomys sp.). Sin embargo, observadores inexpertos pueden confundirlos incluso con egagrópilas de mirlo acuático Cinclus cinclus (Linnaeus, 1758), con excrementos de aves lavados y con heces de gasterópodos. Cuando se encuentran excrementos típicos, que son la mayoría, la distinción visual (y también olfativa) entre los de Galemys y Neomys no resulta compleja; se pueden consultar descripciones fiables de los excrementos de desmán en Queiroz et al. (1998) y de Neomys en Aymerich \& Gosálbez (2004c). Según nuestra experiencia, existe casi siempre una fracción considerable de rastros que en el campo no se pueden asignar con seguridad a Galemys o a Neomys. Esta incertidumbre requiere proseguir la prospección hasta encontrar por lo menos un excremento típico e inconfundible -lo que en general no es muy difícil- o bien, alternativamente, una confirmación posterior mediante análisis de laboratorio. Existen indicios que permiten suponer que una parte no despreciable de las citas de desmán basadas en excrementos corresponden a confusiones con Neomys, en especial en los estudios iniciales que utilizaron este método -cuando aún se suponía que todos los excrementos de Neomys eran de morfología "típica", o sea cortos, prismáticos y puntiagudos- y en varios estudios posteriores que no han aplicado confirmaciones de laboratorio. El riesgo de confusión es tal que, en una guía divulgativa sobre rastros, incluso hemos podido ver una fotografía inequívoca de excrementos de Neomys que aparece como modelo de rastros de Galemys. En los Pirineos, por ejemplo, tenemos motivos para creer que la confusión con excrementos de Neomys es la causa principal de citas con toda probabilidad erróneas en algunas cuencas fluviales aragonesas que se mantienen como válidas en los mapas de referencia actuales (Nores, 2007), en especial en el Ésera, Cinca y Gállego, donde la prospección sistemática (Aymerich \& Gosálbez, 2004a) ha permitido hallar numerosos rastros de Neomys pero ninguno de Galemys. En otras zonas la situación es aún peor, pues hemos podido constatar que en algunos informes inéditos correspondientes a las Montañas Cantábricas se dan como excrementos de desmán egagrópilas de mirlo acuático.

El método más simple para confirmar los rastros en el laboratorio es la observación con lupa binocular de pelos contenidos en las heces. La Tabla 2 muestra los resultados obtenidos durante la prospección del año 2000 en Cataluña, para una muestra de 421 excrementos individuales o letrinas. En el campo, una cuarta parte (24,2\%) de éstos presentaba caracteres dudosos entre Galemys y Neomys, mientras que el resto fue asignado a desmán o a musaraña. Posteriormente este material fue revisado en el labo-

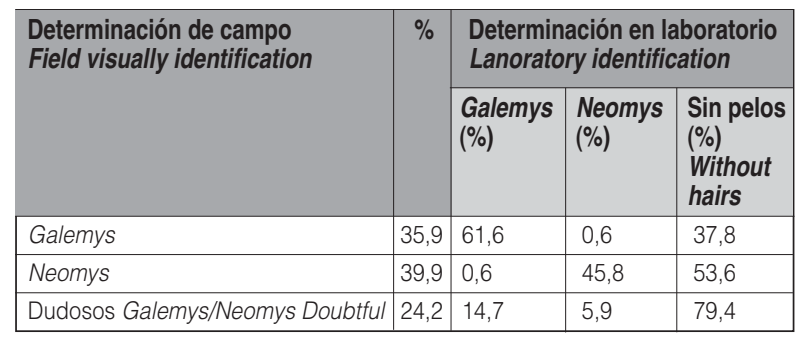

Tabla 2 - Resultados de la verificación en laboratorio, mediante análisis de pelos, de la determinación en el campo de excrementos de Galemys y Neomys $(n=421)$.

Table 2. Results of laboratory testing, through hair analysis, of faeces visually identified as Neomys or Galemys ( $n=421$ ).

ratorio, y se encontraron pelos en un $45,8 \%$ de las muestras. La mayor parte de los excrementos dudosos no contenían pelos, por lo que no pudieron ser identificados, pero entre los que tenían pelos predominaban ampliamente los que correspondían a desmán; esta observación puede sugerir que la mayor parte de rastros dudosos corresponden a esta especie, pero también hay que tener en cuenta que la presencia de pelos parece más habitual en los excrementos de Galemys que en los de Neomys (casi un 16\% más en la muestra comentada). Más interesante es el hecho de que el análisis de laboratorio permitió constatar que el error en la asignación directa a Galemys o Neomys en el campo fue muy bajo, del $0,6 \%$ (una sola muestra en cada caso). Este error casi despreciable indica que este método es altamente fiable para estudiar la distribución del desmán aunque no se aplique una confirmación posterior de laboratorio, pero con la condición de que el equipo de prospección cuente con una experiencia suficiente. En Portugal el porcentaje de error fue también bajo pero superior, de un 8\% (Queiroz et al., 1998).

La identificación de los excrementos de desmán se puede efectuar mediante dos tipos de pelos. El sistema tradicional y fácil es detectar los pelos "en lanza" característicos e inconfundibles del desmán (Poduschka \& Richard, 1985), pero sólo están presentes en una fracción modesta de los excrementos. Las posibilidades de identificación correcta se incrementan notablemente si se analizan los pelos de revestimiento, de forma similar en Galemys y en Neomys, pero con diferencias discriminantes en la médula radical; sin embargo, hay que precisar que la identificación segura con estos pelos es mucho más laboriosa y no siempre viable. En la prospección antes comentada los pelos de revestimiento permitieron confirmar un $69,4 \%$ de los excrementos de desmán y los pelos en lanza un $30,6 \%$.

Si se dispone de medios suficientes también es posible recurrir a una confirmación de las heces mediante técnicas genéticas, pero tampoco garantizan la identificación de todas las muestras, ya que no siempre proporcionan DNA (alrededor de un 50\%). En base a datos de muestras usadas para un trabajo molecular reciente (Igea et al., 2013), mediante la confirmación genética se ha observado un error en la identificación visual de excrementos de Galemys inferior al $5 \%$ para personal experimentado y en 
zonas donde la especie es frecuente, pero que puede llegar hasta un $35 \%$ exn otro tipo de condiciones más generales (en especial cuando la experiencia del personal de campo es heterogénea y se encuentra poca densidad de excrementos). Estos resultados ponen de manifiesto una vez más la relativa dificultad de identificar determinados tipos de excremento y la importancia de la experiencia para realizar una prospección eficiente.

La longitud máxima recomendada de los tramos de prospección es de unos 200 m. Aunque inicialmente Bertrand (1993) prospectó tramos de unos $500 \mathrm{~m}$, de acuerdo con nuestros resultados y con los de Queiroz et al., (1998) en Portugal un recorrido máximo de unos $200 \mathrm{~m}$ es suficiente para detectar la presencia de desmán con una probabilidad muy elevada. De hecho, en ríos con buenas poblaciones de desmán, en la mayor parte de los casos es suficiente con recorrer pocos metros para encontrar un excremento. La Tabla 3 muestra la distancia que fue necesario recorrer hasta encontrar el primer excremento asignado visualmente a desmán en una muestra de 76 tramos positivos. Como se puede observar, en más de la mitad de los casos no hubo que prospectar más de $25 \mathrm{~m}$ para hallar el primer rastro, con 50 m se habría confirmado la presencia en el $67 \%$ de los tramos -porcentaje casi coincidente con el 70\% obtenido en Portugal (Queiroz et al., 1998) y con $100 \mathrm{~m}$ la probabilidad de detección ya es prácticamente del $90 \%$. Los casos en que es necesario recorrer más de $200 \mathrm{~m}$ para detectar el primer excremento son raros pero existen, y en general parecen atribuibles a densidades muy bajas de la especie o a condiciones de prospección desfavorables.

Obviamente un resultado negativo en un tramo no implica que el desmán esté ausente de un determinado río, ya que la distribución y la densidad parecen discontinuas a escala local, tanto espacialmente como temporalmente. Para conocer la distribución es necesario prospectar más de un tramo por curso fluvial. Se recomienda prospectar un mínimo de 2 tramos por curso fluvial, y aumentar la muestra proporcionalmente a las dimensiones (longitud y anchura) del río. Según nuestros resultados, 3-4 tramos son en general suficientes para confirmar la presencia de desmán en los ríos de dimensiones pequeñas o medias, que constituyen la gran mayoría de los disponibles dentro de su área de distribución.

La prospección de tramos de unos 200 m permite muestrear un número alto de localidades en tiempos relativamente cortos. Un equipo experimentado de 2-3 personas puede prospectar entre 5 y 10 tramos por día, en función de sus características, de la rapidez en la detección de rastros y de la facilidad de desplazamiento entre

\begin{tabular}{|c|c|c|c|c|c|c|c|c|}
\hline $\begin{array}{l}\text { Distancia } \\
\text { Distance }\end{array}$ & $<25$ & $25-50$ & $50-75$ & $75-100$ & $\begin{array}{l}100- \\
125\end{array}$ & $\begin{array}{l}125- \\
150\end{array}$ & $\begin{array}{l}150- \\
175\end{array}$ & $\begin{array}{l}175- \\
200\end{array}$ \\
\hline$\%$ & 59,2 & 9,2 & 7,9 & 13,2 & 3,9 & 2,6 & 1,3 & 2,6 \\
\hline
\end{tabular}

Tabla 3. - Distancia $(m)$ recorrida hasta localizar el primer excremento de desmán ( $\mathrm{n}=76$ tramos)

Table 3. Distance $(m)$ traveled to locate the first desman faeces $(n=76$ river sections). tramos. Este ritmo de prospección permite cubrir satisfactoriamente cuencas fluviales completas en pocas semanas. La prospección de excrementos, pues, es el método más eficiente para estudiar la distribución del desmán, ya que requiere un esfuerzo mucho menor que el trampeo y tiene una fiabilidad casi tan alta. Es también el único que permite establecer de modo fiable la distribución en un momento dado (una "foto fija") de la especie en una determinada cuenca fluvial, algo que resulta imprescindible para conocer su estado de conservación a escala regional y para el seguimiento a largo plazo de las poblaciones.

\section{La distribución: una cuestión de escala}

Influencia de la escala espacial y de la escala temporal

Los diversos métodos utilizados para el estudio del desmán, cada uno con sus limitaciones, han condicionado la percepción de su área de distribución y frecuencia. En general, los métodos tradicionales no sistemáticos y basados en datos fragmentarios (recopilación de citas, encuestas y trampeos puntuales) han contribuido a crear una imagen del desmán como especie muy rara -por la escasez de datos- pero con una distribución amplia -por la acumulación de citas de periodos largos, parte de las cuales pueden ser erróneas o debidas a presencia accidentalCon estos métodos se tendía a sobreestimar el área de distribución de la especie suponiendo que, si en una cuenca hidrográfica se había confirmado la presencia del desmán, éste debía estar presente en la mayor parte de cursos fluviales con unas condiciones mínimamente adecuadas (aguas limpias y frescas) y que la única causa de las ausencias locales era la alteración antrópica del medio.

En las últimas décadas, la aplicación del método de la prospección de excrementos ha mostrado que el desmán no es especialmente raro en gran parte de su área, pero que la distribución local es bastante más compleja de lo que se había supuesto. Los datos preliminares hasta ahora obtenidos con trampeos plurianuales en unos mismos tramos confirman esta complejidad de la distribución a escala local. Con la información actual se puede afirmar que la distribución del desmán dentro de una cuenca fluvial muestra discontinuidades espaciales y temporales que no siguen un patrón simple, y que pueden estar vinculadas a factores ambientales naturales, a factores ambientales antrópicos o a la dinámica interna de las poblaciones de la especie. Los datos disponibles son aún insuficientes, pero hacen recomendable abandonar los modelos de distribución fijos (el desmán se distribuye de modo más o menos uniforme por todos los tramos fluviales aparentmente adecuados de una cuenca, con la excepción de aquellos alterados antrópicamente) y sustituirlos por un modelo de distribución dinámico (de modo natural el desmán se distribuye de forma irregular en los tramos fluviales de una cuenca, tanto en el espacio como en el tiempo, y esta irregularidad puede aumentar con la intervención antrópica).

La información disponible sugiere que dentro del área de distribución del desmán se pueden distinguir por lo menos las siguientes situaciones: 


\section{1- Zonas con presencia permanente:}

Cursos fluviales o tramos de algunos cursos fluviales donde siempre se detectan excrementos y donde siempre que se realiza un trampeo con un esfuerzo mínimo de 2 noches se capturan individuos. La presencia permanente es independiente de la abundancia local de la especie, que puede ser más o menos alta, y que a menudo experimenta fluctuaciones. En los Pirineos meridionales la mayor parte de estas zonas de presencia permanente corresponden a cursos fluviales más bien pequeños, con anchuras medias inferiores a $5 \mathrm{~m}$.

Es importante puntualizar que aplicamos la calificación de "permanente" a una escala temporal de una década de controles, ya que no disponemos de seguimientos más prolongados. A causa de estas limitaciones, y considerando que las subpoblaciones de algunos de estos cursos fluviales son pequeñas y parecen bastante desconectadas del resto de subpoblaciones de la cuenca, no se excluye la posibilidad de que en algún caso se trate de poblaciones temporales de ciclo largo, sometidas a una dinámica de colonización-recolonización que puede durar décadas.

\section{2- Zonas con presencia temporal recurrente:}

Tramos de cursos fluviales donde el desmán se detecta frecuentemente, pero no siempre. Los cambios temporales de presencia o ausencia en algunos tramos se han constatado usando simultáneamente los métodos de detección de excrementos y de captura, con resultados coincidentes. Por ahora se desconocen las causas de esta dinámica, pero se supone que podría estar condicionada por las fluctuaciones en la disponibilidad local de alimento o por factores ligados a la reproducción.

\section{3- Zonas con presencia accidental.}

Cursos fluviales o tramos de algunos cursos en los que sólo existen citas puntuales confirmadas de desmán, sin que su presencia haya podido confirmarse con prospecciones sistemáticas y sin que la adecuación del hábitat haya experimentado cambios significativos. Pueden corresponder a esta situación algunas citas de individuos encontrados en cursos fluviales bajos o medios, muy lejos de la distribución conocida en una determinada cuenca fluvial, y que probablemente han sido arrastrados por crecidas del río. En otros casos se consideran accidentales algunas observaciones dentro del área de distribución conocida en una cuenca, pero en tramos o cursos sin presencia permanente ni temporal, que se pueden atribuir a individuos divagantes que se han alejado de las zonas con presencia habitual. Los datos actuales sugieren que en la cuenca alta de los ríos Segre y Noguera Pallaresa el desmán sólo tendría una presencia accidental en gran parte de los ríos principales (más caudalosos, anchos y profundos), mientras que estaría presente de modo habitual en los afluentes laterales menores; es probable que este patrón de distribución local sea generalizable a otras muchas cuencas hidrográficas. Aunque estas observaciones presuntamente accidentales resultan anecdóticas para conocer la distribución real del desmán, son interesantes para interpretar la dinámica poblacional, ya que estos desplazamientos esporádicos serían importantes para mantener la conexión entre subpoblaciones bastante aisladas e incluso podrían favorecer el establecimiento de nuevas subpoblaciones más o menos persistentes.

Es interesante apuntar que, aunque hasta aquí nos hemos referido siempre a la presencia dentro del área de distribución confirmada de la especie a gran escala (cuencas o grandes subcuencas), no se puede excluir que se dé una aparición accidental de desmán también en cuencas fuera de esta área. Estas apariciones esporádicas son potencialmente viables, por ejemplo, por el paso por vía terrestre desde cuencas donde hay poblaciones con desmán hasta cuencas donde no está presente. Aunque de baja probabilidad por ser una especie de hábitos casi completamente acuáticos, podría haber desplazamientos entre cuencas a través de pasos de montaña donde los arroyos de las dos vertientes están muy próximos. Esta hipótesis se plantea como una de las posibles interpretaciones para explicar la distribución observada en las subcuencas de Aragón occidental, desde el Gállego hasta el Beral.

\section{4- Zonas donde está ausente por causas naturales:}

Los resultados de las prospecciones sistemáticas muestran algunas ausencias importantes que afectan a sectores amplios dentro del área de distribución del desmán, ya sean determinados cursos fluviales o tramos muy largos (decenas de km) de otros. Es probable que en algunas de estas zonas el desmán aparezca de modo accidental, pero a efectos prácticos se deben considerar zonas donde está ausente por causas naturales o antrópicas. Estas causas naturales parecen frecuentes y se atribuyen sobre todo a la escasa adecuación del hábitat por limitaciones de alimento o de refugios. Serían ejemplos de estas ausencias naturales largos tramos del río Segre entre Puigcerdà y la Seu d'Urgell (escasa disponibilidad de refugios), muchos afluentes del Segre procedentes del Prepirineo calizo (escasa productividad de los ríos) o la mayor parte del río Unhòla en la cuenca alta del Garona (también por la baja productividad derivada una litología peculiar). Se puede suponer que, en general, estas ausencias debidas a causas naturales son permanentes o por lo menos muy persistentes, ya que es improbable que las condiciones desfavorables del medio derivadas de factores como la litología de la cuenca o la topografía se modifiquen.

\section{5- Zonas donde está ausente por causas antrópicas:}

Es seguro que la perturbación antrópica del medio fluvial ha comportado la regresión y fragmentación del área de distribución del desmán. No obstante, la escasez de datos precisos sobre su distribución pasada hace muchas veces difícil o inviable discriminar las discontinuidades debidas a la acción humana y las que tienen causas natura- 
les. También es probable que en ocasiones ambas causas se solapen, como en el caso de los tramos fluviales en valles anchos, que por causas naturales resultan poco favorables para el desmán y que además son los que generalmente han resultado más perturbados por la actividad humana. Ejemplos de zonas en las que parece claro que se ha producido una fragmentación relativamente reciente del área de distribución a causa de la perturbación antrópica son la red fluvial de Andorra, a causa de la contaminación (Aymerich, 2004), y la cuenca del Ter, especialmente a causa de la intensa implantación de infraestructuras hidráulicas. Sin embargo, estos casos no parecen tan frecuentes como a veces se ha supuesto, de modo que es recomendable una gran cautela en la asignación de la perturbación antrópica como causa de las ausencias de desmán. Por otra parte, a diferencia de las ausencias debidas a causas naturales, las ausencias debidas a perturbaciones antrópicas son potencialment reversibles, por lo que si las causas de la perturbación cesan y se mantienen poblaciones de desmán cercanas es viable una recolonización.

\section{Área de presencia y área de ocupación}

Como se puede apreciar, la complejidad de las situaciones que se dan dentro de los territorios con presencia de desmán hace difícil establecer un área de distribución simple a nivel de cuenca. Una aproximación útil puede ser la distinción entre área de presencia y área de ocupación, siguiendo las definiciones de la UICN (2001).

El área de presencia puede asimilarse al área de distribución en sentido clásico, es decir el perímetro que engloba todas las poblaciones conocidas de la especie. En el caso del desmán esta área englobaría zonas de todas las categorías anteriores, con la excepción de las zonas con presencia accidental debida a arrastre río abajo por crecidas y de las zonas donde la perturbación antrópica del medio es irreversible.

El área de ocupación es la zona dentro del área de presencia que una especie utiliza de forma efectiva y suele ser bastante menor. La determinación del área de ocupación en el caso del desmán se complica a causa de la aparente irregularidad temporal en el uso de determinadas zonas, en las que puede tener una presencia más o menos infrecuente. Una aproximación que nos parece práctica y bastante realista al área de ocupación del desmán es considerar que ésta engloba sólo las zonas con presencia permanente y las zonas con presencia temporal recurrente, o sea las zonas con presencia más o menos habitual.

Tanto el área de presencia como la de ocupación comportan una sobreestimación del área de distribución del desmán, pues siempre incluirán zonas con presencia sólo temporal de la especie. Esta cuestión es importante tenerla en cuenta, pues cuando se trabaja con datos de distribución se tiende a simplificar en exceso, sin tener en cuenta las diferencias de calidad para la especie de las diversas zonas. Lamentablemente es frecuente que estas percepciones simplistas tengan influencia en aspectos relacionados con la gestión, dando lugar a estimaciones poblacionales exageradas y a una planificación inadecuada de las zonas importantes para la conservación.

Como caso práctico, en los dos apartados siguientes se intenta aplicar esta distinción entre áreas de presencia y áreas de ocupación a las cuencas fluviales de los Pirineos mediterráneos, ámbito geográfico en el que se ha centrado nuestro trabajo. La calidad de la información disponible permite una aproximación más fiable al área de presencia que al área de ocupación.

\section{Área de presencia en los Pirineos meridionales}

Los trabajos de prospección que realizamos entre los años 2000 y 2004, siempre basados en la detección de excrementos, permitieron establecer la distribución actual del desmán en Cataluña, Andorra y Aragón (Aymerich et al., 2001; Aymerich, 2004; Aymerich \& Gosálbez, 2004a). La Tabla 4 muestra los resultados de estos estudios, indicando el número de tramos prospectado por cuenca y el porcentaje de tramos en los que se detectó desmán y musarañas acuáticas; se indica la frecuencia de Neomys porque estas musarañas se confunden a menudo con Galemys, tanto visualmente como por los rastros. El ámbito prospectado sistemáticamente comprende la mayor parte de los Pirineos meridionales, que se puede consi-

\begin{tabular}{|c|c|c|c|}
\hline $\begin{array}{l}\text { Cuenca o subcuenca fluvial } \\
\text { (Basin or subbasin) }\end{array}$ & $\begin{array}{l}\text { Tramos } \\
\text { River } \\
\text { section }\end{array}$ & $\begin{array}{l}\% \\
\text { Galemys }\end{array}$ & $\begin{array}{l}\% \\
\text { Neomys }\end{array}$ \\
\hline Muga & 11 & 0 & 0 \\
\hline Fluvià & 11 & 0 & 27,3 \\
\hline Ter & 55 & 20,0 & 69,1 \\
\hline Llobregat & 27 & 0 & 18,5 \\
\hline Segre Cataluña & 119 & 19,3 & 21,0 \\
\hline Segre Andorra (subcuencaValira) & 102 & 20,6 & 54,9 \\
\hline Noguera Pallaresa & 119 & 44,5 & 52,1 \\
\hline Flamisell & 12 & 0 & 100,0 \\
\hline Noguera Ribagorçana & 40 & 0 & 52,5 \\
\hline Isàvena & 11 & 0 & 54,5 \\
\hline Ésera & 46 & 0 & 57,8 \\
\hline Cinca-Ara & 59 & 0 & 75,0 \\
\hline Gállego & 49 & 0 & 54,5 \\
\hline Aragón & 26 & 0 & 61,9 \\
\hline Lubierre & 3 & 0 & 33,3 \\
\hline Estarrún & 8 & 0 & 20,0 \\
\hline Aragón Subordán & 31 & 19,4 & 29,0 \\
\hline Beral & 31 & 0 & 25,8 \\
\hline Garona (vertiente norte de los Pirineos) & 45 & 46,7 & 20,0 \\
\hline
\end{tabular}

Tabla 4. - Resultados de las campañas de prospección en Cataluña, Andorra y Aragón en el período 2000-2004. Se indica el número de tramos prospectados por cuenca o subcuenca y el porcentaje de tramos positivos para Galemys pyrenaicus y para Neomys sp. Se incluyen también los datos de la cuenca atlántica del Garona en el valle de Aran.

Table 4. Results of prospection campaigns in Catalonia, Andorra and Aragon in the period 2000-2004. Table shows the total number of sections prospected by basin and the percentage (\%) of positive sections for Galemys pyrenaicus and Neomys sp. It also includes data from the Atlantic basin of the Garonne in the Aran valley. 
derar el sector geográfico donde la distribución de la especie se conoce actualmente con mayor precisión, tanto por la intensidad de la prospección (760 tramos, más 45 tramos en la cuenca norpirenaica del Garona) como por la sincronía (período de 4 años) de los datos obtenidos. Complementando estas informaciones propias con los datos más parciales de Navarra y de los Pirineos orientales en Francia, la distribución del desmán en el conjunto de la vertiente mediterránea de los Pirineos meridionales es la que se sintetiza a continuación. En la vertiente atlántica de los Pirineos el desmán tiene una distribución mucho más continua (ocupa todas las cuencas fluviales) y mejor conocida desde hace décadas (Peyre, 1956; Richard, 1976; Bertrand, 1994), aunque sería conveniente realizar una actualización y una homogeneización de los datos.

\section{1-Cuencas hidrográficas de los Pirineos orientales}

Las cuencas hidrográficas de los Pirineos orientales están formadas por varios ríos que desembocan directamente en el mar Mediterráneo, tienen un recorrido en general corto $(100-200 \mathrm{~km})$ y caudales modestos. Su régimen hidrográfico es pluvial o nivopluvial. La pluviometría en las zonas de montaña alta y media es relativamente importante (en general $800-1100$ mm anuales) y regular, lo que favorece el mantenimiento del caudal. En zonas de baja altitud -por debajo de 800-500 m, según sectores- las lluvias disminuyen rápidamente y son más estacionales, por lo que los cursos de agua pueden experimentar estiajes marcados. La influencia nival sólo resulta importante en los sectores de cabecera de los ríos que nacen en zonas pirenaicas de gran altitud (más de 2000 m), pero queda muy diluída en los cursos medios (por debajo de los $800 \mathrm{~m}$ ).

\section{1a-Cuencas con poblaciones de desmán:}

En este sector el desmán está presente en 5 cuencas (Ter, Tec, Tet, Aglí y Aude). La distribución detallada en la cuenca del Ter se muestra en Aymerich et al. (2001) y la del resto de cuencas en Bertrand (1994), por lo que no nos extenderemos en este aspecto.

En las cuencas con más influencia mediterránea (Ter, Tet, Tec) el desmán está presente en las cabeceras de los ríos principales y en los afluentes laterales de los tramos medios-altos y altos. En las cuencas del Aglí y el Aude el desmán está presente hasta altitudes inferiores, lo que se relacionaría con el hecho de que buena parte de sus cabeceras se sitúan en el límite de influencia de los frentes atlánticos, lo que garantiza unos aportes más regulares de agua.

Por lo menos en los años 1980 la distribución del desmán parecía bastante continua en las cuatro cuencas dentro de territorio francés, que en general discurren por paisajes rurales y con baja densidad de población. En cambio, en la cuenca del Ter la especie aparece acantonada en las zonas de cabecera del Ter estricto y del río Freser, formando dos poblaciones que en la actualidad parecen claramente separadas. Se supone que antigua- mente las poblaciones de estas dos subcuencas debían estar conectadas, ya que existen hábitats potenciales hasta la confluencia del Ter y el Freser en Ripoll, pero que se produjo una fragmentación relativamente reciente (siglo XX) a consecuencia de la artificialización general de los caudales (construcción de numerosas presas, captaciones y canales de uso industrial).

\section{1b-Cuencas sin poblaciones de desmán:}

El desmán se considera ausente de las cuencas del Llobregat-Cardener, Fluvià y Muga, en las que no se ha detectado ningún indicio de la especie. La indicación en el cuadrado UTM 31T DG17, que aparece en el Atlas de Mamíferos Terrestres de España (Nores, 2007) es errónea, y deriva de una confusión con Neomys sp. en el alto Llobregat, que fue obtenida mediante encuesta y recopilada en Nores et al., (1992).

\section{2- Cuenca hidrográfica del Ebro}

Los ríos de la cuenca del Ebro drenan la mayor parte de la vertiente meridional de los Pirineos. Los afluentes se concentran en dos grandes sistemas, oriental y occidental. Al este se encuentra el sistema Segre-Cinca (subcuencas de los ríos Segre, Noguera Pallaresa-Flamisell, Noguera Ribagorçana, Ésera-Isàbena, Cinca-Ara) drena gran parte de los Pirineos catalanes y el sector oriental de los aragoneses. Al oeste los afluentes del Ebro integran el sistema del Aragón (subcuencas del Aragón, Aragón Subordán, Beral, Esca, Irati, Arga y otras menores), que drena los Pirineos occidentales de Aragón y los de Navarra. Entre estas dos redes fluviales complejas se sitúa la subcuenca del Gállego, que drena la parte central de los Pirineos aragoneses y es relativamente simple, con un único río principal.

El clima de esta cuenca está definido por dos gradientes: un gradiente N-S básicamente altitudinal que causa una disminución muy rápida de la pluviometría, y un gradiente E-W de transición entre zonas de tendencia continental (sistema Segre-Cinca) hasta sectores de clara influencia oceánica (Navarra). El caudal de estos ríos es más importante que el de los de las cuencas pirenaicoorientales. El régimen es marcadamente nival en la mayor parte de los grandes afluentes, que tienen sus cabeceras en las zonas altas de los Pirineos. En las subcuencas más occidentales y en los ríos con cabeceras prepirenaicas el régimen es pluvial o nivopluvial.

Los afluentes que definen cada subcuenca tienen un recorrido general N-S, perpendicular a la cordillera pirenaica, por lo que confluyen en zonas alejadas de las cabeceras, en las depresiones internas prepirenaicas o ya en la depresión del Ebro, en sectores de baja altitud con un contexto general notablemente árido y desfavorable a la presencia de desmán. Debido a estos condicionantes geográficos y climáticos, las poblaciones de las grandes subcuencas pueden considerarse funcionalmente aisladas, ya que la probabilidad de conexión por vía fluvial es nula. 


\section{2a-Subcuencas con poblaciones de desmán:}

Según la información disponible el desmán está presente en 5 grandes subcuencas pirenaicas del Ebro, dos del sistema Segre-Cinca en los Pirineos centro-orientales y cuatro del sistema del Aragón en los Pirineos occidentales. No hay evidencias de presencia en la subcuenca aislada del Gállego.

En el sistema fluvial Segre-Cinca el desmán habita las subcuencas del Segre y del Noguera Pallaresa. La distribución detallada en estas subcuencas se muestra en Aymerich et al. (2001), aunque hay que excluir los datos erróneos referidos a la subcuenca del Flamisell en la Noguera Pallaresa (ver comentario en el apartado siguiente. En las subcuencas del Segre y del Noguera Pallaresa el desmán sigue un patrón de distribución similar al de las cuencas mediterráneas de los Pirineos orientales: tiene una presencia frecuente en los afluentes laterales de los tramos altos (aguas arriba de la Seu d'Urgell y de Gerri de la Sal, respectivamente), pero está casi ausente en los dos ríos principales fuera de las zonas de cabecera. Sin embargo, hay que precisar que resulta muy raro en los afluentes del margen izquierdo del Segre, que nacen en las sierras prepirenaicas. Se desconoce el grado de conexión funcional entre las subpoblaciones de los diversos afluentes laterales, pero potencialmente parece que sería más alto en el Noguera Pallaresa que en el Segre. Es remarcable la situación en la subcuenca del Valira (afluente del margen derecho que drena casi toda Andorra), donde parece que ha desaparecido del río principal a causa de la contaminación del agua por los vertidos urbanos, y actualmente sólo se conocen cinco poblaciones aisladas en afluentes laterales (Aymerich, 2004).

En el sistema fluvial del Aragón, que drena la mayor parte del Pirineo suroccidental, el desmán se encuentra en las subcuencas del Aragón Subordán, Irati y Arga. En la cabecera del Aragón Subordán (valle de Echo o Hecho, por encima del desfiladero de la Boca de lo Infierno) se localiza la única población aragonesa de la especie (Aymerich \& Gosàlbez, 2004a). En Navarra el desmán está más bien distribuido, aunque los datos disponibles son bastante antiguos, heterogéneos e incompletos (Castién \& Gosálbez, 1992; González-Esteban et al., 1999). En la subcuenca del Irati, el desmán estaría presente por lo menos en las zonas de cabecera de los ríos Irati, Urrobi y Erro; en el río Salazar, un curso importante de esta subcuenca situado más hacia el este, los datos que conocemos (alrededores de Otsagabia) son muy escasos y no tienen suficiente calidad para asegurar la presencia del desmán, aunque la consideramos probable. En la subcuenca del Arga la especie está bien documentada en los ríos Arga y Ultzama, aguas arriba de Pamplona y también se ha citado puntualmente en el río Elortz, al sudeste de esa ciudad; según la información disponible, no habría datos seguros del río Arakil y afluentes, con cabeceras en la Montañas Vascas (Aralar, Urbasa). En este sistema del Aragón, parece que actualmente todas las poblaciones de desmán están acantonadas en zonas de cabecera de los varios ríos indicados y que no existe conexión entre ellas por vía fluvial, aunque sí podría existir una conexión limitada por vía terrestre a tra- vés de collados de montaña. Aparentemente este acantonamiento en cabeceras tiene causas naturales en el Aragón Subordán, pero en los ríos navarros derivaría sobre todo de la perturbación antrópica del medio.

\section{2b-Subcuencas con presencia dudosa de desmán:}

La presencia del desmán es incierta en la subcuenca del Ezka (Esca), valle del Roncal (Navarra). En esta subcuenca hay varias citas de desmán que han sido recopiladas por la bibliografía (Castién \& Gosálbez, 1992; Nores, 2007), pero son muy escasas y, según los datos disponibles, parece que todas corresponderían a presuntas observaciones visuales o a excrementos no verificados con examen de pelos. Nuestra experiencia propia en esa zona se limita a una prospección de excrementos anecdótica, con resultado negativo, pero no se puede considerar significativa porque se aplicó un esfuerzo muy bajo. A la vista de la debilidad de la información conocida, creemos preferible no aceptar la presencia del desmán en el valle del Roncal hasta que se disponga de datos seguros.

Más hacia el este, ya en Aragón, otras dos subcuencas pirenaico-occidentales (Aragón y Beral o Veral, esta última adyacente a la del Ezka) también resultan problemáticas. A diferencia de lo que ocurre en el Ezka, en estas subcuencas sí se realizaron prospecciones sistemáticas (Aymerich \& Gosálbez, 2004a), que no permitieron detectar ningún indicio de desmán. De acuerdo con estos resultados la especie debe considerarse ausente en la actualidad de esas dos subcuencas. Sin embargo, existen algunos datos que introducen dudas sobre su posible presencia hasta tiempos muy recientes, por lo que merecen unos comentarios.

En la subcuenca del Aragón el único dato fiable es un individuo de desmán hallado muerto en 1984 en una calle de la ciudad de Jaca, lejos de cualquier curso de agua. Este ejemplar se conserva en el Instituto Pirenaico de Ecología y, por lo tanto, es una cita segura. Se desconoce la procedencia de ese individuo.

Otro dato que aparentemente sería de la cuenca del Aragón es una cita de la base de datos del Atlas de mamíferos de España, reflejada en éste en el cuadrado UTM 30TXN81, y que según consta corresponde a un ejemplar hallado muerto en una fecha indeterminada por $\mathrm{J}$. Thissen en "Puerto la Reina". Desconocemos la ubicación de esta localidad, pero suponemos que puede ser una confusión con Puente la Reina, en la confluencia de los ríos Aragón y Aragón Subordán. Si ésta es efectivamente la localidad donde se halló un desmán muerto, es probable que se tratara de un ejemplar arrastrado desde la cabecera del Aragón Subordán, donde se ha confirmado la presencia reciente del desmán, por lo que no correspondería a la subcuenca estricta del río Aragón.

En la subcuenca del Beral (o Veral), en el valle de Ansó, existe una cita publicada sobre una probable observación de desmán en 1988 (Gautron, 1989), realizada en un arroyo en el límite entre los municipios de Ansó y 
Hecho. La descripción del artículo parece corresponder efectivamente a un desmán, aunque el individuo no fue capturado ni se aporta una fotografía. En años posteriores existen un par de datos más inéditos y sin confirmar, correspondientes a una posible captura con pesca eléctrica y a una presunta observación. Estas informaciones parecen verosímiles, ya que existe hábitat potencial y se ha confirmado la presencia actual del desmán en el alto valle de Hecho (Aragón Subordán). A causa del interés de estas citas, la prospección de excrementos en el río Beral se repitió en tres años consecutivos (una prospección sistemática como en el resto de ríos aragoneses, y dos prospecciones adicionales) y en ninguna ocasión se hallaron indicios de desmán. Siguiendo la metodología habitual, un resultado negativo con esta intensidad de prospección parece que obliga a excluir que exista una población permanente de desmán en el Beral, incluso si la densidad es muy baja, ya que ordinariamente se detecta la presencia de la especie a nivel de subcuenca con un esfuerzo mucho menor.

Las contradicciones entre los resultados de la prospección y otros datos en las subcuencas del Aragón y del Beral se pueden interpretar de tres modos: 1) En tiempos modernos el desmán no ha existido en estas subcuencas, y las citas existentes son debidas a confusiones (Beral) y a un desmán cautivo (Aragón). 2) El desmán se ha extinguido de estas subcuencas en los últimos 20 años. 3) En estas subcuencas no hay una presencia estable de desmán, pero sí existen individuos o poblaciones temporales. Con los datos actuales, consideramos que la hipótesis más probable es la primera, pero se comentan las otras dos.

La hipótesis de una extinción reciente implica cambios drásticos y persistentes en la calidad del hábitat o bien un episodio puntual pero catastrófico. Un deterioro general y persistente del hábitat podría haberse dado en el río Aragón pero no en el Beral, donde la calidad del hábitat actual parece muy alta, por lo que es improbable que se haya producido una extinción por esta causa. La ocurrencia de episodios catastróficos recientes (contaminación química, avenida intensa, sequía persistente) que causaran la extinción es más posible y debe tenerse en cuenta, ya que las características de estas subcuencas fluviales -y de otros ríos aragoneses- las hacen potencialmente muy vulnerables a estos factores de riesgo. Tanto el Aragón (por encima de Jaca) como el Beral tienen en común una red fluvial adecuada para el desmán muy simple, que prácticamente está restringida al río principal. Con un hábitat tan limitado, existe la posibilidad de que un hecho catastrófico puntual afecte a la disponibilidad de alimento en todo el río y cause la muerte de la mayor parte de la población, que ya no conseguiría recuperarse y se extinguiría. En cualquier caso, se trata tan sólo de una hipótesis poco probable y sin ninguna evidencia que la soporte.

La hipótesis de una presencia temporal de desmán en estas subcuencas parece igualmente improbable, pero no se puede descartar. En la actualidad se dispone de evidencias que indican que hay ríos en los que la presencia de desmán no es permanente y también de indicios que sugieren que esta especie puede realizar desplazamientos terrestres entre ríos. Con estos datos no resulta inverosímil que se produzcan entradas esporádicas de individuos de desmán al Aragón desde arroyos de la vertiente atlántica de los Pirineos y al Beral desde el Aragón Subordán. Si estas entradas fueran frecuentes, incluso se podrían llegar a establecer poblaciones temporales y débiles de desmán, que podrían extinguirse a causa de acontecimientos catastróficos más o menos recurrentes, como las avenidas o las sequías.

\section{2c-Subcuencas sin poblaciones de desmán:}

El desmán se considera ausente de las siguientes subcuencas, expuestas en sentido este-oeste: Flamisell, Noguera Ribagorçana, Isàvena, Ésera, Cinca-Ara, GáIlego, Lubierre y Estarrún. Las prospecciones sistemáticas de excrementos en el período 2000-2004 no permitieron detectar ningún indicio de la especie en estas subcuencas, y tampoco se conoce ningún dato de capturas o de observaciones fiables. Se considera que las supuestas citas de desmán reflejadas en mapas de referencia recientes (Nores et al., 2007) deben ser producto de confusiones con individuos o excrementos de musaraña acuática (Neomys sp.), insectívoro semiacuático que resulta frecuente en estos ríos (ver Tabla 4).

Es conveniente precisar que en el Pirineo aragonés gran parte de las citas derivan de muestreos realizados en la década de 1980, cuando se iniciaba el desarrollo del método de prospección de excrementos, por lo que suponemos que se confundieron excrementos atípicos de Neomys con heces de Galemys. El número de citas de supuestos excrementos de desmán de esa época en las subcuencas del Gállego y del Ara (9 y 5 respectivamente) implicaría que la especie contaba con poblaciones bien establecidas, y en ese caso es altamente improbable que se extinguieran en un cuarto de siglo, porque en las dos subcuencas existe todavía una alta disponibilidad de hábitats potenciales y porque en la subcuenca del Ara los ríos casi no han experimentado alteraciones.

En la subcuenca del Flamisell, un afluente del Noguera Pallaresa con confluencia en su curso medio, las localidades publicadas en Aymerich et al. (2001) son erróneas y se deben a una confusión en el etiquetado de las muestras. En contra de lo que se indicaba en ese trabajo, el desmán debe considerarse ausente de la subcuenca. En los años 2001-2002 se realizaron nuevas prospecciones que cubrieron la mayor parte del hábitat potencial y tan sólo se detectaron rastros de Neomys sp.

En relación con las causas de estas ausencias a escala de subcuenca, consideramos que en general se trata de una ausencia natural, debida a una falta de coIonización -o recolonización, pues ha sido citado como fósil en el Würm (46.500 BP) de Gabasa, Huesca (Arribas, 2004)- postglacial de muchos valles surpirenaicos, sin que haya intervenido una extinción más o menos re- 
ciente por causas antrópicas. La hipótesis de no-colonización postglacial de cuencas surpirenaicas por el desmán fue planteada ya tras estudiar la distribución en Cataluña (Aymerich \& Gosálbez, 2002) y se reforzó después de estudiar el patrón de distribución de la especie en el conjunto de los Pirineos meridionales. En síntesis, esta hipótesis propone que el desmán se habría extinguido durante la última glaciación en las cuencas surpirenaicas, que se produjo una recolonización postglacial en sentido W-E que siguió básicamente la red fluvial de la vertiente norpirenaica (en algunos ríos navarros es probable que la recolonización se diera directamente desde la zona cantábrica) y que la especie sólo atravesó hacia las cuencas surpirenaicas allí donde había pasos de montaña adecuados (preferentemente zonas de altitud inferior a 2000 donde los cursos de agua de cabecera de las cuencas mediterráneas y atlánticas se aproximan mucho). En las subcuencas del Segre y del Noguera Pallaresa estas zonas de contacto entre cuencas mediterráneas y atlánticas existen, y desde la subcuenca del Segre el desmán podría haber saltado fácilmente hasta las cuencas de los Pirineos orientales. Por el contrario, en una amplia franja de los Pirineos centrales no existen "pasos fáciles" entre las cuencas fluviales atlánticas y mediterráneas, por lo que se puede considerar que los Pirineos constituyen en este caso una barrera geográfica efectiva para el desmán. Suponemos que este efecto barrera sería la causa básica de la ausencia del desmán en las subcuencas del Flamisell, Noguera Ribagorçana, Ésera y Cinca-Ara. La colonización surpirenaica en sentido E-W de estas subcuencas desde el Noguera Pallaresa o el Segre es improbable, ya sea por via acuática (la confluencia de las subcuencas se produce muchos kilómetros al sur del área de las zonas con presencia de desmán y en tramos ambientalmente inadecuados) o por vía terrestre (los "pasos fáciles" entre subcuencas son también casi inexistentes). Datos moleculares recientes (Igea et al., 2013) son coherentes con un escenario de recolonización postglacial de los Pirineos en sentido $W$-E, ya que muestran una diversidad genética muy baja de las poblaciones pirenaicas de desmán en comparación con las cantábricas, y refuerzan esta hipotésis inferida en base al patrón de distribución de la especie.

Pero esta interpretación de la no-colonización postglacial debida a la existencia de barreras geográficas NS no parece válida para la cuenca del Gállego, ni para las subcuencas menores del Lubierre y el Estarrún en Aragón occidental. En el Gállego una colonización terrestre desde la vertiente norpirenaica es potencialmente fácil, pues existe contacto entre cuencas en una zona de baja altitud. En las subcuencas del Estarrún y del Lubierre una colonización histórica desde el Aragón Subordán también es viable, sin contar con la incierta existencia del desmán en el Aragón hasta tiempos recientes. La ausencia en estas subcuencas es posible que tenga menos relación con la probabilidad de colonización que con unas condiciones territoriales poco adecuadas para sustentar poblaciones de desmán viables a largo plazo. Estas condiciones serían una disponibilidad de hábitat limitada (escasa longitud de los tramos fluviales óptimos para el desmán) y una red fluvial excesivamente simple (limitada al río principal y a escasos afluentes), que harían que una eventual población de desmán tuviera un alto riesgo de extinción en caso de acontecimientos catastróficos. Esta hipótesis se ha planteado también en el apartado anterior para explicar las citas puntuales en las subcuencas del Aragón y del Beral, y como en esos casos no se puede excluir que en las subcuencas del Gállego, Estarrún y Lubierre se puedan producir apariciones esporádicas de desmán o que incluso se lleguen a establecer poblaciones temporales. A pesar de esta posibilidad, no conocemos ningún dato seguro de la especie en estas subcuencas, por lo que por el momento deben ser excluidas del área de distribución.

\section{Área de ocupación en los Pirineos mediterráneos}

El área de ocupación, o superficie en la cual una especie se encuentra de modo más o menos regular, es un parámetro de gran interés para la gestión, ya que resulta imprescindible para realizar una estimación poblacional. El desmán utiliza hábitats lineales, constituidos por una red de cursos de agua con anchuras desde $1 \mathrm{~m}$ hasta más de $10 \mathrm{~m}$. Por este motivo la estimación del área de ocupación como superficie es muy difícil, pero es posible una aproximación al área de ocupación expresándola como longitud.

La Tabla 5 expone la longitud estimada de los tramos fluviales con presencia más o menos regular o habitual de desmán, según cuencas. Se consideran tramos de presencia regular aquellos en los que se supone que el desmán está presente de modo permanente y aquellos en los que tiene una presencia temporal pero recurrente y de alta frecuencia. Estas estimaciones deben interpretarse con cautela, pues la calidad de los datos utilizados es muy diversa (altamente fiable para los ríos catalanes y aragoneses, más grosera para los Pirineos orientales en Francia y para Navarra), pero constituyen una primera aproximación útil al área de ocupación. No se ha considerado la ocupación en las subcuencas del Ezka y el Salazar en Navarra, donde la especie parece efectivamente presente pero casi no está documentada, ni en las de los ríos Arakil (afluente del Arga) y Beral (afluente del Aragón), en los cuales la presencia no está confirmada pero es posible.

De acuerdo con estas estimaciones, el área de ocupación del desmán en el conjunto de las cuencas fluviales de los Pirineos mediterráneos estaría entre 1200 y 1660 $\mathrm{km}$. La mayor parte-alrededor de un $80 \%$ con los datos de la tabla- de esta área se sitúa en la mitad oriental pirenaica. Las poblaciones de cada cuenca pirenaico-oriental o subcuenca del Ebro se pueden considerar aisladas, sin contactos con las poblaciones vecinas o sólo con contactos accidentales, y tienen áreas de ocupación muy diversas, desde sólo 20 km en el Aragón Subordán hasta más de $300 \mathrm{~km}$ en el Segre. Pero hay que tener también en cuenta la fragmentación de las poblaciones dentro de cada cuenca, ya sea por causas naturales o antrópicas, que conduce a la formación de subpoblaciones poco interconectadas. El área de ocupación de estas subpoblaciones 


\begin{tabular}{|l|l|l|}
\hline $\begin{array}{l}\text { Subcuenca } \\
\text { Subbasin }\end{array}$ & $\begin{array}{l}\text { Distribución } \\
\text { estimada }(\mathbf{k m}) \\
\text { Estimate range } \mathbf{( k m})\end{array}$ & Observaciones \\
\hline Ter & $50-100$ & $\begin{array}{l}\text { Poblaciones de las subcuencas } \\
\text { del Ter y el Freser desconectadas } \\
\text { (20-50 km por cuenca) }\end{array}$ \\
\hline Tec & $70-100$ & $\begin{array}{l}\text { Aparentemente sin problemas de } \\
\text { conexión entre subcuencas. }\end{array}$ \\
\hline Tet & $150-200$ & $\begin{array}{l}\text { Poblaciones de las subcuencas } \\
\text { más orientales probablemente } \\
\text { desconectadas del resto. }\end{array}$ \\
\hline Aude & $>150$ & $\begin{array}{l}\text { Población aislada en el río Orbion } \\
\text { (Orbieu), en 20-40 km. Aparentemente } \\
\text { sin problemas graves de conexión en } \\
\text { el resto de la cuenca. }\end{array}$ \\
\hline Aglí & $50-100$ & $\begin{array}{l}\text { Aparentemente sin problemas graves } \\
\text { de conexión entre subpoblaciones. }\end{array}$ \\
\hline Segre & $250-410$ & $\begin{array}{l}\text { Probablemente sólo existe una buena } \\
\text { conexión entre subpoblaciones en la } \\
\text { cuenca superior. En el resto de la cuenca } \\
\text { parece existir escasa conexión entre } \\
\text { subpoblaciones, limitadas a subcuencas } \\
\text { con 10-30 km de hábitat adecuado. }\end{array}$ \\
\hline Noguera Pallaresa & c. 280 & $\begin{array}{l}\text { Aparentemente forma dos grandes } \\
\text { subpoblaciones con unos 100 km de } \\
\text { presencia (alto Noguera Pallaresay } \\
\text { sistema Noguera de Cardós-Vallferrera) } \\
\text { y varias subpoblaciones menores } \\
\text { bastante desconectadas que ocupan } \\
\text { subcuencas de 10-20 km. }\end{array}$ \\
\hline Arga & $\begin{array}{l}\text { Según los datos disponibles se trata } \\
\text { de una población aislada. }\end{array}$ \\
\hline Aragón Subordán & c. 20 & $\begin{array}{l}\text { Poblaciones de los ríos Irati, Erro y } \\
\text { Urrobi quizá desconectadas. Mayor } \\
\text { parte del hábitat potencial en la } \\
\text { subcuenca del lrati (60-80 km). }\end{array}$ \\
\hline $\begin{array}{l}\text { No se considera la posible presencia } \\
\text { en la subcuenca del Arakil. }\end{array}$ \\
\hline
\end{tabular}

Tabla 5. - Estimación orientativa del área de ocupación ( $\mathrm{km}$ de tramos fluviales) de Galemys pyrenaicus en las cuencas mediterráneas de los Pirineos. No se considera subcuenca del Salazar (sistema del Irati, Navarra), porque los datos disponibles son muy débiles.

Table 5. Rough estimate of the area of occupancy (km of river) of Galemys pyrenaicus in Mediterranean basins of the Pyrenees. Salazar subbasin (Irati system) is excluded because available data are very weak.

puede llegar hasta mínimos de unos $10 \mathrm{~km}$. El aislamiento total o parcial de las poblaciones de cuenca y de algunas subpoblaciones hace recomendable que cada una sea tratada como una unidad de gestión.

\section{HÁBITAT}

El desmán es un mamífero semiacuático, que prácticamente siempre se desplaza y alimenta en los ríos. Durante todas las horas de seguimiento de individuos radiomarcados en el periodo 2002-2004 sólo se detectaron fuera del río cuando estaban dentro de los refugios en los márgenes fluviales, y los desplazamientos controlados siempre se realizaron en el agua.

Existen algunas observaciones de desmanes activos fuera del agua, pero se deben considerar excepcionales, no ligadas a la actividad normal de la especie. En general se ha considerado que la mayor parte de estas observaciones terrestres son involuntarias y accidentales, correspondiendo a animales que se habían extraviado después de ser arrastrados por crecidas del río o por canalizaciones artificiales. Sin embargo, algunas raras observaciones sugieren que hay desplazamientos terrestres que podrían ser voluntarios, como es el caso de un individuo observado en el departamento de Ariège en setiembre de 2008, a $2700 \mathrm{~m}$ de altitud y a unos $300 \mathrm{~m}$ del curso de agua más próximo (J. Cron, en: http://abela.ariegenature.fr/Desman), o de otro que se desplazaba entre rocas cercanas al lecho de un torrente de alta montaña en el valle de Mantet (Pirineos orientales). Estas observaciones en zonas de gran altitud resultan especialmente interesantes, pues podrían indicar una tendencia innata de algunos desmanes de continuar la marcha fuera del agua cuando llegan al nacimiento de los pequeños torrentes por los que se desplazaban. En estas situaciones algunos individuos podrían llegar a realizar con éxito desplazamientos terrestres largos y a cambiar de cuenca hidrográfica.

El uso de hábitats acuáticos no fluviales es muy limitado y en general debe considerarse anecdótico, aunque interesante. La presencia de desmanes en aguas estancadas se ha confirmado en más de una ocasión, a partir de observaciones fiables, excrementos o incluso de una filmación reciente en un estanque del macizo de Madres en los Pirineos orientales (S. Abdulhak, com. pers). Pero el uso de las aguas estancadas parece muy poco habitual, ya que en ninguno de los lagos de montaña prospectados en los muestreos pirenaicos fue posible detectar excrementos de desmán, a pesar de existir casi siempre una buena disponibilidad de sustratos adecuados (rocas). Estos resultados coinciden con los de Queiroz et al., (1998) para Portugal, quienes indican que ni los pequeños lagos de montaña ni los embalses artificiales son hábitats adecuados para el desmán. La presencia escasa en lagos y estanques se puede explicar tanto por una menor disponibilidad de presas atractivas (larvas de plecópteros y tricópteros de talla grande) como por una menor accesibilidad a éstas a causa de la profundidad y de la mayor resistencia del agua estancada al buceo, limitación ésta que ya fue indicada por Richard (1985). Por otra parte, el uso esporádico de corrientes de agua subterránea está documentado desde hace tiempo en los Pirineos (Queiroz et al., 1996) y recientemente también en el Sistema Cantábrico (García \& Mateos, 2007).

El uso de un determinado sector fluvial por el desmán está condicionado por varios factores naturales de escala diversa y también por factores antrópicos. Se pueden distinguir por lo menos tres grupos de factores:

1. Factores naturales que inciden en las características del hábitat a gran escala, afectando la idoneidad para el desmán del conjunto de una subcuenca, de un río o de tramos fluviales de gran longitud (varios kms).

2. Factores naturales que inciden en las características del hábitat a escala local, afectando la adecuación para el desmán de tramos fluviales cortos (en general menos de $1 \mathrm{~km}$ ).

3. Factores antrópicos que modifican la adecuación para el desmán de las condiciones naturales de un río o de un tramo fluvial.

En los apartados siguientes se comentan estos tres grupos de factores. 


\section{Hábitat a gran escala}

\section{Antecedentes}

La absoluta dependencia del desmán de los ambientes fluviales hace que muchos de los factores que condicionan la adecuación del hábitat tengan relación con las características del conjunto de una cuenca o subcuenca hidrográfica, y no con las características locales de un determinado tramo de río. Aunque la influencia de estos factores ambientales a gran escala (cuenca o subcuenca) es muy importante y se intuyeron desde los primeros trabajos sistemáticos sobre la especie (Peyre, 1956; Richard, 1985) no fueron tratados de un modo algo detallado hasta hace un par de décadas, en general para interpretar las causas de la distribución.

El factor que fue citado en los estudios pioneros realizados en los Pirineos franceses fue la pluviometría de la cuenca, que condiciona el caudal de los cursos fluviales. Al revisar la distribución del desmán en Francia, Bertrand (1993) señala que todas las localidades de desmán se encuentran en cuencas fluviales que tienen una parte importante con una pluviometría superior a $1000 \mathrm{~mm}$ anuales. Este autor indica que también podría influir el régimen del caudal, señalando que todas las cuencas francesas en las que está presente presentan dos máximos, en mayo y en el otoño. Por el contrario, Bertrand ya señala que la altitud -un factor tradicionalmente considerado importante- no parece condicionar la distribución del desmán de forma directa, sino indirectamente por su relación con la pluviometría, de modo que en las zonas de influencia oceánica -con precipitaciones abundantes y bien repartidas- la especie desciende hasta altitudes muy bajas, mientras que cuando la influencia oceánica se atenúa el desmán tiende a concentrarse en las montañas.

La ampliación progresiva de los estudios sobre distribución al conjunto de la Península Ibérica permitió precisar cuáles eran los factores ambientales de gran escala que condicionan el hábitat del desmán, ampliando la percepción bastante limitada que generaban los estudios en una zona relativamente homogénea como es la vertiente norte de los Pirineos.

Nores et al. (1993) analizan la distribución del desmán en España y establecen que su presencia está correlacionada positivamente con las precipitaciones (por su influencia en el caudal de los ríos) y con la pendiente (que no está necesariamente vinculada con la altitud), confirmando y precisando algunos de los factores ya citados o intuidos en los estudios franceses. Pero también aportan como novedad importante la correlación positiva con la regularidad del flujo de agua anual y con un bajo coeficiente de irregularidad del flujo; este coeficiente está ligado a las precipitaciones, pero también a la innivación y a la regulación cárstica, limitando pues la influencia decisiva que hasta ese momento se suponía de las precipitaciones totales. Por lo tanto, la incorporación a los análisis de cuencas fluviales con fuerte influencia mediterránea y fluctuaciones del nivel de agua permitió concretar un factor ambiental básico para el desmán, que es la regularidad del flujo de agua, y que sólo había sido in- tuido en el Pirineo francés, donde los cursos fluviales no suelen tener estiajes marcados. Otra contribución importante de Nores \& García-Alvarez (1995) al análisis de los factores ambientales a gran escala es la introducción del probable vínculo entre población mínima viable y red fluvial disponible, una cuestión que es básica para la gestión de la especie. Estos autores, sin embargo, se limitan a apuntar el factor sin desarrollarlo, comentando que en zonas oceánicas existe mucha disponibilidad de hábitat potencial incluso en cuencas fluviales pequeñas, mientras que en las zona mediterráneas la red fluvial suele ser mucho más simple y el hábitat potencial a menudo queda restringido a los ríos principales.

En Portugal Queiroz et al., (1998) se centran especialmente en el análisis del hábitat a escala local. Sin embargo relativizan la importancia de la regularidad del flujo de agua, ya que indican que el desmán puede presentarse puntualmente en cursos de agua con estiajes marcado, algo ya señalado también para Portugal por Quaresma (1995), pero precisando que eso ocurre siempre con la condición de que estos cursos de agua fluctuantes estén conectados con ríos permanentes. Este dato es menos anecdótico de lo que pueda parecer y resulta muy interesante por dos motivos. Por un lado refuerza la importancia de los factores ambientales a escala de cuenca, que aparecen como más determinantes que los factores de escala local para la existencia de poblaciones viables de desmán. Por otra parte resulta muy destacable porque pone de manifiesto que la presencia de desmán en un curso fluvial no es necesariamente permanente, en contra de lo que se había supuesto tradicionalmente, y en concordancia con lo que sugieren los datos que hemos acumulado con las campañas sucesivas de muestreo y capturas en los Pirineos meridionales. Dicho de otro modo, estas observaciones aparentemente anecdóticas en Portugal son el primer indicio consistente de que los factores de hábitat a escala local no tienen porqué ser permanentes, pero los factores ambientales a escala de cuenca sí deben mantenerse más o menos adecuados de forma permanente: puede haber tramos de río o afluentes que sean hábitats temporales adecuados para el desmán, pero una cuenca fluvial siempre debe asegurar una disponibilidad mínima de hábitats adecuados. Esta cuestión es básica para la evaluación de la población mínima viable, que sin duda está ligada al hábitat mínimo disponible, y en consecuencia para la gestión de la especie.

Factores ambientales de gran escala en los Pirineos meridionales

La mayor parte de las cuencas fluviales de los Pirineos meridionales tienen una clara influencia climática mediterránea, que se traduce en una pluviometría más irregular y en general menor que la de los Pirineos septentrionales de marcado carácter atlántico. En Aymerich \& Gosálbez (2002) se analizaron los factores que condicionan el hábitat a gran escala en Cataluña, donde se sitúa la mayor parte de la población de desmán en los Pirineos de in- 
fluencia mediterránea. Esta información se amplió o concretó con los resultados de campañas posteriores, con las cuales se prospectó el desmán en Andorra y Aragón. Los resultados obtenidos confirman, en general, la incidencia de la mayor parte de los factores ambientales indicados en trabajos previos, aunque con precisiones.

De entrada hay que decir que no parece existir ningún factor ambiental natural que individualmente determine la presencia del desmán a gran escala (cuenca fluvial), como sucede también con los factores que condicionan su presencia a escala local (tramos fluviales). A escala media (subcuenca) sí existe un factor individual que puede determinar la ausencia del desmán: la litología dominante en la cuenca de drenaje; este factor no había sido citado explícitamente en trabajos previos, porque los casos en que actúa en solitario son escasos y en general afecta más a la densidad de la especie que a su ausencia o presencia. El resto de factores ambientales a gran escala están más o menos interrelacionados y prácticamente siempre hay por lo menos dos factores que condicionan el hábitat del desmán, ya sea actuando de forma directa o indirecta. Se excluyen de estas consideraciones los factores antrópicos, que sí pueden condicionar individualmente el hábitat a gran escala y se comentan en un apartado propio.

Además de los factores ambientales que definen la calidad de hábitat, es básico tener en cuenta la cantidad de hábitat, que es un factor tanto o más determinante para explicar la presencia del desmán a escala de cuenca fluvial. En otras palabras, la presencia de "hábitats de calidad" en una cuenca no es suficiente para que exista desmán si estos hábitats no tienen una determinada extensión y/o conectividad. La información recopilada en los Pirineos meridionales indica que resulta fundamental una disponibilidad mínima de hábitat potencial, en la línea de lo sugerido por Nores et al. (1993) y seguramente éste es el factor que más incide en el mantenimiento de una población mínima viable. Sin embargo, en la viabilidad de las poblaciones pueden influir otros factores además de la extensión del hábitat, en especial la complejidad de la red fluvial. La disponibilidad mínima de hábitat potencial debe depender básicamente de la disponibilidad de alimento para el desmán (productividad total, distribución espacial y fluctuaciones), que es muy diversa según los cursos fluviales, por lo que no es viable establecer una extensión-tipo expresada en $\mathrm{km}$ de río o en $\mathrm{m} 2$ de lecho fluvial. El análisis de este factor sólo resulta viable a escala regional, considerando redes fluviales de características similares. De acuerdo con los datos actuales, en los Pirineos meridionales la disponibilidad mínima de hábitat se situaría alrededor de los $20 \mathrm{~km}$ de red fluvial adecuada para el desmán, ya que todas las poblaciones muy aisladas por causas naturales o antrópicas se encuentran en subcuencas con esta extensión mínima. Es probable que esta cifra se pueda extrapolar a muchas zonas de influencia mediterránea, pero en las cuencas de clima oceánico podría ser más baja.

Una vez asegurada esta disponibilidad mínima de hábitat potencial, adquiere importancia la calidad del há- bitat, ya sea a escala amplia o local. Esta calidad del hábitat se obtiene por diversas combinaciones de factores. Los factores ambientales que en los Pirineos meridionales tienen alguna incidencia a escala de cuenca o subcuenca son los siguientes:

\section{1- Regularidad del caudal:}

Es un factor ambiental básico y que actúa de modo directo sobre la presencia del desmán, ya sólo se encuentran poblaciones en zonas fluviales amplias (subcuencas) en las que la mayor parte de los cursos de agua mantienen buenos niveles de agua a lo largo de todo el año, sin experimentar los estiajes marcados que son característicos de los ríos mediterráneos. El caudal poco fluctuante se puede conseguir gracias a una pluviometría alta y regular, tal como han indicado casi todos los autores que han analizado la distribución y el hábitat del desmán, pero también gracias a la innivación o a la regulación cárstica, como pusieron de manifiesto Nores et al., (1993). En los Pirineos de influencia mediterránea, donde las lluvias son bastante irregulares, se ha evidenciado que el mantenimiento del caudal depende de una buena innivación en la cabecera de las cuencas, que garantiza una liberación progresiva del agua a los ríos hasta el verano; por este motivo la distribución del desmán está limitada a cuencas con una parte importante de su cabecera en altitudes superiores a 2000 m y en ríos con régimen hídrico nival o nivo-pluvial. Es muy probable que las precipitaciones sean suficientes para garantizar un caudal regular en las subcuencas navarras de los Pirineos, ya que tienen una influencia oceánica muy marcada, aunque en estos sectores la innivación también suele ser importante. Sin embargo, no se ha observado ninguna subcuenca fluvial en la que la regulación cárstica del caudal sea un factor determinante para explicar la presencia del desmán.

\section{2- Pluviometría:}

La pluviometría incide en la presencia del desmán de modo indirecto y limitado, mediante su influencia en el caudal de los cursos fluviales. En líneas generales, parece un factor determinante en zonas de influencia atlántica, con precipitaciones muy regulares, pero secundario en las zonas de influencia mediterránea, que tienen precipitaciones con marcada irregularidad estacional e interanual. A diferencia de lo que se ha indicado para los Pirineos septentrionales de influencia atlántica (Bertrand, 1993), en los Pirineos meridionales de influencia mediterránea la pluviometría anual no explica la presencia del desmán a escala de cuenca o subcuenca. Existen poblaciones importantes de desmán en zonas donde la mayor parte de los ríos discurre por entornos con precipitaciones medias inferiores a $900 \mathrm{~mm}$ (cuenca superior del Noguera Pallaresa) y, en cambio, está ausente de redes fluviales de zonas con precipitaciones superiores a 1000 mm (cuenca alta y media del Fluvià) pero con marcadas fluctuaciones estacionales e interanuales; la diferencia entre estas zonas está en la innivación de las 
cabeceras, importante en el Noguera Pallaresa y muy débil en el Fluvià. En zonas de influencia mediterránea, pues, las precipitaciones en forma de nieve en la cabecera fluvial son un factor mucho más determinante que las precipitaciones totales en el resto de la cuenca y que afectan el caudal circulante en los ríos. La pluviometría local de los tramos fluviales con poblaciones de desmán en los Pirineos meridionales va desde $600 \mathrm{~mm}$ hasta más de $1200 \mathrm{~mm}$, pero siempre se trata de tramos con una clara influencia nival en el régimen hídrico. Aunque la pluviometría del entorno se mantenga constante, el desmán desaparece de los tramos fluviales en los que la influencia nival en el caudal ya está muy atenuada.

Aunque la irregularidad de la pluviometría parece claramente negativa para el desmán no se conoce con detalle de qué modo actúa. Parece que el factor principal sería su incidencia en la disponibilidad y predictabilidad del alimento, ya que los cursos fluviales con caudal irregular tienen también poblaciones de invertebrados muy fluctuantes. Pero la irregularidad del caudal también incrementa la probabilidad de crecidas de carácter catastrófico, que podrían causar una mortalidad elevada de desmanes. Es posible que la concurrencia de ambos factores haga que los ríos mediterráneos de régimen hídrico pluvial sean demasiado impredecibles para sustentar poblaciones viables de desmán, que estarían sometidas a situaciones catastróficas de alta frecuencia.

\section{3- Materiales geológicos:}

La litología de la cuenca de drenaje de un curso fluvial determina las características físico-químicas del agua circulante, por lo que influye mucho en su productividad biológica. A medida que aumenta el orden de los cursos fluviales, la confluencia de varios afluentes va diluyendo la influencia de la litología, que sólo resulta intensa en cursos de primer y segundo orden, con subcuencas pequeñas. Los materiales geológicos de la cuenca tienen siempre una influencia notable en la densidad del desmán en un determinado río, ya que es un factor que condiciona mucho la disponibilidad de alimento (macroinvertebrados acuáticos). En algunos casos incluso puede suceder que la litología sea responsable de la ausencia habitual del desmán a escala de subcuenca. Estas raras situaciones parecen darse sólo en pequeñas subcuencas formadas por un único curso fluvial, en las que la litología hace que el agua sea oligotrófica y probablemente no tenga una productividad suficiente para sustentar una población de desmán. Este sería el factor principal que explica la ausencia del desmán en varias subcuencas de la sierra del Cadí, en los Pirineos orientales, con aguas muy carbonatadas y oligotróficas. Parece suceder algo parecido en un afluente de cabecera del Garona, el río Unhòla, en el que además del carbonato cálcico pueden influir los compuestos de hierro en el agua. Fuera de los Pirineos también se ha observado una presencia sorprendentemente baja de desmán en varios ríos cantábricos de los Picos de Europa, que podría explicarse también porque tienen aguas muy carbonatadas.

\section{4- Complejidad de la red fluvial:}

Es probable que la complejidad de la red fluvial tenga también alguna influencia en la presencia del desmán a escala de cuenca y subcuenca, ya que prácticamente no se conocen poblaciones de desmán que estén completamente aisladas en cuencas con una red muy simple, formada sólo por un río principal o por este más unos pocos afluentes poco favorables (caudal escaso y/o irregular). La única población conocida en esta situación es la del río Aragón Subordán, en el valle aragonés de Echo. Una red fluvial muy simple, con toda o casi toda la población de desmán concentrada en un solo río, hace que la especie resulte potencialmente muy vulnerable a eventos catastróficos (avenidas, sequías, enfermedades,...) que podrían provocar mortalidades masivas y comprometer la viabilidad de la población residual. Por el contrario, en redes complejas, aunque eventos catastróficos afectaran a una parte de la población, con el tiempo es posible una recolonización desde zonas no afectadas. Este podría ser uno de los factores que expliquen la ausencia del desmán en varias cuencas del Pirineo aragonés (Aragón, Gállego y quizá Beral), en las que sólo el río principal parece realmente favorable para la especie.

\section{5- Temperatura:}

La temperatura media anual de los sectores donde habitan todas las poblaciones de desmán en los Pirineos mediterráneos es igual o inferior a $10^{\circ} \mathrm{C}$, y además las temperaturas medias del mes más frío (enero) son inferiores a $2^{\circ} \mathrm{C}$ y las del mes más cálido (agosto) inferiores a $20^{\circ} \mathrm{C}$. Podría ser que la temperatura tuviera alguna influencia directa en la presencia del desmán, por ejemplo condicionando unas comunidades de macroinvertebrados acuáticos favorables (biomasa total, composición taxonómica, distribución por tallas, etc), pero es un aspecto casi desconocido.

\section{6- Pendiente:}

La pendiente es un factor que condiciona la presencia del desmán sobre todo a escala local (tramo fluvial), pero también a escala media. Influye directamente en la disponibilidad de hábitat a escala local, ya que está correlacionada con varios factores determinantes (en especial la granulometría del lecho, la cantidad de refugios y la heterogeneidad de las riberas). Es lógico, pues, que en zonas montañosas el desmán tenga más extensión de hábitat potencial disponible y sea más probable que existan poblaciones viables. Cuando los cursos fluviales se alejan de las montañas los factores favorables a escala local se reducen y están cada vez más localizados, por lo que el hábitat general resulta poco adecuado para el desmán y seguramente insuficiente para sustentar poblaciones viables. Pero hay que tener en cuenta que estas condiciones desfavorables también se pueden dar en el interior de zonas montañosas, allí donde existen valles muy abiertos. Estas situaciones desfavorables es frecuente que se den en tramos fluviales más o menos 
cortos (menos de $5 \mathrm{~km}$ ), pero ocasionalmente pueden afectar zonas muy extensas, como es el caso particular del curso alto del Segre desde Puigcerdà hasta la Seu d'Urgell (unos 50 km), donde el desmán no parece tener una presencia estable en el río principal y en cambio existen poblaciones en los afluentes laterales.

Aunque las pendientes pronunciadas son en general favorables para el desmán, cuando son muy fuertes también pueden ser un factor negativo. Se supone que inciden aumentando el carácter torrencial de los cursos de agua, que de modo recurrente -por el deshielo y por las tempestades estivales- experimentan crecidas con mucha energía cinética, a causa de las cuales el hábitat debe resultar demasiado inestable o impredecible para sustentar poblaciones viables de desmán. En general el desmán está ausente de pequeñas subcuencas formadas por torrentes permanentes pero poco caudalosos y con pendientes fuertes en casi todo su recorrido. Está menos claro que la pendiente sea determinante en subcuencas con cursos de agua más caudalosos, pero es el factor que aparece como más probable para explicar la aparente ausencia del desmán en algunas subcuencas del Noguera Pallaresa de tamaño medio, como son las de Escart y Qüanca.

La rareza extrema del desmán en los Pirineos aragoneses también podría estar relacionada con la pendiente, ya que muchas cuencas de este sector combinan las dos situaciones desfavorables. Por un lado, aunque estén rodeados de montañas altas, los ríos principales forman pronto valles anchos y de fondo llano, con características locales poco adecuadas para el desmán. Pero, además, los afluentes laterales suelen ser arroyos con pendientes muy fuertes, que experimentan muchas crecidas bruscas y con gran carga cinética. Estas crecidas también afectan directamente a los ríos principales, por lo que son al mismo tiempo un medio poco adecuado por factores de escala local (escasez de refugios, granulometría media,...) y altamente inestable por factores de escala media (alta frecuencia de crecidas potencialmente catastróficas).

\section{7- Altitud:}

La altitud es un factor que actúa indirectamente sobre la presencia del desmán, y que casi nunca condiciona su presencia a escala de cuenca o subcuenca. En contra de lo que se había supuesto en algunos estudios pioneros, se trata de una especie ligada a zonas con pendientes fuertes, pero no orófila. En la franja atlántica desde los Pirineos occidentales hasta el norte de Portugal es frecuente encontrarlo a baja altitud (casi hasta el nivel del mar), aunque siempre en sectores de relieve vigoroso. La asociación del desmán con zonas altas se da básicamente en los sectores marginales o subóptimos de su área de distribución, donde las condiciones climáticas de las zonas de baja altitud no permiten la existencia de cursos fluviales adecuados para la especie. En estos sectores la altitud actúa indirectamente sobre la presencia del desmán debido a su influencia en la regularidad del caudal de los ríos, que sólo está garantizado por la pluviometría (en forma de lluvia o de nieve) en las zonas de montaña. Este es el caso de los Pirineos de influencia mediterránea, en los que -como se viene repitiendo- la innivación es un factor básico en la distribución del desmán. En este sector la altitud influye en la presencia del desmán de dos modos: 1) La altitud de la cabecera de cuenca determina la presencia o ausencia del desmán, de tal modo que sólo hay poblaciones en cuencas con una parte apreciable de la cabecera a más de 2000 m, altitud que garantiza una innivación notable. 2) La presencia del desmán en un curso fluvial llega hasta donde la influencia nival en el régimen hídrico de los ríos es marcada, con una altitud mínima absoluta entre 700 y 500 m según cuencas, y con mayor parte de las poblaciones en altitudes por encima de $1000 \mathrm{~m}$. En consecuencia, en los Pirineos mediterráneos no existen poblaciones de desmán en el curso bajo de los ríos ni en subcuencas que no tienen cabeceras a más de 2000 m, y además es muy raro en el curso medio. En cambio, en los Pirineos atlánticos (Bertrand, 1993), donde el caudal de los ríos depende menos de la nieve, desciende a menudo por debajo de 500 m y resulta habitual entre 500 y 1000 m.

La altitud influye también en el límite superior de presencia del desmán, pero de un modo más limitado. El desmán es muy escaso a gran altitud, por encima de 1900-2000 m, donde los cursos fluviales tienen un régimen netamente nival y en general mantienen caudal durante todo el año. De acuerdo con la información disponible, las causas de la gran rareza de la especie en zonas de gran altitud estarían relacionadas sobre todo con la disponibilidad de alimento, por dos razones: 1) La productividad de los cursos de agua de alta montaña experimenta fluctuaciones estacionales más marcadas que en zonas de menor altitud; y 2) El acceso a los invertebrados acuáticos debe resultar difícil y energéticamente costosa durante 3-5 meses al año, a causa de la congelación de una parte considerable del agua circulante. Con estas condiciones es difícil que los cursos de agua situados a gran altitud, y en especial los poco caudalosos, puedan sustentar de modo permanente poblaciones de desmán. Es más probable que la presencia de esta especie en la alta montaña sea sólo temporal o estacional, y no es muy arriesgado suponer que puedan producirse desplazamientos estacionales de individuos río arriba, similares a los que se conocen en el caso del mirlo acuático, que explota la alta montaña en verano, después de haber nidificado en cotas más bajas.

\section{8- Vegetación:}

No hay evidencias de una influencia de la vegetación de la cuenca en la presencia actual del desmán. Es seguro que no es un factor determinante en el hábitat a gran escala, ya que existen poblaciones de desmán en cuencas y subcuencas en las que dominan coberturas vegetales muy diversas. Sin embargo, es probable que influya de modo indirecto en la densidad de las poblaciones, a causa de su incidencia en la productividad de las comunidades fluviales. En general las poblaciones de ma- 
croinvertebrados detritívoros -que constituyen la mayor parte del alimento del desmán- son favorecidas si en la cuenca hay una cobertura forestal importante (en especial de caducifolios). La cobertura forestal también favorece la regularidad del caudal de los ríos, limitando la amplitud de las crecidas y dando más estabilidad a las comunidades bióticas fluviales. Otro efecto positivo de la cobertura forestal es la reducción de los aportes al agua de tierras procedentes de la erosión, que si son importantes pueden afectar negativamente a las comunidades de invertebrados acuáticos. Por estos motivos es razonable pensar que puede existir una relación positiva entre cobertura forestal y densidad de desmán, aunque también se podrían conseguir efectos similares con coberturas densas de matorral o prado.

Una cuestión interesante y completamente desconocida es el efecto que históricamente pueda haber tenido la evolución de la cobertura vegetal en la actual distribución del desmán a escala de cuenca o subcuenca, pero se puede suponer que habrá tenido una influencia significativa, ya que es bien sabido que la desforestación de las cuencas es un factor que incide de forma intensa en la hidrología y en las comunidades de invertebrados fluviales. Hasta mediados del siglo XX los valles pirenaicos estaban mucho más desforestados que en la actualidad, y en algunas zonas la deforestación llegó a ser casi completa entre los siglos XVII y XIX. La desforestación extensiva favoreció la erosión, incrementando los aportes de tierras a los ríos, y también debió incrementar la frecuencia de las crecidas de carácter catastrófico y la inestabilidad de las comunidades bióticas fluviales. Se puede asumir que, bajo estas condiciones, muchos cursos de agua pirenaicos eran más inadecuados como hábitat para el desmán que en la actualidad. Es bastante probable que la deforestación fuera la causa histórica de extinciones en algunas subcuencas, que más tarde pueden haber sido recolonizadas o no. Resulta más incierto si la deforestación puede haber provocado -como causa única o en conjunción con otros factores- la extinción del desmán en el conjunto de alguna cuenca pirenaica. En este sentido, resulta sospechoso que algunas cuencas del Pirineo aragonés (Gállego, Aragón, Beral) sin causas claras que expliquen la aparente ausencia actual del desmán (no hay barreras geográficas claras y tienen disponibilidad de hábitat potencial, aunque limitado) sean también algunas de las que históricamente experimentaron deforestaciones más intensas; aunque no existan evidencias que lo indiquen, no se puede excluir que en estas cuencas la deforestación extensiva incrementara la inestabilidad del hábitat y se sumara a otros factores desfavorables (escasez de hábitat potencial, baja complejidad de la red fluvial, torrencialidad elevada de los ríos a causa de la orografía), induciendo mortalidades catastróficas en unas poblaciones de desmán naturalmente pequeñas, hasta llevarlas a la extinción.

\section{Hábitat a escala local}

El estudio del hábitat del desmán a escala local ha sido muy parcial. Los escasos trabajos realizados se han centrado en las características físicas de los cursos fluviales, por la relativa facilidad de muestreo, y solo ocasionalmente en las físico-químicas del agua. Sin embargo no existen estudios que relacionen la presencia o la densidad del desmán con el factor seguramente determinante, que es la disponibilidad de alimento (macroinvertebrados acuáticos). No hay que confundir este tipo de información con los datos sobre poblaciones de macroinvertebrados en ríos con poblaciones de desmán, que son relativamente frecuentes, ya sea como resultado de trabajos específicos (e.g. Bertrand, 1994) o de trabajos más rutinarios enmarcados en estudios de limnología o de control de calidad del agua. Las características físicas de los cursos fluviales y las físico-químicas del agua aportan información indirecta sobre la productividad de los ríos y la disponibilidad de alimento para el desmán, pero se trata siempre de aproximaciones demasiado groseras. Es importante, pues, advertir que los conocimientos sobre el hábitat local del desmán -tanto los publicados hasta la fecha que aquí se sintetizan como las nuevas aportaciones propias- se deben interpretar con cautela, ya que resultan claramente insuficientes para explicar las variaciones locales en la presencia de la especie. La interpretación de este tipo de resultados requiere aplicar siempre dos precisiones: 1) los factores que aparecen como favorables lo serán siempre que se cumpla la condición previa de que exista una buena disponibilidad de alimento (macroinvertebrados acuáticos); y 2) aunque se den factores en principio poco favorables, el desmán puede estar igualmente presente si la disponibilidad de alimento es muy elevada.

A grandes rasgos, las características básicas del hábitat del desmán fueron establecidas por Peyre (1956), quien de modo muy sintético relaciona esta especie con los "ríos trucheros". De acuerdo con este autor, los principales factores que determinan la idoneidad de un tramo fluvial para el desmán serían cinco: aguas oxigenadas, de corriente rápida y temperaturas frescas, con poblaciones importantes de invertebrados acuáticos y existencia de abrigos naturales en los márgenes del curso de agua. Se trata de una caracterización bastante acertada, que en general ha sido confirmada por estudios posteriores, si bien con la introducción de varias precisiones. Así, por ejemplo, Castién \& Gosálbez (1992) y Queiroz et al. (1998) amplían la presencia del desmán hasta algunos tramos fluviales de la zona de los ciprínidos, con menor corriente y aguas menos frescas, mientras que Quaresma (1995) lo detecta incluso en algunos cursos de agua temporales.

Nores \& García-Alvarez (1995) realizan el primer análisis detallado de la selección del hábitat del desmán a escala local y determinan que el principal factor favorable es la granulometría alta del lecho fluvial (predominio bloques), seguido de pendientes moderadas (10-30 m/km), profundidades máximas de $50-75 \mathrm{~cm}$, riberas no artificializadas y ausencia de contaminación. Por el contrario, aparecen como claramente desfavorables los tramos con granulometrías finas y contaminación notable.

Queiroz et al., (1998), con una muestra más amplia y metodológicamente homogénea de tramos fluviales, 
obtienen resultados bastante similares. Hallan una selección positiva de riberas con abundantes rocas, lechos con bloques y rocas, profundidades de $50-100 \mathrm{~cm}$, pendiente media o fuerte ( $>4 \%$ ) y ausencia de plantas emergidas en el lecho (indicadores de medios lénticos y granulometrías bajas).

A pesar de destacar la selección positiva de estos factores, Queiroz et al., (1998) señalan que se puede detectar la presencia del desmán en tramos fluviales de características muy diversas. Coinciden en este aspecto con nuestros resultados en los Pirineos, donde también ha sido detectado en tramos heterogéneos. La realidad es que resulta bastante difícil caracterizar un hábitat-tipo para el desmán. Aunque la imagen clásica del "río truchero" sigue siendo una referencia aceptable, en la práctica es bastante frecuente que sea imposible detectarlo en cursos de agua supuestamente idóneos y, por el contrario, aparece en otros en apariencia poco adecuados.

La dificultad de caracterizar cuantitativamente el hábitat local de la especie se pone de manifiesto con el análisis de los datos inéditos obtenidos con las prospecciones realizadas en Cataluña (Aymerich et al., 2000), Aragón (Aymerich \& Gosálbez, 2004a) y Andorra (Aymerich, 2004), que se comentan de modo sintético en los párrafos siguientes y que, en ningún caso, permitieron establecer una relación clara entre la presencia del desmán y unos parámetros ambientales concretos. Estos datos más bien parecen indicar que el desmán es una especie relativamente adaptable, siempre que disponga de unas condiciones mínimas que se pueden obtener por diversas combinaciones de factores.

Con los datos de las campañas de prospección realizadas en Cataluña, considerando el parámetro "presencia de desmán" y 11 parámetros ambientales para cada tramo fluvial, la presencia de desmán resultó la variable con una correlación más débil con todas las restantes. Analizando la correlación individual entre la variable presencia de Galemys y cada parámetro ambiental tan sólo se observó una relación positiva bastante débil con la granulometría, la disponibilidad de refugios y la heterogeneidad de los márgenes fluviales (respectivamente, R de Spearman: 0.187928, 0.274403 y 0.249884).

Aunque la precisión de los datos obtenidos en esas campañas -y en las de Aragón y Andorra- no permite análisis muy detallados sobre el hábitat, ya que el objetivo prioritario era conocer la distribución de la especie, se han realizado aproximaciones a este aspecto mediante el índice de electividad de Ivlev (para el conjunto de las cuencas fluviales prospectadas) y un Análisis de Correlaciones Múltiples (solo para las cuencas catalanas).

La Tabla 6 indica la selección obtenida con la aplicación del índice de electividad de Ivlev (Ivlev, 1961) para diversos parámetros ambientales individuales. Si bien este índice se ha usado especialmente para estudiar la selección de alimentos en función de su disponibilidad, también permite una aproximación sencilla a la selección del hábitat, en especial cuando se usan descriptores simples y se dispone de una muestra amplia. Se consideró que hay una selección fuerte cuando el índice E>0,4 y débil cuando $0,2<E<0,4$. Los resultados fueron bastante dispares según cuencas fluviales, por lo que se mues-

\begin{tabular}{|c|c|c|c|c|c|c|}
\hline & $\begin{array}{l}\text { Clases } \\
\text { Classes }\end{array}$ & $\begin{array}{l}\text { Galemys } \\
\text { Ter }\end{array}$ & $\begin{array}{l}\text { Galemys } \\
\text { Valira } \\
\text { (Andorra) }\end{array}$ & \begin{tabular}{|l|} 
Galemys \\
Noguera \\
Pallaresa
\end{tabular} & $\begin{array}{l}\text { Galemys } \\
\text { Garona }\end{array}$ & $\begin{array}{l}\text { Neomys } \\
\text { Aragón }\end{array}$ \\
\hline \begin{tabular}{|l|} 
Muestra \\
(n tramos) \\
Sample \\
(n sections)
\end{tabular} & & 48 & 102 & 105 & 44 & 238 \\
\hline \multirow{4}{*}{$\begin{array}{l}\text { Altitud (m) } \\
\text { Altitude (m) }\end{array}$} & $<1000$ & -- & $(-)$ & - & 0 & 0 \\
\hline & $1000-1400$ & 0 & 0 & 0 & 0 & 0 \\
\hline & \begin{tabular}{|l}
$1400-1800$ \\
\end{tabular} & $(+)$ & 0 & 0 & 0 & 0 \\
\hline & $>1800$ & $(+)$ & - & $(0)$ & $(-)$ & $(-)$ \\
\hline \multirow{4}{*}{$\begin{array}{l}\text { Anchura }(m) \\
\text { Width }(m)\end{array}$} & $<2$ & + & -- & 0 & -- & - \\
\hline & $2-5$ & -- & + & 0 & 0 & 0 \\
\hline & $5-10$ & -- & 0 & 0 & + & 0 \\
\hline & \begin{tabular}{|l|}
$>10$ \\
\end{tabular} & & & \begin{tabular}{|l}
$(-)$ \\
\end{tabular} & $(--)$ & - \\
\hline \multirow{3}{*}{\begin{tabular}{|l} 
Profundidad \\
máxima $(\mathrm{cm})$ \\
Maximum \\
depth $(\mathrm{cm})$ \\
\end{tabular}} & $<50$ & 0 & -- & 0 & 0 & 0 \\
\hline & 50-100 & 0 & + & 0 & 0 & 0 \\
\hline & \begin{tabular}{|l|}
$>100$ \\
\end{tabular} & $(--)$ & - & 0 & 0 & 0 \\
\hline \multirow{4}{*}{$\begin{array}{l}\text { Pendiente (\%) } \\
\text { Slope (\%) }\end{array}$} & $<2$ & & & \begin{tabular}{|l|}
$(--)$ \\
\end{tabular} & & 0 \\
\hline & $2-5$ & -- & 0 & 0 & 0 & 0 \\
\hline & $5-10$ & + & 0 & 0 & 0 & 0 \\
\hline & $>10$ & -- & 0 & 0 & 0 & 0 \\
\hline \multirow{5}{*}{$\begin{array}{l}\text { Granulometría } \\
\text { (indice) } \\
\text { Granulometry } \\
\text { (index) }\end{array}$} & 1 & $(--)$ & & $(-)$ & $(--)$ & $(--)$ \\
\hline & 2 & 0 & $(--)$ & 0 & $(--)$ & 0 \\
\hline & \begin{tabular}{|l}
3 \\
\end{tabular} & 0 & - & 0 & 0 & - \\
\hline & \begin{tabular}{|l}
4 \\
\end{tabular} & + & 0 & 0 & 0 & 0 \\
\hline & \begin{tabular}{|l}
5 \\
\end{tabular} & & ++ & 0 & 0 & \\
\hline \multirow{4}{*}{$\begin{array}{l}\text { Heterogenei- } \\
\text { dad márge- } \\
\text { nes (indice) } \\
\text { Banks hetero- } \\
\text { genity (index) }\end{array}$} & 1 & $(0)$ & 0 & $(+)$ & $(+)$ & 0 \\
\hline & \begin{tabular}{|l}
2 \\
\end{tabular} & -- & 0 & -- & -- & - \\
\hline & 3 & 0 & 0 & 0- & 0 & 0 \\
\hline & 4 & + & 0 & 0 & 0 & 0 \\
\hline \multirow{3}{*}{$\begin{array}{l}\text { Disponibilidad } \\
\text { de cavidades } \\
\text { (indice) } \\
\text { Cavities availa- } \\
\text { blity (index) } \\
\end{array}$} & 1 & -- & - & -- & -- & - \\
\hline & 2 & + & - & 0 & 0 & 0 \\
\hline & 3 & 0 & + & 0 & 0 & + \\
\hline \multirow{8}{*}{$\begin{array}{l}\text { Vegetación } \\
\text { dominante } \\
\text { Dominant } \\
\text { vegetation }\end{array}$} & \begin{tabular}{|l|} 
Prado \\
Meadows \\
\end{tabular} & & -- & (0) & 0 & 0 \\
\hline & $\begin{array}{l}\text { Herbazales } \\
\text { Tall grass }\end{array}$ & & + & 0 & $(--)$ & 0 \\
\hline & $\begin{array}{l}\text { Forestal no } \\
\text { riparia }\end{array}$ & $(+)$ & 0 & \begin{tabular}{|l|}
$(0)$ \\
\end{tabular} & 0 & 0 \\
\hline & $\begin{array}{l}\text { No riparian } \\
\text { forests }\end{array}$ & & & & & \\
\hline & \begin{tabular}{|l|} 
Sauceda \\
Willows
\end{tabular} & -- & \begin{tabular}{|l|}
$(-)$ \\
\end{tabular} & 0 & (0) & 0 \\
\hline & $\begin{array}{l}\text { Bosque } \\
\text { higrófilo } \\
\text { mixto }\end{array}$ & $(--)$ & 0 & 0 & 0 & 0 \\
\hline & $\begin{array}{l}\text { Mixed } \\
\text { hygrophilous } \\
\text { forest }\end{array}$ & & & & & \\
\hline & \begin{tabular}{|l} 
Aliseda \\
Alder forest
\end{tabular} & 0 & $(++)$ & 0 & 0 & 0 \\
\hline \multirow{5}{*}{$\begin{array}{l}\text { Sombra } \\
\text { (indice) } \\
\text { Shadow } \\
\text { (index) }\end{array}$} & 1 & $(+)$ & -- & -- & -- & 0 \\
\hline & \begin{tabular}{|l}
2 \\
\end{tabular} & -- & 0 & 0 & (0) & 0 \\
\hline & 3 & -- & 0 & 0 & 0 & 0 \\
\hline & \begin{tabular}{|l|}
4 \\
\end{tabular} & + & + & 0 & 0 & 0 \\
\hline & 5 & + & $(--)$ & 0 & 0 & 0 \\
\hline
\end{tabular}

Tabla 6. - Selección de varios parámetros ambientales locales por cuencas, según el índice de electividad de lvlev. 0: sin selección. ++/--: selección positiva o negativa fuerte. + +-: selección positiva o negativa débil. (+/-) selección positiva o negativa aparente, pero muestra poco significativa ( $<10 \%$ tramos). Los índices expresan el incremento relativo del valor del parámetro correspondiente. Table 6. Selection of various local environmental parameters in rivers, according to the Ivlev electivity index. 0: no selection. ++/--: Strong positive or negative selection. + / -: Weak positive or negative selection. (+/-) Apparent positive or negative selection, but unrepresentative sample ( $<10 \%$ of sections) Indices express the relative increase in the value of the respective parameter. 
tran por separado los de tres cuencas pirenaico-mediterráneas (Ter, Valira -afluente del Segre- y Noguera Pallaresa) y de una cuenca pirenaico-atlántica (cabecera del Garona). Estas cuatro cuencas pueden considerarse bastante representativas de situaciones diferentes: la del Noguera Pallaresa y Garona representan cuencas con una red fluvial poco perturbada por la actividad antrópica, respectivamente en las zonas de influencia mediterránea y atlántica de los Pirineos; las del Valira y el Ter representan cuencas alteradas antrópicamente, en las cuales el desmán ha sufrido una retracción y probablemente ha quedado acantonado en zonas marginales (cabeceras y afluentes pequeños). También se presentan los resultados obtenidos con Neomys sp. en los Pirineos aragoneses.

En la Tabla 6 se puede observar que en las dos cuencas con cursos de agua poco alterados (Noguera Pallaresa y Garona) el desmán se muesta como una especie bastante generalista, que sólo selecciona de modo claro unas pocas categorías y que, de modo sorprendente, éstas corresponden a parámetros que no están relacionados directamente con el medio acuático: selecciona negativamente los tramos con márgenes homogéneos (predominio claro de playas de grava o cantos o bien de taludes terrosos), la baja disponibilidad de cavidades donde esconderse (en general bajo rocas situadas en la ribera o en medio de la corriente) y los ambientes muy luminosos. Los dos primeros factores están muy interrelacionados (en los tramos con riberas heterogéneas casi siempre existen más cavidades) y su influencia se explica sobre todo por la importancia de las cavidades-refugio situadas en las riberas, que son persistentes y probablemente tienen una función social clave para las poblaciones de desmán. La interpretación de la selección negativa de los tramos con luminosidad alta es más incierta, pero es probable que no tenga una influencia directa, sino que sea un indicador de la concurrencia de varios factores poco favorables que con frecuencia están asociados a la ausencia de sombra (cauces anchos, riberas homogéneas con escasos refugios, granulometría baja, etc) (Fig 3).

La comparación de los resultados del Noguera Pallaresa con los del Garona indica que existen escasas diferencias en la selección del hábitat a escala local en las zonas de influencia atlántica y de influencia mediterránea. Parece claro que la selección negativa de las altitudes inferiores a $1000 \mathrm{~m}$ en la cuenca mediterránea es debida a un factor ambiental de gran escala, la dependencia de los ríos con influencia nival, situación que no se daría en la cuenca atlántica, en la que estas altitudes aparecen como neutras. Se desconoce la causa de las diferencias que se observan en la selección de la anchura del cauce, pero también podrían tener una relación indirecta con los factores climáticos y la altitud. En las cabeceras fluviales de zonas de influencia atlántica la pluviometría elevada hace que las dimensiones medias de los cursos de agua sean mayores que en las de influencia mediterránea, por lo que es probable que gran parte de los tramos de la cuenca del Garona con anchura menor de $2 \mathrm{~m}$ sean torrentes situados a gran altitud, desfavorables para el desmán por su baja productividad y las heladas persistentes. Por su parte, la débil selección positiva de los tramos de anchura media (5-10 m) en el Garona podría indicar una tendencia a utilizar más los ríos de fondo de valle altamente productivos en las zonas atlánticas, mientras que en las zonas de influencia mediterránea estos ríos no serían seleccionados porque una parte de ellos ya presenta un caudal más fluctuante.

En las dos cuencas poco perturbadas, el desmán no selecciona claramente ninguna categoría aparte de las ya citadas. Sólo se intuye la selección negativa de determinadas categorías extremas (cauces de anchura superior a $10 \mathrm{~m}$, granulometrías muy bajas y pendientes inferiores al $2 \%$ ), lo que es más o menos coherente con los resultados de Nores \& García-Alvarez (1995) y Queiroz et al., (1998), pero en todos estos casos la muestra es

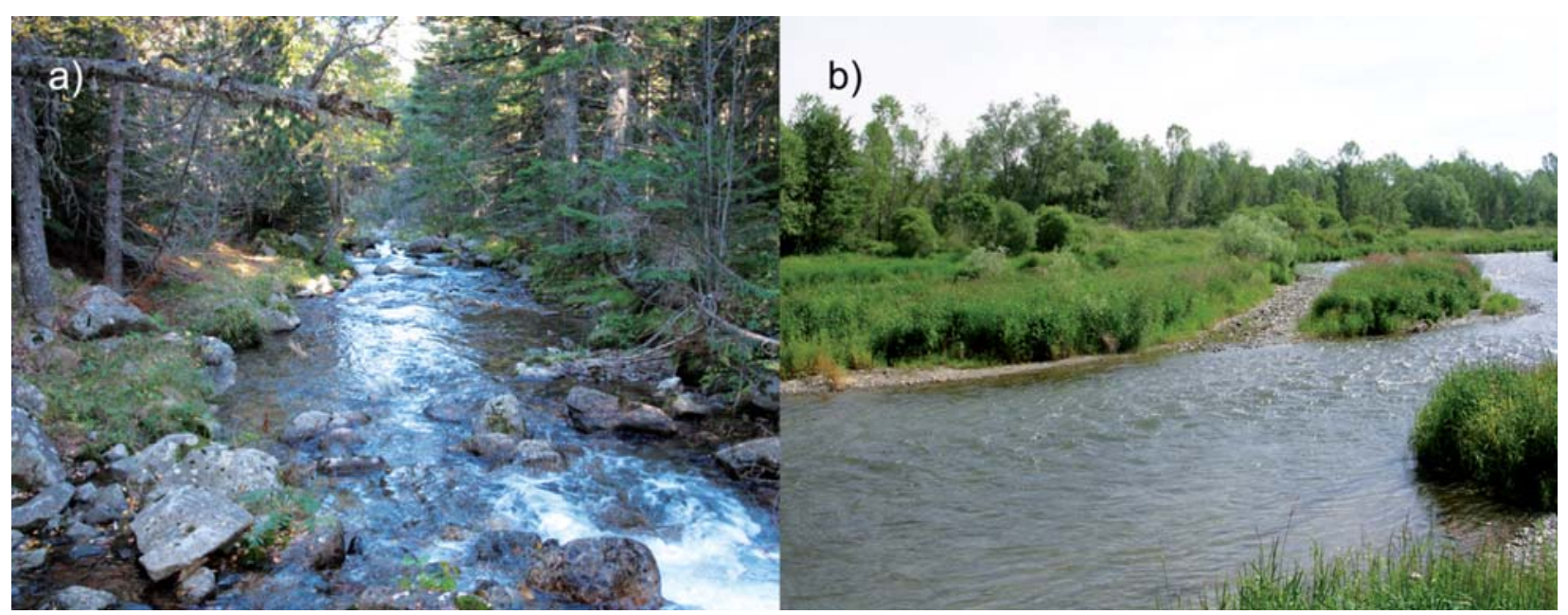

Fig. 3. - a) Hábitat óptimo (río Toran, cuenca del Garona) (Autor: José Castresana); b) hábitat no favorable (río Segre en la Cerdanya) para el desmán ibérico. (Autor: Pere Aymerich).

Fig. 3. - a) Optimal habitat (Toran river, Garona basin) (Author: José Castresana); b) Non-favourable habitat (Segre river, Cerdanya region) for the Iberian desman. (Author: Pere Aymerich). 
poco representativa. Estas tres categorías están relacionadas casi siempre con tramos fluviales que discurren por terrenos bastante llanos, correspondientes a fondos de valle en el curso superior de los ríos o bien a tramos que ya se sitúan en el curso medio. Su selección negativa sería un indicador del vínculo del desmán con zonas de relieve montañoso, aunque no necesariamente altas.

Resulta interesante que en las dos cuencas perturbadas antrópicamente (Ter y Valira) el desmán muestre una selección más marcada de las categorías de muchos parámetros ambientales. Se supone que este hecho es debido básicamente a la retracción reciente del área de presencia de la especie hacia las zonas con menor influencia humana Así, en la cuenca del Ter la selección negativa de los ríos anchos (2-10 m), de las pendientes moderadas (2-5\%) y de los bosques ribereños de sauces (asociados en general a fondos de valle y a depósitos de gravas) puede explicarse como una consecuencia del acantonamiento del desmán en algunos pequeños afluentes laterales y en las cabeceras de los ríos principales. En la cuenca del Valira la regresión del desmán ha sido menos uniforme que en la del Ter, por lo que parte de las selecciones aparentes deben ser artefactos derivados de la diversa representación territorial de las categorías, pero también se pueden relacionar con la desaparición del desmán en los valles principales algunas selecciones (negativa de las granulometrías medias, las riberas con prados y las profundidades superiores a $1 \mathrm{~m}$, positiva de las granulometrías más altas y de condiciones de sombra altas).

El análisis de correlaciones múltiples de los datos de hábitat local en Cataluña no indica una correlación clara entre la presencia de desmán y unas determinadas características del curso fluvial, no permite caracterizar un "río-tipo" para el desmán. Sin embargo, sí pone de manifiesto la influencia positiva o negativa clara de algunos factores, en especial con los asociadas a las características de las riberas. Según este análisis, los parámetros con influencia clara en la presencia de desmán serían estos:

Variables asociadas al caudal y a la cuenca:

Favorables: Pendiente media-alta (5-10\%).

Desfavorables: Granulometrías medias (predominio de gravas).

\section{Variables asociadas a las riberas:}

Favorables: Márgenes fluviales muy heterogéneos (con bloques de roca, taludes terrosos, pequeñas playas, etc), disponibilidad media o alta de refugios, vegetación forestal y niveles altos de sombra.

Desfavorables: Márgenes fluviales homogéneos (predominio de playas o de roca madre), disponibilidad baja de refugios y niveles de sombra bajos.

El resto de variables o clases analizados (se indican en la Tabla 6) no mostró ninguna influencia clara en la pre- sencia de desmán, pero hay que precisar que la muestra disponible de algunas clases era demasiado baja para permitir un análisis fiable.

La conclusión que se puede extraer de estos resultados es que el desmán aparece como una especie ligada a cursos fluviales de zonas de relieve montañoso, pero poco estricta en la selección de las características del hábitat a escala local. El factor que resulta más determinante es la disponibilidad de refugios adecuados, que habitualmente está ligada a unas riberas heterogéneas (alternancia de bloques de roca, taludes terrosos, pequeñas playas, etc) y estructuralmente complejas. La selección regional de otros factores parece secundaria, como resultado de condicionantes climáticos generales (por ejemplo, la preferencia por zonas altas en las cuencas mediterráneas) o de perturbaciones antrópicas (retracción reciente de la especie hacia cursos de agua pequeños en zonas marginales, como en los casos del Ter y el Valira). Cuando se realicen estudios sobre el hábitat de la especie a escala local o regional es importante tener en cuenta el efecto de estas "falsas selecciones" de origen antrópico, ya que deben resultar bastante habituales a causa de la perturbación de muchas cuencas fluviales, y pueden conducir al error de considerar como hábitat característico del desmán lo que en realidad puede ser un hábitat subóptimo.

En lo que se refiere al carácter especialista o generalista del desmán, es ilustrativa la comparación de los resultados obtenidos en las dos cuencas fluviales poco peturbadas con las de las musarañas acuáticas (Neomys sp.) en el conjunto de cuencas del Pirineo aragonés. Llama la atención que el desmán, especie de área global restringida y que a menudo se considera de requerimientos ambientales muy estrictos, no se muestra mucho más selectivo que Neomys sp., que suelen considerarse generalistas y tienen áreas de distribución amplias. Las musarañas acuáticas se muestran aún menos exigentes que el desmán, ya que ninguna categoría tiene selección positiva o negativa clara, pero ambos géneros aparecen como mamíferos semiacuáticos bastante generalistas y con tendencias similares en la selección local del hábitat.

\section{Influencia de los factores antrópicos}

El hábitat del desmán recibe influencias humanas desde hace siglos. Tradicionalmente, hasta el siglo XX, los principales factores antrópicos que incidían en el hábitat debieron ser la deforestación de las cuencas -que tiende a incrementar las fluctuaciones del caudal y la turbidez del agua- y la eutrofización del agua a causa de los vertidos de residuos orgánicos (procedentes de la actividad ganadera y de los núcleos rurales). La deforestación es un factor con más potencial de perturbación, ya que con frecuencia actúa a gran escala, mientras que el efecto de los vertidos de residuos debía ser limitado, incidiendo en tramos fluviales no muy largos. Estos factores actuaban probablemente sobre la mayor parte de los hábitats del desmán, ya que desde la Edad Media hasta el siglo XX casi toda su área de distribución tenía una 
fuerte implantación de la población rural y de las actividades ganaderas. De forma más localizada y concentrada básicamente en algunos fondos de valle, también debía haber contaminación química, relacionada con actividades mineras y manufactureras, y una alteración moderada del caudal por pequeñas obras hidráulicas de regadío o industriales.

En el siglo XX, y en especial en su segunda mitad, esta situación tradicional experimentó una transformación profunda. Por un lado cesó la deforestación y se inició un proceso inverso de reforestación, que en general se considera que resultó favorable para el desmán. En la mayor parte de su distribución también decreció de modo espectacular la población rural, que comportó sin duda la reducción de la contaminación orgánica difusa. En cambio aumentó la densidad de población humana en muchos fondos de valle, con el consiguiente aumento de la contaminación orgánica y química de los ríos. También se produjo un incremento muy importante de la regulación artificial del caudal de los cursos de agua. En una primera fase, en especial hasta el primer tercio del siglo XX, esta regulación artificial de los ríos se realizó mediante presas y canales modestos con fines industriales, que se concentraban en los fondos de valle; aunque individualmente estas obras hidráulicas suelen tener un impacto débil, en algunos sectores pirenaicos -como en el Ter y otras cuencas de la Cataluña oriental- proliferaron y, en conjunto, ocasionaron una perturbación profunda de la dinámica fluvial. En una fase más avanzada, con especial intensidad en el segundo tercio de siglo, la regulación artificial del caudal tuvo como objetivo principal la producción hidroeléctrica y ocasionó la construcción de obras hidráulicas de mayores dimensiones, que se extendieron por todo el territorio, incluyendo muchas cabeceras fluviales en la alta montaña. A la contaminación y a la regulación del caudal, hay que añadir como nuevos factores de perturbación importantes del hábitat la artificialización y canalización de las riberas, las captaciones de agua para consumo urbano o turístico y los movimientos masivos de tierras relacionados con grandes obras públicas.

En resumen, en el siglo XX se pasó de una perturbación extensiva, difusa y casi siempre de baja intensidad del hábitat del desmán hasta una perturbación más concentrada y de alta intensidad, potencialmente más destructiva. En la actualidad gran parte del hábitat del desmán tiene menos perturbaciones de origen antrópico que hace uno o dos siglos. Pero otra parte -en especial los ríos de los valles principales- sufre una presión humana mucho más intensa, que en algunas zonas ha comportado una degradación intensa del hábitat fluvial.

En los Pirineos meridionales la distribución territorial de las perturbaciones antrópicas es muy desigual. Los dos extremos pirenaicos, en Cataluña y Euskadi, concentran la perturbación por regulaciones artificiales del caudal de la "primera fase", ligadas a fondos de valle y a usos industriales. La regulación hidráulica de "segunda fase", de mayor magnitud y con fines hidroeléctricos, es muy intensa en las cuencas del Noguera Pallaresa y del Noguera Ribagorçana (esta segunda sin poblaciones de desmán) y se presenta de modo muy difuso en el resto de cuencas. La

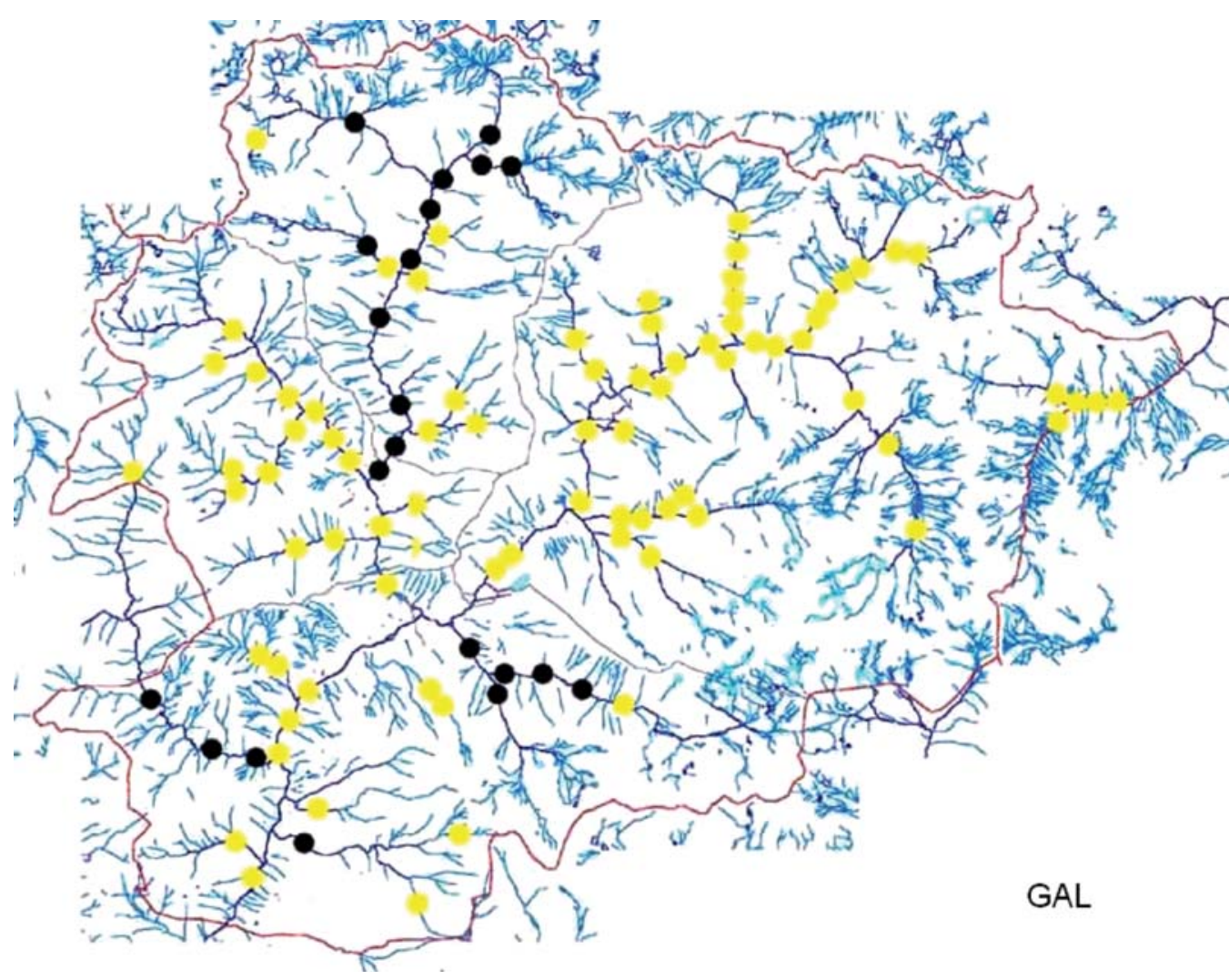

Fig. 4. - Distribución del desmán en Andorra. ). Claro ejemplo de área fragmentada en tiempos recientes a causa de las perturbaciones antrópicas, en especial por contaminación del agua. Los puntos negros indican presencia de desmán durante la prospección, los puntos amarillos ausencia. (Fuente original: Aymerich, 2004.

Fig. 4. - Distribution of the Iberian desman in Andorra. A clear example of recently fragmented distribution due to anthropic pressure, especially due to water pollution. Black dots indicate positive presence and yellow dots absence of the species during the survey. (Original source: Aymerich, 2004. 
contaminación por vertidos urbanos sólo alcanza niveles muy altos en la subcuenca del Valira en Andorra, que se presenta como un laboratorio natural excelente para estudiar los efectos a largo término de este factor en las poblaciones de desmán (Fig 4). Existe una contaminación orgánica menos importante en el resto de valles pirenaicos, procedente de los núcleos urbanos pequeños o medios, de las instalaciones turísticas y de instalaciones ganaderas intensivas; temporalmente, esta contaminación puede llegar a niveles notables, en especial cerca de núcleos urbanos medios como Jaca o Puigcerdà. En todos los valles pirenaicos hay también perturbaciones localizadas persistentes debidas a captaciones de agua y a la artificialización de las riberas (rectificación de cauces, construcción de muros, degradación del bosque de ribera) y perturbaciones temporales debidas a vertidos de tierras a los cursos de agua durante la ejecución de obras públicas.

La influencia de los diversos factores de perturbación antrópica sobre el hábitat del desmán y sobre sus poblaciones ha sido tratada en la mayor parte de los estudios sobre la especie, por su interés para la conservación de una especie que suele considerarse rara y amenazada. Una buena revisión de los posibles factores de perturbación actuales se puede consultar en Queiroz et al., (1996), donde se citan como factores principales las captaciones de agua, el deterioro de la calidad del agua (orgánica y química), la destrucción de los bosques de ribera, la reforestación de las cuencas y las obras hidráulicas. Sin embargo, todas las aproximaciones realizadas a estos factores de perturbación han sido indirectas, infiriendo los efectos en el desmán a partir de los efectos más o menos conocidos de las perturbaciones sobre los invertebrados acuáticos, y a menudo han sido demasiado intuitivas. Es probable que, en líneas generales, la mayor parte de conclusiones extraídas con estas aproximaciones sean bastante acertadas, pero el conocimiento de los efectos concretos de las diversas perturbaciones antrópicas en el desmán requiere aún la realización de estudios rigurosos y prolongados.

Nuestra experiencia con el desmán en los Pirineos meridionales no ha aportado mucha información nueva o precisa sobre el efecto de las perturbaciones antrópicas, pero sí que ha permitido matizar con datos algunas suposiciones poco documentadas y también se han obtenido algunas observaciones anecdóticas pero de gran utilidad para la comprensión de los efectos de determinadas perturbaciones o para la gestión.

La caracterización del hábitat durante las campañas de prospección del desmán incluía tan solo los dos factores antrópicos que inicialmente se consideraron de mayor potencial de perturbación en el análisis de los factores: eutrofización por contaminación orgánica y regulación artificial del caudal. Para la eutrofización se consideraron cuatro categorías, desde la ausencia de vertidos orgánicos hasta la contaminación muy evidente. Para la regulación artificial la variable utilizada fue la distancia del tramo a presas que retenían o derivaban el caudal, considerando tres categorías: ausencia de presas, a más de $1 \mathrm{~km}$ aguas abajo de presas y a menos de $1 \mathrm{~km}$ de presas.
El análisis conjunto de los datos de Cataluña insinúa un rechazo de los tramos en los que los dos factores de perturbación antrópica tienen niveles medios o altos, pero también indica claramente una tolerancia a los niveles de perturbación bajos. Los resultados son algo diferentes según el análisis aplicado a los datos. Por lo que se refiere a la contaminación, con el análisis de correspondencias múltiples (ACM) no aparece un rechazo claro de los tramos eutrofizados, pero sí una asociación débil de la presencia de desmán con los tramos sin indicios de contaminación. Con el índice de electividad de Ivlev (E) aparece una selección negativa de los tramos con contaminación media (en Cataluña no se prospectaron tramos con contaminación alta) y, en cambio, la selección de los tramos sin eutrofización y con eutrofización débil es similar y neutra. En cuanto a la regulación artificial del caudal, con el ACM sólo se intuye una asociación débil entre la presencia de desmán y los ríos sin presas, mientras que el índice E muestra una selección negativa aunque débil de los tramos situados a menos de $1 \mathrm{~km}$ de una presa y un selección neutra de los tramos situados a más de $1 \mathrm{~km}$.

El análisis de los datos de Andorra (Aymerich, 2004) aporta más información útil sobre la influencia de la contaminación de los ríos en el desmán, gracias al hecho de que la cuenca del Valira es la única del área de distribució pirenaica de la especie donde existen tramos muy importantes de río con niveles de contaminación por residuos urbanos muy altos y persistentes desde hace unas tres décadas. En Andorra los tramos con eutrofización media mostraron una selección negativa débil pero clara y los tramos muy contaminados una selección negativa total (no se detectó desmán en ningún tramo muy contaminado), mientras que los tramos sin eutrofización y con eutrofización débil resultaron de selección neutra. Aún más interesante es el hecho de que la distribución actual del desmán en Andorra parece indicar de forma clara que se ha producido un proceso relativamente reciente de fragmentación del hábitat y de las poblaciones de desmán, que ha tenido como causa casi única la contaminación del agua, y que ha conducido a la extinción total de la especie en algunas subcuencas y al acantonamiento en otras de pequeñas poblaciones aisladas.

En resumen, los datos cuantitativos obtenidos con las prospecciones sistemáticas en los Pirineos meridionales indican que la contaminación y la regulación del caudal influyen efectivamente en la presencia del desmán, pero sólo cuando se presentan de un modo intenso. La tolerancia a niveles bajos de contaminación orgánica no es una sorpresa, pues ya había sido citada puntualmente en Navarra, Galicia y Portugal (Castién \& Gosálbez, 1995; Santamarina, 1993; Queiroz et al., 1998), pero sí constituye novedad la constatación de la contaminación como factor de fragmentación del área y de extinción a escala de subcuenca. Los datos obtenidos sobre la influencia de la regulación hidráulica del caudal indican que este factor incide en la presencia local de la especie, aunque también sugieren que su influencia puede ser menor de lo que se suponía en algunas primeras aproximaciones intuitivas (Bertrand, 1993; Queiroz et al,. 1993). 
Considerando la escasez de información fiable sobre el efecto de las perturbaciones antrópicas y su interés práctico para la conservación del desmán, a continuación se presenta una aproximación sintética a los principales factores detectados en los Pirineos meridionales. Esta síntesis se basa especialmente en datos empíricos (cuantitativos o cualitativos) referidos al desmán, pero también en la evaluación de la probable influencia indirecta por el efecto sobre variables ambientales bien documentadas.

\section{1- Contaminación orgánica (eutrofización):}

No afecta a la presencia del desmán en niveles bajos, correspondientes a vertidos puntuales de la ganadería, de casas aisladas o de pequeños núcleos rurales. Estos niveles bajos incluso podrían favorecer al desmán cuando se dan en aguas naturalmente oligotróficas, ya que comportan un incremento de la disponibilidad local de alimento.

Tiene un efecto negativo a partir de niveles medios (eutrofización fácilmente detectable a simple vista), que suelen corresponder a pequeños núcleos urbanos o a instalaciones turísticas con depuración deficiente del agua. En relación con estos niveles medios de contaminación es importante precisar que el análisis de los datos cuantitativos, que sólo detecta una débil selección negativa, puede resultar bastante engañoso y seguramente subestima su influencia real. La razón es que muchos de estos tramos en los que se detecta una contaminación media durante los muestreos registran episodios más o menos frecuentes de contaminación alta, que generalmente se dan en los meses estivales, cuando las instalaciones de depuración del agua no tienen capacidad suficiente para tratar los vertidos; esta situación es muy habitual, ya que el diseño de las instalaciones de depuración suele subestimar la población humana temporal en las localidades de montaña. Cuando estos episodios de contaminación puntual fuerte se producen de modo muy recurrente es probable que conduzcan a la extinción local del desmán o a una reducción muy significativa de su densidad, ya que comportan una reducción drástica de la disponibilidad de alimento durante semanas o meses. Estas situaciones suelen darse en los fondos de valle con mayor presencia humana, donde no son de detección evidente porque muchas veces no se manifiestan con los indicadores habituales de calidad del agua y además suelen solaparse con factores naturales desfavorables que enmascaran o diluyen su efecto. Ejemplos de zonas en las que los episodios de contaminación puntual alta (y de contaminación media habitual) parecen tener una responsabilidad alta en la ausencia habitual del desmán son los cursos bajos de los ríos Noguera de Cardós (cuenca del Noguera Pallaresa) y Segadell (cuenca del Ter), mientras que el curso medio y bajo del río Alp (cuenca del Segre) sería un ejemplo de disminución de la densidad por esta causa.

Cuando la contaminación orgánica es alta y persistente (claramente perceptible a simple vista e indicadores biológicos de baja calidad) resulta incompatible con la pre- sencia del desmán. Esta situación sólo se da en zonas urbanas importantes y con sistemas de depuración muy deficientes, que afortunadamente son excepcionales en los Pirineos, donde prácticamente están limitadas a Andorra Es importante remarcar que si esta contaminación orgánica alta afecta tramos fluviales de longitud grande (varios $\mathrm{kms}$ ) puede conducir a una fragmentación de las poblaciones comparable a la que en los ecosistemas terretres tendrían las barreras antrópicas muy impermeables (grandes infraestructuras y transformaciones extensivas del uso del suelo), conduciendo en casos extremos a extinciones de la especie a escala de subcuenca. El caso de los ríos de Andorra es muy ilustrativo de las consecuencias a medio plazo de este factor de perturbación.

\section{2- Contaminación química:}

Parte de los efectos de los vertidos residuales urbanos debe ser atribuible a la contaminación química, en especial en casos tan importantes como Andorra, pero se desconoce el impacto concreto de esta contaminación con el desmán. En los Pirineos meridionales no se ha detectado ningún caso de influencia clara de este factor.

Hay que precisar que un posible factor de contaminación química que se ha citado reiteradamente como potencialmente negativo (Richard, 1985; Queiroz et al., 1996) es el uso de productos anticongelantes (sales potásicas o sódicas y otras sustancias químicas) en las carreteras, pero existen poblaciones de desmán en numerosos cursos de agua adyacentes a carreteras donde el uso de estos productos es muy frecuente desde hace décadas. En los últimos tiempos también representan un riesgo potencial algunos productos que se utlizan para la producción de nieve artificial en las estaciones de esquí, pero por el momento no se ha confirmado ningún efecto negativo concreto y se mantienen poblaciones de desmán en los ríos que drenan estas estaciones de esquí.

\section{3- Presas-Regulación artificial del caudal:}

Los datos disponibles indican que la regulación del caudal afecta a la presencia del desmán en los tramos inmediatamente inferiores a la presa. Estos tramos son los que experimentan fluctuaciones de caudal más bruscas y sin relación con el régimen hídrico natural del río, lo que hace que el medio fluvial sea inestable y causa estrés en las comunidades bióticas. Se supone que la regulación artificial del caudal debe actuar negativamente sobre el desmán de dos formas: 1) haciendo que la disponibilidad de alimento sea poco predecible, a causa de las fluctuaciones irregulares en las comunidades de macroinvertebrados; y 2) afectando a la disponibilidad y la calidad de los refugios situados en las riberas, que a consecuencia de las fluctuaciones frecuentes del nivel de agua pueden pasar en poco tiempo de resultar adecuados a no serlo, tanto porque pueden quedar muy alejados del agua como porque pueden pasar a estar inundados.

La distancia a la que deja de percibirse el efecto negativo de la regulación artificial seguramente depende de 
la gestión del agua en cada caso particular, sin que pueda generalizarse. El análisis de los datos pirenaicos parece indicar que a partir de $1 \mathrm{~km}$ de distancia bajo las presas ya tendría poca influencia en el desmán, pero los datos disponibles aún son insuficientes.

Las consecuencias a medio plazo de la regulación artificial del caudal deben ser similares a las de la contaminación media o alta del agua, ya que comportan una pérdida de calidad como hábitat para el desmán de tramos más o menos largos de río. Cuando las perturbaciones causadas por la regulación del caudal son importantes y persistentes pueden conducir a la fragmentación de las poblaciones y, en algunos casos, seguramente a la extinción a escala de subcuenca. La información obtenida sobre esta cuestión en los Pirineos es limitada y poco coherente, pero indica que por lo menos en algunos casos se produce una fragmentación grave. Las cuencas fluviales que aportan datos más fiables son las que están muy alteradas por regulaciones hidráulicas antiguas, de finales del siglo XIX y principios del $X X$, de las que existen dos ejemplos excelentes en los dos extremos pirenaicos: el Bidasoa y el Ter. Castién \& Gosálbez (1995) señalan que el desmán ha persistido aparentemente bien en la cuenca del Bidasoa a pesar de la profunda alteración causada por las construcciones hidroeléctricas durante todo el siglo XX, aunque desconocemos si se observa alguna fragmentación. En la cuenca del Ter el desmán también ha persistido hasta la actualidad, pero es muy patente la fragmentación debida a la proliferación de instalaciones hidráulicas: en esta cuenca el desmán se presenta en forma de subpoblaciones aparentemente aisladas -y algunas de viabilidad dudosa- en algunos afluentes laterales y en el curso superior de los dos ríos principales. Es probable que la respuesta diferente de las poblaciones de desmán del Bidasoa y el Ter a unas perturbaciones antrópicas similares refleje una mayor vulnerabilidad de las poblaciones situadas en zonas subóptimas (cuencas mediterráneas: Ter) en comparación con las que viven en zonas óptimas (cuencas atlánticas: Bidasoa).

Un caso particular de regulación artificial del caudal son los vaciados masivos de los embalses, muy esporádicos y relacionados en general con operaciones de mantenimiento. El efecto de estos vaciados parece que puede ser más comparable a las grandes crecidas y a otros eventos de carácter catastrófico que al de las fluctuaciones habituales de caudal bajo las presas, aunque con el añadido de la anoxia si se liberan sedimentos profundos. Tienen un gran potencial de perturbación del medio fluvial y seguramente pueden provocar mortalidades altas de desmán, pero ambos se podrían recuperar en un plazo de meses o años.

\section{4- Presas-Efecto barrera:}

Las presas constituyen obstáculos físicos que cierran los cursos fluviales y pueden resultar difíciles o imposibles de superar para un animal pequeño y de movilidad habitualmente acuática como el desmán. El efecto barrera de las presas es bien conocido para los peces, y también se ha constatado que puede afectar en algún grado a mamíferos semiacuáticos como la nutria, por lo que resulta lógico suponer que también afecta al desmán. Se trata de otro factor antrópico con gran potencial de fragmentación de las poblaciones de desmán, pero la información disponible sobre esta cuestión es muy pobre.

Hay que tener en cuenta que, además de un excelente nadador, el desmán es un buen trepador, por lo que potencialmente podría superar algunas presas. Con los radioseguimientos realizados en el río Tor (cuenca del Noguera Pallaresa) constatamos que pueden trepar sin dificultad aparente por cascadas casi verticales de unos $5 \mathrm{~m}$ de altura y también por pequeñas presas de unos $2 \mathrm{~m}$. Con esta información resulta razonable pensar que las pequeñas presas, que son la mayoría de las que se encuentran en su hábitat, deben tener un efecto barrera limitado o nulo. Un dato anecdótico que sustenta esta suposición es la persistencia durante 15 años de una población aparentemente saludable de desmán en un tramo de 6 km del río Romadriu en el que en 1996 se construyeron tres presas con alturas desde 2 hasta $8 \mathrm{~m}$. Se desconoce a partir de qué altura una presa constituye una barrera efectiva y, por otra parte, hay que tener en cuenta que el efecto barrera también debe depender de otras características de estas (situación, flujo de agua, verticalidad, rugosidad, existencia de escaleras para peces, etc) que faciliten más o menos que el desmán trepe.

\section{5- Captaciones de agua:}

Las captaciones de agua para consumo urbano o turístico pueden tener consecuencias similares a las de la regulación artificial del caudal con presas, aunque de menor escala. Si una captación hace disminuir mucho el caudal, puede hacer que el hábitat de tramos de río más o menos largos sea inadecuado para el desmán, fragmentando las poblaciones. En general las captaciones se limitan a períodos cortos (semanas o meses), por lo que la fragmentación es temporal y poco grave, aunque en algunos tramos puede resultar muy recurrente. El efecto de las captaciones se agrava porque en los Pirineos mediterráneos el mayor incremento en la demanda de agua es para usos turísticos y coincide con las épocas del año en que el caudal natural del río suele ser menor (julio-agosto e invierno) y existe más riesgo de contaminación orgánica.

No se han documentado casos concretos de ausencia de desmán a causa de captaciones de agua no ligadas a presas, pero es probable que algunas discontinuidades atribuidas a contaminación orgánica frecuente también estén relacionadas con el descenso del caudal a causa de las captaciones.

\section{6- Artificialización de las riberas:}

Las obras hidráulicas que artificializan los márgenes fluviales son potencialmente muy negativas para el desmán, por lo menos cuando comportan realizar movi- 
mientos de tierras. La artificialización de las riberas comporta una homogeneización de los márgenes fluviales, y la consecuencia más negativa para el desmán de estos trabajos es la destrucción de los refugios situados en las riberas, bajo rocas o raíces de árboles, que son un factor básico para su presencia local. Los muros artificiales pueden ofrecer refugios alternativos (conocemos varios casos, y de hecho parece algo bastante frecuente), con la condición de que estén en contacto directo con el agua. Pero esta condición no se da en muchas ocasiones, ya que resulta frecuente que entre los muros de canalización y el agua quede una franja amplia no inundada. Un efecto secundario de las canalizaciones es la perturbación del río aguas abajo por el vertido de tierras durante las obras, que puede provocar un descenso temporal en la disponibilidad de alimento para el desmán.

Aunque en general este factor puede considerarse negativo o poco favorable, sólo actúa a escala muy limitada (tramos fluviales de decenas o centenares de metros) y sus consecuencias son muy diversas en función del tipo de obra realizada. Si los trabajos sólo afectan tramos cortos, lo más probable es que tan sólo tengan incidencia en la densidad local del desmán. Hay numerosos ejemplos de tramos fluviales parcialmente canalizados en los que el desmán está presente.

\section{7- Ejecución de grandes obras públicas:}

La ejecución de carreteras y otras obras públicas próximas a cursos fluviales suele tener asociado el vertido de tierras y de hormigón al agua, que siempre se produce en algún grado aunque se adopten medidas preventivas para evitarlo. Cuando los vertidos son pequeños el efecto sobre las comunidades acuáticas es débil, similar al de una crecida tras el deshielo o una tempestad, y no debería resultar negativo para el desmán. Pero cuando los vertidos son masivos sus efectos pueden tener carácter catastrófico, como los de grandes avenidas o el vaciado de embalses. En estos casos podrían producirse mortalidades altas de desmán y un deterioro severo del hábitat que puede persistir durante meses.

No se han documentado mortalidades de desmán ni la destrucción de su hábitat a consecuencia de obras públicas. A pesar de la falta de datos concretos, se considera muy probable que en algún momento se hayan producido, ya que no es infrecuente que haya mortalidades de trucha Salmo trutta Linnaeus, 1758 por esta causa, y hay que tener en cuenta que las poblaciones de desmán son potencialmente más sensibles y de recuperación más lenta que las de truchas. En cualquier caso, la ejecución de obras públicas debe considerarse un factor de riesgo de alta frecuencia.

\section{8- Introducción de especies alóctonas:}

Las especies alóctonas pueden considerarse un factor de perturbación antrópico indirecto, porque la actividad humana es responsable de su introducción y, casi siempre, de su expansión. La especie alóctona que su- pone un mayor riesgo potencial para el desmán es el visón americano Neovison vison (Schreber, 1777), que actualmente se ha establecido con éxito en varias partes del área de distribución de Galemys y ha provocado la regresión de otro mamífero semiacuático, la rata de agua europea Arvicola terrestris (Linnaeus, 1758) en diversas regiones europeas (Macdonald \& Strachan, 1999; Macdonald et al., 2002). La presión del visón americano ha sido citada reiteradamente como una de las causas de regresión del desmán en la España central, pero sin datos que lo confirmen. En los Pirineos meridionales las zonas de mayor riesgo son los dos extremos, en la Cataluña oriental y Navarra, donde actualmente ya contactan las áreas del desmán y el visón americano.

Aunque no existe ningún dato sobre esta cuestión, no se puede excluir que algunas plantas alóctonas invasoras también puedan tener incidencia en las poblaciones, ya que tienen una alta capacidad para modificar la vegetación de ribera y posiblemente también influyen en la productividad de las comunidades acuáticas. En los Pirineos podrían representar algún riesgo el arbusto de las mariposas Buddleja davidii Franch. y Fallopia japonica (Houtt.) Ronse Decr.

\section{ACTIVIDAD Y USO DEL ESPACIO \\ Antecedentes}

Si se exceptúan los estudios sobre individuos cautivos (Richard, 1985) y algunas observaciones de campo anecdóticas, hasta hace muy poco -con la publicación de parte de nuestros resultados (Melero et al., 2012)- toda la literatura científica existente sobre estos aspectos consistía en los trabajos de radioseguimiento realizados hace tres décadas por Stone (1985, 1987a, 1987b). Los resultados de este autor presentan al desmán como un animal muy rutinario y de comportamiento territorial, altamente agresivo con sus congéneres. Según Stone (1987b), el desmán tiene un patrón de actividad bimodal, con un periodo de actividad principal nocturno y un periodo secundario diurno; además los horarios de inicio y fin de cada periodo de actividad serían muy similares (casi sincrónicos) para todos los individuos residentes en un determinado sector fluvial. Por lo que se refiere al uso del espacio y la organización espacial, según Stone (1985, 1987a) y de modo muy simplificado, el desmán se caracterizaría por: a) organizarse básicamente en parejas territoriales que defienden tramos de río exclusivos, aunque habría una cierta tolerancia hacia los jóvenes en dispersión; b) dentro de esos territorios, los miembros de la pareja habitualmente se evitarían para prevenir encuentros agresivos, con la excepción de la época de reproducción; el principal mecanismo para evitarse sería realizar siempre desplazamientos en sentidos opuestos del río una vez salen de los refugios de descanso respectivos, de modo que nunca coincidirían físicamente; c) cada individuo dispondría típicamente de un refugio (por excepción dos) de uso exclusivo, que no compartiría n con su pareja; d) el mecanismo para evitar encuentros agresivos entre vecinos sería bastante similar al utilizado 
para prevenir agresiones entre miembros de la pareja: los desplazamientos de todos los machos en un determinado periodo de actividad tendrían siempre el mismo sentido (río arriba o río abajo), de modo que nunca coincidirían en las fronteras territoriales; en las hembras el riesgo de contactos con los vecinos sería mínimo, porque tenderían a excluir de sus desplazamientos los extremos del territorio.

\section{Material y métodos}

Nuestros datos sobre actividad y uso del espacio a corto plazo proceden, básicamente de 6 campañas de captura, marcaje y radioseguimiento realizadas entre 2002 y 2004 en el río Tor (Pirineos centrales, Cataluña). Datos complementarios se han obtenido en marcajes y seguimientos en el río Alp y, anecdóticamente, en el río Castellana, ambos en los Pirineos orientales. La informa- ción sobre uso del espacio a largo plazo procede de estas mismas campañas y de las nuevas campañas de captura y recaptura realizadas entre 2006 y 2010 en el río Tor; en este último periodo los individuos solo eran marcados con transponders (chips de identificación), no con emisores de radio.

Las capturas se han realizado con nasas semisumergidas, parecidas a las utilizadas para capturar anguilas, dispuestas en los márgenes del río con la boca de entrada en el sentido de contracorriente (Fig 1). Las nasas se han dispuesto activas sólo durante las horas nocturnas para evitar capturas durante el día y que el animal pudiera morir por inanición. Durante la noche se han revisado a intervalos de 3 horas para asegurar la captura del animal vivo. Una vez capturado el animal se procedía a su procesamiento: toma de medidas corporales, establecimiento del sexo y de la edad, anestesia e implantación subcutánea de radioemisor y/o transponder (Fig 5).



Fig. 5. - Manipulación de un desmán capturado. Analisis de la dentición para establecer la edad. (Autor: Pere Aymerich).

Fig. 5. - Handling of a livetrapped Iberian desman. Age estimation through teeth analysis. (Autor: Pere Aymerich) 
Los emisores utilizados fueron de la marca Biotrack, de menos de $4 \mathrm{~g}$ de peso y con una batería con autonomía máxima de 1 mes (generalmente menor, de 5-20 días. Los animales eran liberados en el punto de captura, entre 30 y 180 minutos después de ésta.

Los datos más precisos fueron obtenidos de 19 individuos (17 en el río Tor) a los que se pudo realizar un radioseguimiento durante un mínimo de 5 días tras su captura, y en general 2-3 semanas (máximo 4 semanas). Otros 38 desmanes han sido marcados con emisores y/o transponders y han proporcionado datos parciales útiles para el estudio del uso del espacio (solapamiento de dominios vitales, persistencia en tramos de río concretos, uso de refugios, etc).

El radioseguimiento se realizó tanto de noche como de día, para poder establecer los parámetros relacionados con la actividad, ocupación del hábitat y utilización del espacio. El receptor utilizado fue el modelo RX$8910 \mathrm{HE}$ de la marca Telivit, combinado con tres tipos de antena, en función de la precisión deseada: 1) antena externa tipo "Yagi" para distancias medianas o largas, 2) antena interna en $\mathrm{H}$ para localizar individuos en un radio pequeño, con una precisión de hasta $1 \mathrm{~m}$, y 3) antena externa, direccional, cuando se ha querido localizar individuos con una precisión de hasta 0,2 m, utilizada para detectar los individuos durante su descanso en el nido. La señal recibida solamente ha indicado la localización del emisor, pero no si el animal estaba en movimiento o en reposo. La actividad se ha determinado a partir de los cambios de posición entre dos controles o mediante el seguimiento continuado durante un determinado período de tiempo. El sistema no permite determinar si un animal que aparezca como quieto está inactivo (durmiendo) o activo.

Como objetivo preferente se optó por obtener localizaciones puntuales, discretas, de los individuos seguidos. No obstante, en alguna ocasión se realizaron seguimientos continuos, de hasta 5 horas, de determinados individuos. La regularidad media para las localizaciones individuales ha sido de 60'-90' durante la actividad nocturna y durante el período habitual de descanso diurno, mientras que para el horario más habitual de actividad diurna el control se realizó cada 30'-60'; el objetivo de este seguimiento más intenso de las horas de actividad diurna ha sido el de poder detectar las eventuales salidas cortas (inferiores a 60').

\section{Actividad}

El método de seguimiento utilizado sólo permite detectar la actividad de un individuo cuando éste se desplaza, pero no la actividad "in situ" (cuidado del pelaje, por ejemplo). Debido a esta limitación metodológica, a partir de ahora utilizaremos actividad como sinónimo de "fuera del refugio", aunque hay que tener presente que no todo el tiempo que está fuera del refugio un individuo debe estar necesariamente activo (puede haber breves intervalos de descanso, en los que incluso puede dormir), ni tampoco siempre que está dentro de la madriguera tiene que dormir.

\section{Actividad media}

El tiempo medio que un individuo está activo en una jornada se sitúa entre 9 y 10 horas, con escasas diferencias según la época del año. Esta estimación se ha obtenido en base al análisis de 1660 controles de actividad horarios, el $60 \%$ en otoño y el $40 \%$ en primavera-inicio de verano. Según los datos obtenidos el porcentaje de tiempo medio que un individuo está fuera de su refugio en cada jornada se sitúa hacia el 40\%, similar pero algo inferior al $47 \%$ indicado por Stone (1987b). Con la excepción de breves descansos bajo rocas (en general menos de 5 minutos), los individuos están todo este tiempo en el agua y presumiblemente buscando alimento.

El tiempo medio de actividad registrado para cada individuo ha sido considerablemente más diverso que la media total. Las medias individuales durante los periodos de seguimiento han ido desde sólo 425 minutos (7h 05 ') hasta 713 minutos (11h 53 '), entre el $29,5 \%$ y el $49,5 \%$ de la jornada. Las dos medias extremas son de una misma época (otoño) y es probable que sólo reflejen circunstancias particulares de esos individuos durante los días de seguimiento. Esta variabilidad es notablemente superior a la detectada por Stone (1987b), de 10h 18m-12h 00m.

No se observa que las variaciones en la actividad estén relacionadas con el sexo, la clase de edad ni la época del año. Se trataría más bien de una variabilidad individual aparente, seguramente sesgada por el tamaño de la muestra, y es probable que una muestra más amplia de cada individuo diera unas medias menos apartadas de las totales.

\section{Distribución de la actividad en la jornada}

La actividad total de una jornada se distribuye, según la época del año, en 2 ó 3 períodos (excepcionalmente 4) de importancia desigual. La actividad es mayoritariamente nocturna, aunque la proporción entre día y noche varía según la época del año, tendiendo a aumentar el porcentaje de actividad diurna a medida que se acorta la duración de la noche. Los patrones observados según meses son:

- Septiembre-octubre: La duración de la noche es de aproximadamente $11 \mathrm{~h} 30 \mathrm{~m}$. La actividad suele estar dividida en 3 períodos: 2 largos de actividad nocturna separados por un descanso (excepcionalmente la actividad nocturna puede ser continua, sin descanso) y 1 periodo corto de actividad diurna (que excepcionalmente puede ser inexistente o extremadamente corto).

- Abril-mayo: La noche se ha acortado hasta unas 9h. Aunque se observan a menudo los 3 períodos ( 2 nocturnos y 1 diurno), pero son menos regulares. Es frecuente que la actividad nocturna se concentre en un solo periodo, sin descanso intermedio. Este descanso, cuando existe, tiende a ser más corto que en otoño. Por el contrario, la actividad diurna tiende a alargarse, y se puede llegar a dividir en dos periodos.

- Junio: La noche tiene una duración mínima, de unas 7h 30m. La actividad se concentra habitualmente en sólo 
2 periodos: 1 nocturno y 1 diurno. Es muy poco frecuente que la actividad nocturna se divida en dos períodos, con descanso intermedio. También la actividad diurna puede realizarse en dos períodos.

Los datos disponibles de otras épocas son muy escasos, pero refuerzan este patrón general. La hembra seguida en pleno verano (julio) en el río de Alp (Cerdanya) mostró el mismo patrón que los seguidos en Tor en junio: 1 período de actividad nocturna largo y 1 de actividad diurna corto. No hemos realizado seguimientos en invierno, pero un dato anecdótico muestra un patrón muy similar al de otoño en Tor, pero con alargamiento del descanso nocturno: un macho seguido durante una sola jornada de enero en el río Castellana distribuyó la actividad entre 2 períodos nocturnos (con un descanso muy largo, de 5 horas) y 1 de diurno.

El patrón anual, pues, se basaría en un periodo principal de actividad en la noche (con descanso intermedio cuando la noche es larga y sin descanso cuando es corta) y un periodo secundario de actividad durante las horas de luz (que se alarga cuando la noche es corta, y que puede duplicarse en algunos casos). Considerando las fases de actividad, se distinguirían dos patrones estacionales básicos:

1) En primavera-verano un patrón bimodal, con una fase de actividad larga nocturna y una fase corta de actividad diurna.

2) En otoño-invierno un patrón trimodal, con dos fases de actividad nocturna, separadas por un descanso más o menos largo, y una breve fase de actividad diurna.

En el único trabajo publicado sobre esta cuestión (Stone, 1987b) se encontró un patrón bimodal para seguimientos realizados únicamente en primavera-verano, concordando pues con nuestros resultados para esa época.

Las Figuras 6a y 6b permiten visualizar este cambio de patrón de actividad según las estaciones.

a)



b)

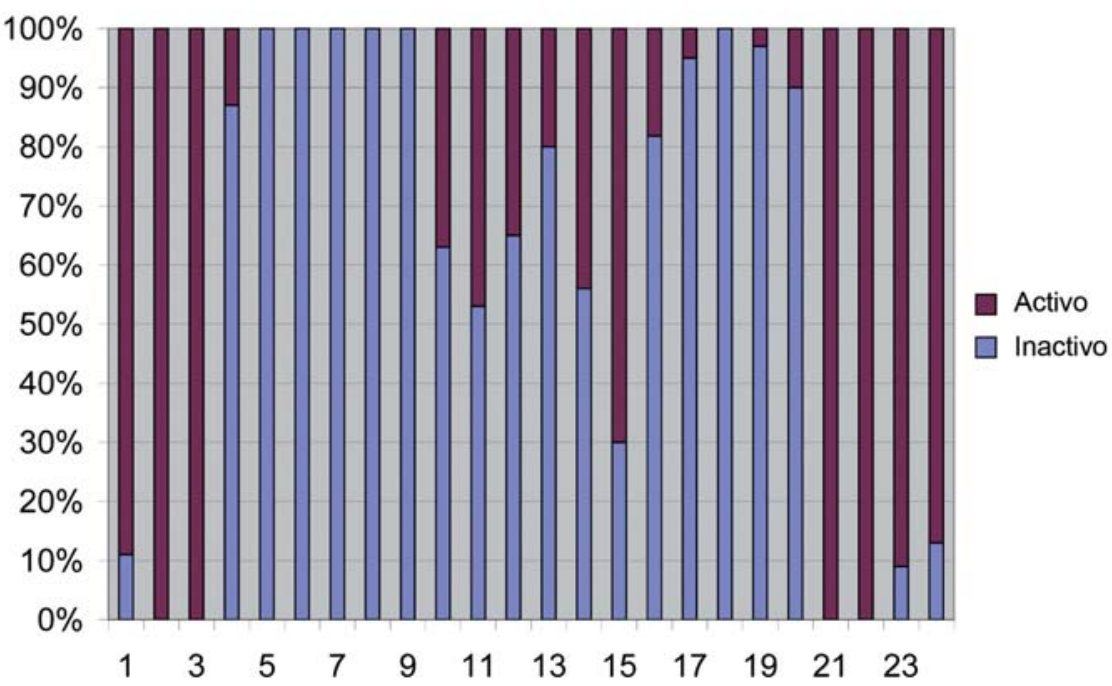

Fig. 6. - a) Actividad en setiembre-octubre, expresada como porcentaje (\%) de controles horarios de individuos activos 0 inactivos en cada franja horaria $(n=$ 1012 controles horarios): b) Actividad en junio, expresada como porcentaje (\%) de controles horarios de individuos activos o inactivos en cada franja horaria ( $n=442$ controles horarios).

Fig. 6. - a) Activity in September-October, expressed as percentage (\%) of hourly controls with active or inactive individuals ( $n=1012$ hourly controls); b) Activity in June, expressed as percentage $(\%)$ of hourly controls with active or inactive individuals $(n=442$ time controls). 
Aunque tenga actividad tanto de noche como de día, el desmán se muestra como una especie básicamente nocturna, que tiende de forma clara a maximizar el período de actividad durante las horas de oscuridad. Es de suponer que la mayor parte del alimento necesario lo obtiene de noche. Es posible que la importancia trófica de la actividad diurna sea inversamente proporcional al éxito obtenido en los desplazamientos nocturnos, de tal manera que su duración dependería del hambre del individuo. Si las necesidades tróficas han quedado bien cubiertas durante la noche, de día podría ser que el animal no salga o que sólo lo haga por otras causas fisiológicas (existencia de un reloj interno o necesidad de defecar, por ejemplo). Esto explicaría las observaciones de individuos que no han salido de día, que lo han hecho durante periodos muy breves o que han sido observados fuera de la madriguera sin que aparentemente tengan actividad predatoria.

Horarios y duración de los periodos de actividad y del descanso nocturno

La actividad nocturna -repartida en dos períodos, con descanso intermedio, o en uno solo- se desarrolla típicamente desde el anochecer hasta el alba. En todas las estaciones del año, la activación de los individuos tiene lugar típicamente desde unos minutos antes del anochecer hasta una hora después, mientras que el regreso al refugio para el descanso diurno se da en general desde media hora antes del alba hasta unos 15 minutos después. Cuando hay descanso nocturno intermedio, su horario de inicio y final es muy variable, aunque en general se da alrededor de la medianoche.

La actividad nocturna total puede tener una duración muy variable, entre 5h 30' y 11 h, aunque lo más habitual es que se sitúe entre $7 \mathrm{~h}$ y $9 \mathrm{~h}$. El porcentaje de la noche en que los individuos están activos tiene una relación inversa con la duración de la actividad nocturna: cuando más actividad muestran (septiembre-octubre) sólo están activos un $75 \%$ de la noche, mientras que cuando menos dura la actividad (junio) están activos casi toda la noche.

La actividad diurna tiene siempre menos duración que la nocturna y tiende a ser notablemente más irregular que ésta. La duración media es bastante superior en el inicio de verano (2h 17') que en otoño (93'), pero la variabilidad es muy amplia en ambas épocas (60'-270' en verano, 30'-250' en otoño). La actividad media ocupa casi un $12 \%$ de las horas de luz disponibles en otoño y algo menos del 14\% en verano. Los horarios de inicio y fin de la actividad diurna son también muy irregulares, pero se concentra alrededor del mediodía.

La existencia de un periodo de descanso nocturno, hacia medianoche, es uno de los descubrimientos de nuestros seguimientos, ya que este descanso no había sido detectado por Stone (1987b), seguramente porque realizó los seguimientos en periodos del año en que este descanso es inexistente o muy raro. La duración de los descansos controlados en otoño -cuando son habitualesse ha situado entre 45 y 240 minutos, con una media de 147 minutos $(n=30)$.
Las Figuras 6a y 6b permiten visualizar de forma aproximada los horarios de actividad y descanso típicos en verano y en otoño.

\section{Dominio vital (área de campeo)}

Se considera dominio vital del desmán el tramo de río recorrido con más o menos regularidad por un individuo durante los periodos de radioseguimiento. No hay que confundir dominio vital con territorio, ya que los dominios suelen ser compartidos simultáneamente con otros individuos, con todas las combinaciones posibles de sexo y edad.

\section{Extensión del dominio vital}

El dominio vital es lineal, y para los individuos radioseguidos en el río Tor $(n=18)$ su longitud habitual se situó entre 400 y $660 \mathrm{~m}$. Excepcionalmente, en el mismo río, existen casos de dominios inferiores (320 m para un individuo juvenil) y mayores (2300 m y $1350 \mathrm{~m}$, atribuibles a desplazamientos puntuales atípicos de individuos adultos). La extensión del dominio vital es más homogénea en otoño que en primavera. No se observan diferencias apreciables en función de la edad y del sexo. En otoño la extensión del dominio vital de los diferentes individuos radioseguidos oscila entre 430 y $660 \mathrm{~m}(\mathrm{n}=10)$, en cambio en primavera la variabilidad ha sido mayor, entre 320 y $2300 \mathrm{~m})(n=7)$.

\section{Uso del dominio vital}

Durante la actividad nocturna los individuos hacen recorridos por el río en los que usan su dominio vital de modo bastante diverso. Casi siempre lo recorren por lo menos una vez de modo casi completo, pero también pueden limitarse a visitar sólo una parte o a recorrerlo completamente dos veces. La irregularidad en el uso del dominio es mayor en otoño que en primavera. En otoño los individuos tienden a usar cada noche todo el dominio o la mayor parte de este, mientras que en primavera es más habitual que sólo hagan un uso parcial del conjunto del domino. En los controles de otoño ( $n=46$ seguimientos) sólo hicieron un uso parcial en el $19,6 \%$ de los casos, mientras que en primavera ( $n=22)$ fue así en el $63,6 \%$. Las diferencias estacionales se muestran más grandes si se tiene en cuenta que en todos los casos de uso parcial en otoño los individuos usaron más de la mitad del dominio (50-80\%), pero en primavera el porcentaje utilizado raramente llega o excede la mitad (15-60\%).

En estos desplazamientos nocturnos es habitual que haya más de un cambio de sentido en la progresión a lo largo del río, de modo que el movimiento pasa de ascendente a descendente o viceversa. Como consecuencia de estos cambios de sentido, hay partes más o menos extensas del dominio que son recorridas más de dos veces en una noche, lo que ha sido observado en el $64,7 \%$ de las veces $(n=68)$. El uso repetido de un mismo tramo del dominio se da tanto en otoño (60.9\% de las noches) como en primavera $(72.7 \%)$. No tiene relación, por tanto, con la exis- 
tencia o no de dos períodos diferentes de actividad nocturna separados por un descanso en el refugio, ya que estos descansos son habituales en otoño pero muy raros en primavera

La longitud de río utilizada durante los períodos de actividad diurna suele ser mucho menor que la utilizada durante la actividad nocturna, y casi siempre representa una parte pequeña del dominio vital. Las diferencias estacionales en el uso del dominio durante la actividad diurna son mucho menos marcadas que durante la noche. En otoño la media del porcentaje del dominio total utilizado durante las salidas diurnas $(n=34)$ es del $11,6 \%$ (rango 1-42\%). En primavera esta media $(n=39)$ es del $6,2 \%$ (rango 0,4 a $28 \%$ ) si se consideran los dominios totales (incluyendo los desplazamientos extremos e inhabituales), pero sube hasta el 9,0\% (rango 0.8-30\%) si se calcula sobre los dominios habituales (excluyendo los extremos). Los desplazamientos durante la actividad diurna son casi siempre unidireccionales (salida del refugio, ascenso o descenso, y retorno).

\section{Uso compartido de los dominios vitales}

A pesar de las limitaciones metodológicas (brevedad de los radioseguimientos e incertidumbre relativa sobre la captura efectiva de todos los ejemplares presentes en un tramo), en muchos casos se ha constatado que el dominio vital de un individuo no es utilizado exclusivamente por este individuo. De hecho, para el 75\% ( $n=33$; se consideran independientemente las recapturas del mismo individuo) de individuos capturados en Tor se tiene la evidencia de que compartían su dominio vital con otros ejemplares, en una u otra medida. Para el $25 \%$ restante no se obtuvieron pruebas de la presencia de otros individuos, pero tampoco se puede afirmar que estuvieran solos.

Hay que precisar, de entrada, que con el radioseguimiento no se ha obtenido ningún dato de solapamiento en el sentido más habitual del término, es decir de superposición parcial de los dominios por la periferia de los mismos. Siempre se ha tratado de coincidencias muy grandes (superiores al 50\%, y hasta el 100\%) entre los dominios de dos individuos, que además compartían en algún grado los refugios. Ocasionalmente se ha constatado que 3 y 4 individuos pueden coincidir en un mismo tramo, por lo menos parcialmente, aunque en estos casos no ha sido posible realizar un seguimiento simultáneo prolongado de todos los individuos implicados, por lo que se desconoce el grado en que compartían dominio y la duración de este uso compartido.

Aparentemente, el uso compartido de dominios sería superior en otoño que en primavera, y en las hembras que en los machos. Esto podría sugerir una tendencia a ser más sociables cuando se acerca la época de apareamiento y una menor tendencia de los machos a compartir dominio. No obstante estos datos deben ser interpretados con mucha cautela debido a que la muestra es pequeña y a excepciones muy significativas, como es el hecho de que los dos casos de 3 y 4 individuos compartiendo dominio implicaran sólo a machos y que haya datos de dos individuos adultos del mismo sexo que comparten dominio en otoño.
En nuestra opinión, lo más probable es que todos los individuos compartan, en un momento u otro, su dominio vital.

\section{Desplazamientos en el dominio vital}

\section{Velocidad de desplazamiento}

El desmán se desplaza prácticamente siempre por dentro del agua, moviéndose a velocidades muy diversas según el tipo de actividad que desarrolle. Los datos disponibles sobre velocidades las hemos calculado a partir del tiempo pasado entre cambios de posición, se trata de velocidades medias. Las velocidades puntuales superan ampliamente los extremos medios registrados.

Simplificando, se pueden distinguir tres tipos de desplazamiento, según la velocidad:

1) Lentos: Velocidades inferiores a $1 \mathrm{~m} /$ minuto. Se observan cuando están buscando alimento durante periodos prolongados en un área reducida. Pueden alternar la búsqueda de presas con breves períodos de descanso bajo alguna roca.

2) Regulares: Velocidades entre 1 y 6 m/minuto. Según las observaciones, parece que corresponderían a la alternancia de periodos cortos de búsqueda de alimento y periodos cortos de desplazamiento.

3) Rápidos: Velocidades superiores a $6 \mathrm{~m} /$ minuto. Los máximos registrados son de $32 \mathrm{~m} /$ minuto en sentido descendente (a favor de corriente) y de $12 \mathrm{~m} / \mathrm{min}$ en sentido ascendente (a contracorriente). Estos desplazamientos rápidos pueden darse en dos situaciones: 1) intercalados con los lentos o los regulares, cuando la distancia recorrida suele ser corta (pocas decenas de metros), o 2) aisladamente, con carácter direccional claro, sin que el animal se detenga a buscar alimento, caso en que la distancia recorrida suele ser larga (del orden de cientos de metros)

Los desplazamientos de velocidad regular son los habituales. El claro predominio de estos movimientos parece indicar que la estrategia habitual de búsqueda de alimento es una exploración rutinaria del dominio vital.

La frecuencia y duración de los desplazamientos lentos es muy variable, en función de los individuos, la jornada y la época del año. Seguramente están condicionados por la disponibilidad de concentraciones de presas en tramos de longitud pequeña. Los movimientos lentos prolongados durante tiempos largos (superiores a 1 hora) son más habituales en primavera que en otoño, pero se han observado en ambas estaciones.

En cuanto a los desplazamientos rápidos, los de corto alcance son frecuentes, pero los de largo alcance (direccionales) se dan más raramente. La causa de estos movimientos direccionales no es nada clara. La mayor parte están asociados a la salida o -sobre todo- al regreso a la madriguera durante la actividad nocturna, pero no siempre es así. Los movimientos direccionales de regreso a la madriguera serían los más fácilmente interpretables, ya que parece lógico que un individuo no se detenga si ya se ha alimentado lo suficiente o quiere evitar entrar en la guarida 
después del alba; la frecuencia de los retornos rápidos es mayor que la de las salidas rápidas, pero es más habitual que regresen con velocidades regulares (de 35 retornos controlados en otoño, sólo el 25,7\% fueron rápidos). Las salidas rápidas de la madriguera por la noche son poco frecuentes (11,8\% para $n=93$ controles) y nunca han sido observadas durante las salidas diurnas. Son los movimientos rápidos más sorprendentes y las causas son desconocidas. Sin embargo podemos pensar que pueden estar relacionadas con la alimentación, concretamente con el recuerdo de un tramo con alimento abundante, que volverían a explotar, ya que en algunos casos se constató que un mismo individuo realizaba salidas rápidas en noches consecutiva y se dirigía hacia el mismo tramo de río, donde una vez llegaba permanecía tiempos largos haciendo movimientos lentos, característicos de la búsqueda de alimento.

\section{Distancias recorridas}

Las distancias totales recorridas por un individuo durante una noche en el río Tor han sido desde $200 \mathrm{~m}$ hasta $2720 \mathrm{~m}$, con una media de 978,7 m ( $\mathrm{n}=61)$. Los datos desglosados por estaciones se muestran en la Tabla 7. Las distancias recorridas reflejan también las diferencias estacionales en el uso del espacio, que tiende a ser claramente más irregular en primavera. Aunque la media de las distancias no es muy diferente entre las dos estaciones (sólo $165 \mathrm{~m}$ menos en primavera que en otoño), la amplitud de los rangos es muy superior en primavera que en otoño, tanto si se consideran los valores absolutos como las medias de cada individuo. En otoño se puede prever, con un margen de error no muy grande, que la distancia que un individuo recorrerá en una noche estará alrededor de los 1000 m. En cambio, la distancia recorrida en una noche primaveral es más difícilmente previsible. Buena parte de las diferencias observadas se podrían explicar por la falta (o extrema rareza) de los descansos nocturnos y por la duración menor de la actividad nocturna en la primavera, pero no todas.

Las distancias recorridas durante el día son mucho menores que durante la noche. Representan aproximadamente un $10 \%$ de las distancias recorridas por la noche. Como ocurre en la noche, durante el otoño es cuando realizan desplazamientos medios más largos, algo que resulta sorprendente si se tiene en cuenta que la duración de la

\begin{tabular}{|c|c|c|}
\hline $\begin{array}{l}\text { Estación } \\
\text { Season }\end{array}$ & $\begin{array}{l}\text { Media }(\mathrm{m}) \\
\operatorname{Mean}(\mathrm{m})\end{array}$ & $\begin{array}{l}\text { Rango (m) } \\
\text { Range (m) }\end{array}$ \\
\hline \multicolumn{3}{|l|}{ Noche Night } \\
\hline $\begin{array}{l}\text { Otoño }(\mathrm{n}=40) \\
\text { Autumn }\end{array}$ & 1035,5 & $600-1670$ \\
\hline $\begin{array}{c}\text { Primavera-verano }(\mathrm{n}=21) \\
\text { Spring-summer }\end{array}$ & 870,5 & $200-2720$ \\
\hline \multicolumn{3}{|l|}{ Día Day } \\
\hline $\begin{array}{l}\text { Otoño }(\mathrm{n}=34) \\
\text { Autumn }\end{array}$ & 126,5 & $10-520$ \\
\hline $\begin{array}{c}\text { Primavera-verano }(\mathrm{n}=41) \\
\text { Spring-summer }\end{array}$ & 77,4 & $10-300$ \\
\hline
\end{tabular}

Tabla 7. - Distancias totales recorridas por un desmán durante la actividad nocturna y diurna.

Table 7. Total distance traveled by a desman during the day and night activity. actividad diurna es claramente mayor en primavera-verano; esta diferencia quizá esté relacionada con una mayor facilidad para encontrar alimento en este último período.

\section{Refugios}

Cuando el desmán no está activo en el río, se refugia en cavidades naturales situadas en la orilla (Fig 7). En estos refugios descansa y se reproduce, y probablemente también desarrolla otras actividades sociales.

Los radioseguimientos en los Pirineos han permitido localizar 33 refugios de desmán. Estos se hallan siempre en la ribera, con la cámara de descanso a $40-120 \mathrm{~cm}$ del agua, resultados básicamente coincidentes con los de Stone (1987a), quien encontró cámaras hasta $100 \mathrm{~cm}$ del agua, mediante excavación. El acceso a la cámara es casi siempre por una galería con acceso directo desde el agua, semisumergida o sumergida, a la que entran por agujeros pequeños (5-20 cm de ancho). Sólo en un caso se detectó un refugio esporádico con acceso situado fuera del agua, pero a corta distancia $(10 \mathrm{~cm})$, en una galería abandonada de Arvicola sapidus. Los refugios se sitúan generalmente bajo grandes bloques rocosos, de diámetro superior a $1 \mathrm{~m}$, aunque también se han localizado bajo acúmulos de rocas más pequeñas e incluso en estructuras artificiales (un muro, una pequeña presa y una minicentral eléctrica).

Uno de los descubrimientos más relevantes de nuestros trabajos es que, en contra de lo que se suponía, los refugios son estructuras compartidas por varios individuos y persistentes. Se ha constatado que los refugios pueden ser utilizados simultáneamente y de forma pacífica por lo menos por dos individuos adultos, con todas las combinaciones posibles de sexos (se han documentado tres casos de macho y hembra, un caso de dos hembras y un caso de dos machos), lo que excluye que el uso compartido esté ligado a una relación de pareja. Aunque no se tengan datos, creemos probable que en algunos casos puedan descansar simultáneamente más de dos individuos en un refugio. Pero es que, además de ser compartidos de modo coetáneo, los refugios también son utilizados por varios individuos en periodos diferentes. En la zona central de nuestros estudios en el río Tor se controlaron 12 refugios durante tres años, y 8 de estos $(66,7 \%)$ se verificó que fueron reutilizados por diferentes individuos en diferentes temporadas. Por lo menos 4 de los refugios fueron utilizados cada año entre 2002 y 2004, y siempre por individuos adultos diferentes (entre 3 y 6 individuos controlados durante este periodo en cada refugio).

Aunque se había dicho que lo normal es que cada individuo de desmán utilice un solo refugio (Stone, 1987a), nuestros trabajos indican lo contrario. Durante los breves periodos de radioseguimiento (entre una y cuatro semanas) el $75 \%$ de los individuos controlados $(n=20)$ usó más de un refugio. El número de refugios por individuo en estos periodos cortos varió entre 1 y 6 (media 2,3). A lo largo de su vida es probable que el número de refugios utilizados por un individuo sea muy superior, ya que el hecho de que unos 


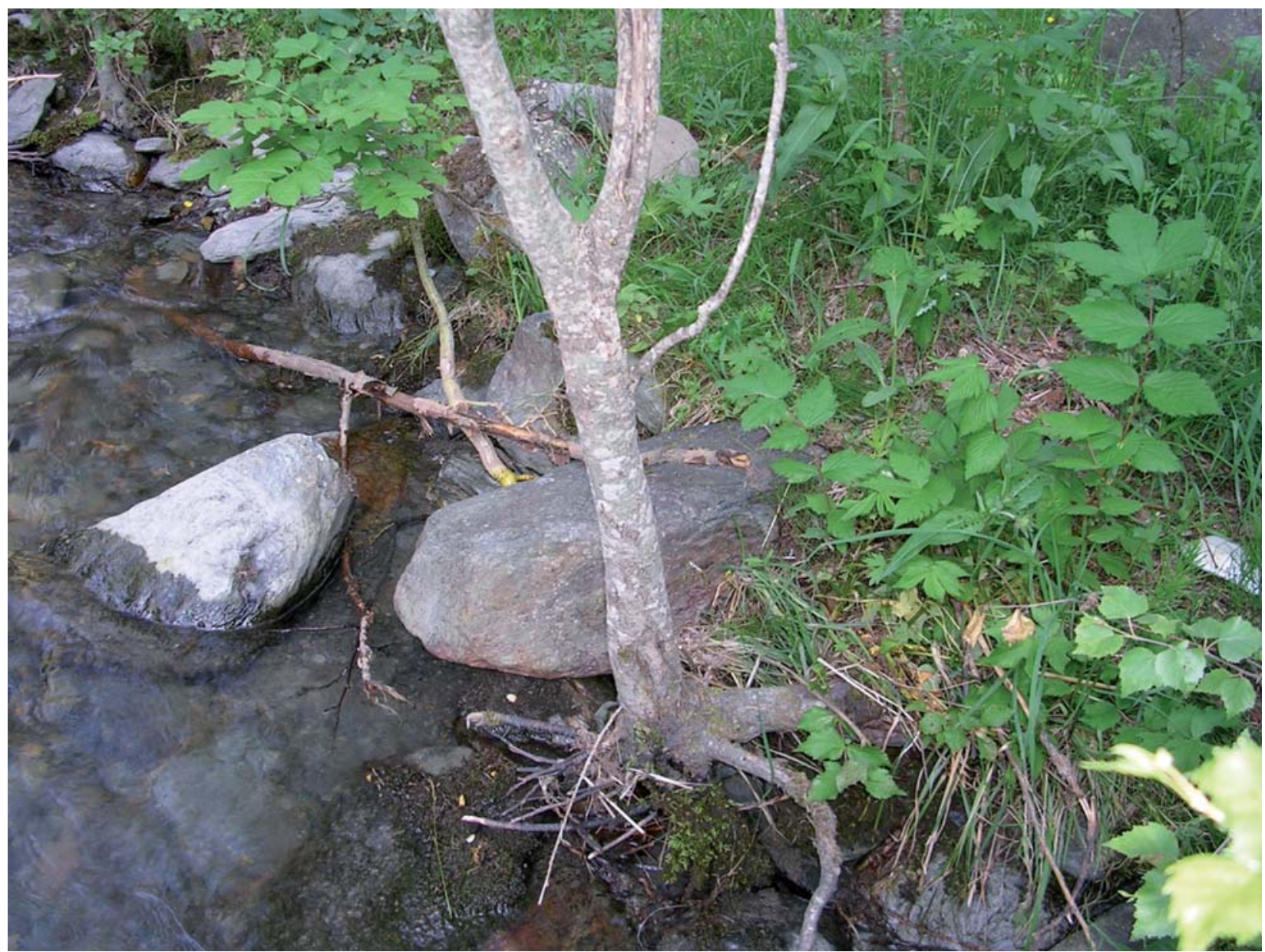

Fig. 7. - Localización de un refugio de desmán bajo la roca tras el árbol. (Autor: Pere Aymerich).

Fig. 7. - Location of an Iberian desman resting site below the rock behind the tree. (Author: Pere Aymerich).

mismos refugios sean usados por diferentes individuos en diferentes años sugiere que los desmanes cambian de zona de residencia temporal, y se puede suponer que en cada tramo de residencia utilizarán diferentes refugios.

Las implicaciones de estos datos sobre el uso de los refugios en el conocimiento del comportamiento y de la organización socioespacial del desmán son muy importantes, y la cuestión se ha desarrollado con más detalle en Melero et al. (2012). Por un lado, el simple hecho de que individuos del mismo sexo puedan compartir simultáneamente refugios invalida por completo el supuesto comportamiento altamente solitario y agresivo de la especie (Richard, 1985) y su supuesta organización socioespacial en parejas territoriales (Stone, 1987a). Por otra parte, el uso de unos mismos refugios por diferentes individuos en diferentes años indica que los refugios serían estructuras permanentes y de uso social, compartidos por los varios individuos que viven en un río. Y además, el recambio frecuente de los individuos que descansan en un refugio sugiere que el desmán no está ligado permanentemente a un determinado tramo de río, sino que cambia frecuentemente de tramo y de refugios. Considerando el uso compartido tanto a corto plazo como a largo plazo, es posible que los refugios puedan tener una función de puntos de encuentro y comunicación para los individuos que forman una población de desmán.

La nueva información sobre los refugios tiene también consecuencias en la gestión de la especie. En general, se ha tendido a considerar que lo fundamental para el desmán eran las condiciones de los cursos de agua, y que la gestión debía centrarse en la calidad de estos. En cambio, casi no se había prestado atención a las condiciones de las riberas, y se había supuesto que los refugios no serían factores limitantes, ya que se trataría de simples cavidades de uso individual. Pero la utilización de los refugios por diferentes individuos sugiere que son un recurso limitado (no sirve como refugio cualquier cavidad) y que muy probablemente tienen un papel clave en la organización socioespacial de las poblaciones de desmán. Si se asume que los refugios son elementos singulares e importantes para las poblaciones de desmán, las perturbaciones en las riberas que los destruyan podrían resultar tan negativas para la conservación de la especie como la alteración de la calidad o la cantidad del agua. En consecuencia, habría que incorporar la conservación de las franjas de ribera a las medidas de gestión del desmán. 


\section{Organización socioespacial}

Los descubrimientos sobre la persistencia y el uso compartido de los refugios nos obligaron a revisar a fondo toda la información publicada hasta la fecha sobre la organización socioespacial del desmán, derivada de los trabajos de Richard (1985) y Stone (1985, 1987a), y que establecía que se trata de un animal territorial, con gran agresividad intraespecífica y que se organiza en parejas que poseen tramos de río de uso exclusivo. Este modelo ha sido asumido como referencia cierta hasta ahora y también nosotros lo utilizamos como punto de partida al iniciar los trabajos de seguimiento. Sin embargo, los datos sobre el uso de refugios y otros indicios observados (cambios de dominio, uso simultáneo de un tramo por más de dos individuos, tasas de recaptura, fluctuaciones en el número de individuos presentes en un tramo, etc) entraban en clara contradicción con este modelo territorial, lo que nos ha llevado a replantear su validez.

En la actualidad disponemos de datos que demuestran que el modelo de organización socioespacial establecido por Stone (1987a) y considerado la referencia básica no es válido: el desmán no es una especie que se estructura en el espacio en parejas territoriales con dominios exclusivos. Esto se puede afirmar con la información actual, pero los datos son aún insuficientes para ofrecer un modelo alternativo suficientemente sólido. La información fragmentaria que invalida la territorialidad y sugiere un modelo de organización diferente se desarrolla en un artículo específico en curso de elaboración, por lo que no se expone detalladamente en el presente trabajo sintético y aquí nos limitamos a apuntar la hipótesis socioespacial alternativa.

La hipótesis en la que trabajamos desde hace unos años es que el desmán es una especie no territorial, y que los individuos de una población comparten tramos de río extensos que usan con diferente intensidad en diferentes periodos. Según esta hipótesis, los individuos de desmán se desplazarían a lo largo de un río y se establecerían temporalmente en unos determinados tramos. Durante estos establecimientos temporales usarían los refugios persistentes y comunitarios disponibles en ese tramo, y se alimentarían en dominios vitales más o menos constantes (que en los Pirineos meridionales tienen longitudes típicas de alrededor de $500 \mathrm{~m}$ ). La persistencia de un individuo en un determinado tramo podría prolongarse desde unos pocos días hasta varios meses, en función de factores aún poco conocidos, pero seguramente ligados a la disponibilidad de alimento y a la actividad reproductora. Pero no se trataría de territorios permanentes utilizados por un individuo durante toda su vida, ya que nunca se ha constatado su permanencia durante períodos de más de medio año y, en cambio, sí hay alguna evidencia de cambio de dominio vital en años consecutivos, hasta distancias de 1,5 $\mathrm{km}$. Según este modelo hipotético, tanto un río como los refugios distribuidos a lo largo de sus riberas serían de uso compartido por un número indeterminado de desmanes (probablemente varias decenas), que tendrían una relación mutua de alta tolerancia o quizá claramente sociable.

Se trataría de una organización socioespacial que se podría calificar de comunal y fluida. Este modelo es anta- gónico con el modelo territorial vigente hasta ahora y en cambio es muy similar al que se supone para el desmán ruso, una especie que siempre se ha considerado que no tiene territorios fijos, es de tendencia nómada y tiene un comportamiento muy sociable. De hecho, no debería suponer una gran sorpresa esta similitud en la organización socioespacial con la especie filogenéticamente más próxima al desmán, sino que lo sorprendente sería lo contrario, es decir que dos especies próximas tuvieran comportamientos sociales tan diferentes. En el desmán ruso el comportamiento sociable y no territorial se ha relacionado con el hecho de ocupar un hábitat con grandes fluctuaciones espaciales, las llanuras de inundación de grandes ríos. En el desmán la extensión del hábitat potencial es más o menos constante, pero no lo es la disponibilidad de alimento, ya que las poblaciones de macroinvertebrados acuáticos suelen experimentar fluctuaciones importantes, por lo que el hábitat sería también inestable, y esto explicaría que evolutivamente tenga ventajas adaptativas una organización socioespacial no territorial.

\section{CONCLUSIONES Y PERSPECTIVAS}

Después de una década de realizar trabajos diversos relacionados con el desmán y de evaluar la información existente, consideramos que el conocimiento de esta especie es aún insuficiente. Este déficit de conocimientos es atribuible en gran parte a la dificultad que comporta su estudio en condiciones naturales, lo que hace del desmán un material poco rentable para los proyectos de investigación. También ha influido mucho el hecho de que el patrón de actividad, el uso del espacio y la organización social se dieran por bien conocidos tras los trabajos de Stone (1985, 1987a), por lo que en los últimos veinte años la mayor parte de proyectos sobre el desmán se han centrado en aspectos relacionados con la conservación. Pero, como se ha ido comentado en apartados precedentes, nuestros resultados indican que muchas conclusiones de estos trabajos fueron precipitadas y excesivamente simplistas, de modo que con los datos actuales se muestran como erróneas o muy parciales. Ahora sabemos que el comportamiento del desmán en libertad es bastante más complejo de lo que se había supuesto durante mucho tiempo, y esto requiere mejorar la información disponible sobre varios aspectos y revisar críticamente lo que se ha publicado.

Siendo el desmán una especie que se considera de alto interés conservacionista, es lógico que sean prioritarios los trabajos con aplicaciones claras en la gestión de la especie. A modo de conclusión, en los puntos siguientes exponemos los aspectos que presentan déficits de conocimiento importantes y en los cuales, en nuestra opinión, habría que centrar los esfuerzos en los próximos años, con el objetivo final de disponer de una información sólida para gestionar correctamente esta especie.

\section{Distribución}

Existen todavía lagunas muy importantes en el conocimiento de la distribución del desmán, que afectan a la 
mayor parte de su área, y en particular a la distribución a escala media (presencia-ausencia en subcuencas). Este déficit de información corológica es atribuible al esfuerzo insuficiente que se ha aplicado en muchas zonas, pero también al uso frecuente de métodos con bajo rendimiento. Los trabajos realizados en el último cuarto de siglo muestran de forma clara que el método más eficiente para conocer la distribución del desmán a escala media es la prospección de excrementos. Para que sea eficaz es necesario que los equipos de prospección tengan formación y experiencia. Además es conveniente validar por lo menos una parte de las determinaciones visuales con análisis de pelos o con análisis genéticos. También es viable establecer la distribución a media escala sin análisis posteriores, dando como válidos sólo aquellos excrementos que morfológicamente no ofrezcan dudas, pero esto puede representar desestimar hasta un 50\% de las muestras obtenidas y probablemente obligaría a recorrer tramos fluviales más largos, con lo que aumenta el tiempo destinado a trabajo de campo.

La distribución actual a gran escala -de cuencas fluviales enteras o de grandes subcuencas- parece que está condicionada sobre todo por causas biogeográficas (existencia de barreras naturales que impiden la colonización por el desmán) y por causas antrópicas (aparentes extinciones regionales en algunas cuencas, aunque la información sobre este aspecto es algunas veces débil). Además, en algunos casos también podrían actuar factores limitantes ambientales que hacen que algunas cuencas sean inadecuadas para sostener poblaciones de desmán viables a largo plazo (red fluvial poco extensa, régimen torrencial de los cursos de agua,...). En cualquier caso, hay que tener en cuenta los factores naturales para explicar algunas ausencias a gran escala del desmán.

En la distribución a escala media y pequeña -subcuencas medias, ríos y tramos de río- también inciden factores naturales y antrópicos, y además es probable que influya bastante la dinámica propia de las poblaciones de desmán. Sin considerar las regresiones o extinciones por causas antrópicas, la distribución del desmán parece que se puede explicar por tres factores principales: disponibilidad de alimento (macroinvertebrados acuáticos), accesibilidad del alimento (limitada especialmente por la profundidad del agua en cursos medianos y grandes, y por el hielo en cursos pequeños) y disponibilidad de refugios adecuados en la ribera. Estos tres factores se presentan de modo irregular en una red fluvial, con variaciones espaciales y temporales que con toda probabilidad afectan a la presencia del desmán. Hay que dejar de lado la visión de que, si no han actuado factores antrópicos negativos, la distribución del desmán sería casi continua en los cursos fluviales con tipologías aparentemente adecuadas de su área de distribución. Existen evidencias de que la distribución es discontinua en el espacio de forma natural, de modo que no está presente en todos los cursos fluviales o tramos que desde una perspectiva humana pueden parecer buenos o incluso óptimos. $Y$ hay también fuertes indicios de que la distribución es discontinua temporalmente, con zonas de presencia permanente, de presencia no constante pero recurrente (periódica o irregular) y de presencia sólo esporádica o accidental. En resumen, la información obtenida con nuestros trabajos sugiere que hay que pasar de un modelo de distribución fijo o estático a un modelo dinámico. Este cambio conceptual no resulta nada trivial, ya que incide de forma importante en muchos aspectos referidos a la conservación de la especie: con el modelo estático -hasta hoy dominante- cualquier cambio en la presencia local solía atribuirse automáticamente a regresiones, mientras que con el modelo dinámico se plantean varias interpretaciones alternativas.

Aunque creemos que el modelo de distribución dinámica es aplicable básicamente a la presencia a lo largo de un curso fluvial, no se puede excluir que en algunas pequeñas subcuencas -en especial en las periféricas- situadas dentro del área habitual del desmán se den procesos de colonizaciones, extinciones y recolonizaciones. Es más improbable, pero no imposible, que estos procesos se den a escala de cuencas o grandes subcuencas (como por ejemplo en algunos ríos del Pirineo aragonés).

\section{Organización social}

Nuestros resultados evidencian que no es válido el modelo de organización social basado en parejas territoriales establecidas en tramos exclusivos de río, que generalmente ha sido aceptado como referencia desde los trabajos de Stone (1987a). Disponemos de una cantidad considerable de datos que sugieren que se trata de una especie no territorial, más o menos sociable (esta sociabilidad incluye el uso compartido de los refugios) y con dominios vitales (áreas de campeo) individuales cambiantes. Sin embargo, la información sobre este aspecto es aún fragmentaria y no permite establecer con firmeza un nuevo modelo de organización social.

Nos encontramos, pues, en una situación de transición en que no se dispone de un modelo de referencia sobre la organización socioespacial de la especie, ya que el modelo vigente desde los años 1980 se ha demostado que no sirve, pero todavía no se ha podido definir satisfactoriamente un modelo alternativo. Esta incertidumbre condiciona los estudios sobre muchos otros aspectos de la biología del desmán y su gestión, por lo que una de nuestras prioridades actuales es obtener datos que permitan contrastar con alta fiabilidad la validez de la hipótesis alternativa que hemos formulado.

\section{Demografía}

No se conoce casi nada sobre la dinámica de las poblaciones de desmán. Este es, sin duda, uno de los campos en los que es necesario realizar más trabajos, pero la obtención de datos fiables resulta muy complicada a causa del gran esfuerzo que requiere la captura de individuos y de la complejidad de la interpretación de los datos. Desde el año 2004 estamos realizando campañas periódicas de captura y recaptura para intentar mejorar la información poblacional, pero por el momento tan sólo se dispone de datos parciales. 
Gran parte de las dificultades para estudiar la dinámica poblacional del desmán deriva de los nuevos conocimientos sobre la variabilidad en su distribución local y sobre su organización social, comentados en los párrafos anteriores, que introducen una gran incertidumbre en la interpretación de los datos obtenidos mediante muestreos puntuales. Con el modelo de organización social territorial derivado de los trabajos de Stone (1987a) se infería una distribución más o menos regular a lo largo de los ríos, por lo que se podía asumir que los datos poblacionales obtenidos en unos pocos tramos eran extrapolables, lo que permitía teóricamente estimaciones de densidades-tipo como las publicadas en Nores et al., (1998). Pero con los nuevos datos sobre la organización socioespacial de la especie estas estimaciones -y todas las obtenidas con trampeos puntuales- serían bastante anecdóticas, ya que tan sólo reflejarían las densidades en unos tramos fluviales y unas fechas concretas.

Los problemas que plantean los estudios poblacionales hacen que no se disponga de información adecuada sobre dos aspectos básicos para la gestión del desmán: 1) No existe por ahora ningún método fiable para estimar la población existente en un determinado río o cuenca. 2) Se desconoce cuál es la talla mínima de una población viable a medio plazo. Por el momento tan sólo se pueden realizar aproximaciones especulativas y limitadas a un determinado contexto ambiental. Por ejemplo, en nuestro caso, las campañas recurrentes de captura en el río Tor sugieren que en los "hábitats típicos" (si es que existen) de desmán en los Pirineos meridionales las densidades medias serían de sólo unos 2 individuos $/ \mathrm{km}$, que es bastante menos de lo que se había supuesto a partir de muestreos puntuales y de extrapolaciones derivadas de la extensión del dominio vital individual obtenido mediante radioseguimiento. Esto no excluye que en determinados momentos las densidades locales puedan subir hasta 5-6 individuos $/ \mathrm{km}$, pero tampoco que lleguen hasta 0 individuos $/ \mathrm{km}$ en tramos fluviales que habían sido considerados de presencia habitual en base a muestreos para establecer la distribución. Si se asume que estas densidades medias son extrapolables a cursos fluviales similares, podría haber poblaciones aparentemente viables con unos 50 individuos, ya que se conocen poblaciones persistentes que están aisladas o semiaisladas en subcuencas con unos $20 \mathrm{~km}$ de hábitat potencial.

Además, hay que considerar la posibilidad de que a escala de cuenca el desmán presente una dinámica metapoblacional, lo que dificultaría aún más la interpretación de las variaciones que se observen. En base a la información fragmentaria proporcionada por los datos de distribución, parece que lo más probable es que se trate de metapoblaciones de modelo irregular o parcheado, constituidas por un conjunto de poblaciones locales establecidas en sectores fluviales adecuados y parcialmente interconectadas gracias a desplazamientos de individuos a lo largo de sectores sin poblaciones permanentes. Sin embargo, tampoco se puede excluir que siga un modelo de población central y poblaciones satélites, siendo estas últimas más inestables. O también se podrían combinar los dos modelos a distinto nivel, con una metapoblación parcheada extensa en las zonas centrales del área de distribución en una determinada cuenca y poblaciones satélites en las zonas marginales.

\section{Genética de poblaciones}

La información genética sobre el desmán era casi nula hasta la reciente publicación de lgea et al. (2013), que ha supuesto un gran avance en el conocimiento de la estructuración de la diversidad genética a gran escala y de la filogenia. Sin embargo, este trabajo plantea nuevos interrogantes que deberían ser resueltos, en particular determinar cual es el grado de separación funcional entre los dos grandes clados genéticos (que aparentemente casi no se mezclan) y aclarar la relación entre estos dos grandes clados y las dos subespecies descritas morfológicamente para el desmán (subsp. pyrenaicus y subsp. rufulus). Aparte, queda mucho por hacer en relación con el estudio de datos genéticos a escala media o intrapoblacional, algo que probablemente mejorará cuando finalicen trabajos que actualmente se realizan en el marco del Plan de Acción francés para el desmán.

Conservación: evaluación del estatus y adopción de medidas

La singularidad y la rareza del desmán han motivado una preocupación justificada por su conservación, lo que ha conducido a su inclusión en listas de especies amenazadas y a su protección legal, así como al desarrollo de varios proyectos y actuaciones que tienen como principal objetivo preservar al desmán. Sin embargo, la información necesaria para su gestión es manifiestamente deficiente, por lo que en bastantes casos las decisiones adoptadas han sido demasiado intuitivas.

El déficit de información condiciona algo tan básico como la evaluación fiable de su estado de conservación. Los criterios internacionales vigentes para evaluar el estado de conservación de una especie (UICN 2001) se fundamentan en los datos sobre su regresión o sobre el tamaño poblacional. En el caso del desmán, como se ha indicado, los datos poblacionales son casi nulos, por lo que la evaluación debe sustentarse de modo exclusivo en la regresión del área de distribución. Pero la estimación fiable de las regresiones resulta muy difícil o imposible en muchos sectores, por la fragilidad de los datos corológicos sobre la especie, tanto actuales como históricos. Bastantes de los datos históricos sobre distribución pueden ser erróneos, debidos a confusiones con otras especies (en particular Neomys sp.), razón por la cual la regresión aparente en algunas zonas sería falsa. Incluso cuando los datos son seguros puede ser difícil confirmar que esa zona formaba parte del área de distribución histórica del desmán, ya que podría tratarse de sectores donde su presencia sólo es accidental; esto hay que tenerlo en cuenta sobre todo cuando se trata de citas muy aisladas de animales muertos, que podrían corresponder a individuos transportados a muchos quilómetros de sus zonas de origen por avenidas. 
En la práctica la regresión del desmán sólo se puede asegurar cuando se dispone de datos completamente seguros de presencia histórica en una cuenca fluvial y se han realizado prospecciones recientes intensivas con resultados negativos, dos condiciones que casi nunca coinciden. En el ámbito pirenaico -en el cual hemos centrado nuestros trabajos- y siguiendo este criterio, no se ha podido constatar ningún caso de extinción a escala de cuenca o subcuenca. Al contrario, las prospecciones realizadas en la última década han permitido ampliar notablemente el área de distribución confirmada de la especie. En otras zonas que sólo conocemos parcialmente se han indicado regresiones muy importantes (Sistemas Ibérico y Cantábrico) e incluso extinciones totales (en cuencas del Sistema Central), que no se pueden excluir, pero nuestra impresión es que en algunos casos las prospecciones realizadas son insuficientes y que en otros la regresión se ha sobreestimado porque en la distribución de referencia se habían considerado datos erróneos. A causa del déficit de información histórica, tal vez se deba asumir que no conoceremos nunca con seguridad la regresión experimentada por la especie en el siglo XX. Pero es inexcusable que a principios del siglo XXI no se conozca con fiabilidad la distribución actual del desmán en la mayor parte de su área, por lo que el estudio de esta cuestión debería ser la prioridad en las políticas de conservación de la especie.

Cuando se conozca con suficiente precisión la distribución regional del desmán -algo que por ahora sólo ocurre en una parte minoritaria de su área global- el siguiente paso debería ser la adopción de medidas que garanticen la preservación de las poblaciones existentes. Pero el diseño de estas medidas también está limitado por la información insuficiente sobre aspectos básicos de la demografía, la organización social y el uso del espacio. Aparentemente, los modelos derivados de los trabajos de Stone $(1985,1987 a)$ permitían una gestión bastante sencilla basada en la conservación de determinados tramos fluviales con presencia de la especie, pero los datos obtenidos con nuestros trabajos invalidan estos modelos y complican notablemente la gestión. Los datos actuales sugieren que las poblaciones de desmán tienen dinámicas complejas (probablemente metapoblacionales), que habitualmente tienen densidades inferiores a las previstas, que para ser viables requieren redes fluviales bastante extensas y que no están condicionadas únicamente por las características del hábitat acuático. Aunque la información actual aún sea fragmentaria, este escenario hace recomendable que la conservación del desmán se base en la gestión integral de subcuencas fluviales (ríos de tamaño medio con sus afluentes).

Preventivamente se pueden adoptar medidas de conservación de tipo genérico para preservar una cierta calidad del agua y de los hábitats de ribera. Pero sería erróneo suponer que la conservación del desmán se garantiza usando como referencia los indicadores y técnicas habituales para la gestión de los hábitats fluviales. Unos niveles de calidad considerados buenos para las poblaciones de invertebrados, de peces o del bosque de ribera pueden resultar insuficientes para el desmán, ya que sus necesida- des de recursos son más altas y la capacidad de recuperación de sus poblaciones mucho menor. En este aspecto, el desmán es un excelente indicador de la calidad del conjunto del hábitat fluvial (curso de agua más riberas), ya que su persistencia sólo parece posible si no se han producido perturbaciones importantes durante periodos prolongados.

A medio plazo es deseable que las medidas concretas que se apliquen en cada unidad de gestión del desmán (subcuenca o río) tengan una base científica, para lo que resulta imprescindible realizar estudios sobre los aspectos menos conocidos de la biología de la especie y sobre los factores de riesgo que afectan a las poblaciones. Queda, pues, mucho trabajo pendiente para afrontar con garantías la conservación del desmán.

\section{AGRADECIMIENTOS}

Los diversos trabajos realizados durante estos años han sido financiados con fondos del Departament de Medi Ambient de la Generalitat de Catalunya (Servei de Fauna i Flora, Parc Natural de l'Alt Pirineu), del Departamento de Medio Ambiente del Gobierno de Aragón, del Ministeri de Medi Ambient de Andorra y del Ministerio de Ciencia y Tecnología de España. Expresamos nuestro agradecimiento a todas las personas que en algún momento han participado en el trabajo de campo, y de modo especial a Sisco Mañas, Yolanda Melero, Cesca Casadesús, Jose Castresana y Javier Igea.

\section{BIBLIOGRAFÍA}

Aguirre-Mendi, P. 2004. Distribución y estado de conservación del desmán ibérico (Galemys pyrenaicus) en la comunidad autónoma de La Rioja. Zubía 22: 55-85.

Arribas, O. 2004. Fauna y paisaje de los Pirineos en la era glaciar. Lynx Edicions. Barcelona

Aymerich, P. 2004. Els micromamífers semiaquàtics d'Andorra: distribució i estat de conservació. Hàbitats 9: 26-34

Aymerich, P. Casadesús, F., Pachés, O. Gosálbez, J. 2000. L'almesquera (Galemys pyrenaicus) a Catalunya. Distribució i caracterització de l'hàbitat. Departament de Medi Ambient, Generalitat de Catalunya. Informe inédito.

Aymerich, P., Casadesús, F., Gosálbez, J. 2001. Distribució de Galemys pyrenaicus (Insectivora, Talpidae) a Catalunya. Orsis 16: $47-70$.

Aymerich, P., Gosálbez, J. 2002. Factors de distribució de Galemys pyrenaicus (Insectivora, Talpidae) a Catalunya. Orsis 17 21-36

Aymerich, P., Gosálbez, J. 2004a. Distribución y hábitat del desmán ibérico (Galemys pyrenaicus) y de las musarañas acuáticas (Neomys sp.) en el Pirineo aragonés y en el Moncayo. Departamento de Medio Ambiente, Gobierno de Aragón. Informe inédito.

Aymerich, P., Gosálbez, J. 2004b. La prospección de excrementos como metodología para el estudio de la distribución de los musgaños (Neomys sp.). Galemys 16(2): 83-90.

Aymerich, P., Gosálbez, J. 2004c. Guía de indicios de los mamíferos: musgaño común (Neomys fodiens), musgaño de Cabrera (Neomys anomalus). Galemys 16(2): 79-82. 
Aymerich, P., Gosálbez, J. 2009. El desmán ibérico en los Pirineos. Quercus 279: 24-30.

Bertrand, A. 1986. Le Desman, Galemys pyrenaicus. Distribution dans les Pyrénées françaises, 1e. Ariège et Haute-Garonne. Ministère de l'Environnement, Direction de la Protection de la Nature. Informe inédito.

Bertrand, A. 1993. Répartition géographique du Desman des Pyrénées Galemys pyrenaicus dans les Pyrénées françaises. Proceedings of the Meeting on the Pyrenean Desman. Lisboa. Sept. 1992

Bertrand, A. 1994. Répartition géographique et ecologie alimentaire du desman des Pyrénées Galemys pyrenaicus (Geoffroy, 1881) dans les Pyrénées françaises. Thèse diplôme universitaire. Université Paul Sabatier. Toulouse.

Cabrera, A. 1914. Fauna Ibérica: Mamíferos. Museo Nacional de Ciencias Naturales. Madrid.

Castién, E., Gosálbez, J. 1992. Distribución geográfica y hábitats ocupados por Galemys pyrenaicus (Geoffroy, 1811) (Insectivora, Talpidae) en los Pirineos occidentales. Doñana Acta Vertebrata 19 (1-2): 37-44

Castién, E., Gosálbez, J. 1995. Diet of Galemys pyrenaicus (Geoffroy, 1811) in the north of the Iberian Peninsula. Netherlands J. Zool. (3-4): 422-430

García, P., Mateos, I. 2007. Comportamiento cavernícola del desmán ibérico (Galemys pyrenaicus) en la montaña palentina. Galemys 19(1): 41-44.

Gautron, R. 1989. A propósito de una nueva cita de desmán pirenaico en el Altoaragón: nota mastozoológica. Lucas Mallada, 1: 189-193.

González-Esteban, J., Castién, E., Gosálbez, J. 1999. Morphological and colour variation in the Pyrenan desman Galemys pyrenaicus (Geoffroy, 1811). Z. Säugetierkd. 64 (1): 1-11.

González-Esteban, J., Villate, I., Castién, E., Rey, I., Gosálbez J. 2002. Age determination of Galemys pyrenaicus. Acta Theriologica $47(1)$ : 107-112

González-Esteban, J., Villate, I., Castién, E. 2003. A comparison of methodologies used in the detection of the Pyrenean desman Galemys pyrenaicus (E. Geoffroy, 1811). Mamm. Biol. 68: 387-390.

Gosálbez, J. 1987. Insectívors i rosegadors de Catalunya. Metodologia d'estudi i catàleg faunístic. Ketres Ed. Barcelona.

Igea, J., Aymerich, P., Fernández, A., González, J., Gómez, A. Alonso, R., Gosàlbez, J., Castresana, J. 2013. Phylogeography and postglacial expansion of the endangered semi-aquatic mammal Galemys pyrenaicus. BMC Evol. Biol. 13: 115.

Ivlev, V.S. 1961. Experimental ecology of the feeding of fishes. Yale University Press. New Haven, Connecticut.

Mason, C.F., Mc Donald, M. 1987 The use of spraints for surveying Otter Lutra lutra populations: an evaluation. Biol. Conserv. 41: 167-177.

Macdonald, D.W., Strachan, R. 1999. The mink and the watervole: analyses for conservation. Widlife Conservation Unit and Environment Agency. Oxford.

Macdonald, D.W., Sidorovich, V.E., Anisomowa, E.I., Sidorovich, N.V., Johnson, P.J. 2002. The impact of American mink Mustela vison and European mink Mustela lutreola on water voles Arvicola terrestris in Belarus. Ecography 25(3): 295-302.

Marsol, L., Castells, X. 1989. Observacions zoològiques a les valls d'Àneu. Collegats 3: 53-57.

Melero, Y., Aymerich, P., Luque, J.J., Gosàlbez, J. 2012. New insigths into social and space use of the endangered Pyrenean desman (Galemys pyrenaicus). Eur. J. Wildl. Res. 58: 185-193.
Morueta-Holme, N., Flojgaard, C., Svenning, J.C. 2010. Climate change risks and conservation implications for a threatened small-range mammal species. PloS ONE 5(4): 1-12.

Nores, C. 2007. Desmán ibérico (Galemys pyrenaicus). En: Atlas y Libro Rojo de los mamíferos terrestres de España. L.J. Palomo (Ed.): 92-98. SECEM-Ministerio de Medio Ambiente. Madrid.

Nores, C., García-Álvarez, E. 1995. Valoración del hábitat de Galemys pyrenaicus en España. Seminar on the biology and conservation of european desmans and water shrews (Galemys pyrenaicus, Desmana moschata, Neomys spp). Council of Europe T-PVS (95) 32: 58-62.

Nores, C., Ojeda, F., Ruano, A., Villate, I., González, J., Cano, J.M., García, H.E. 1992. Aproximación a la metodología y estudio del área de distribución, estatus de población y selección de hábitat del Desmán (Galemys pyrenaicus) en la Península Ibérica. Universidad de Oviedo. Informe inédito.

Nores, C., Ojeda, F., Ruano, A., Villate, I., González, J., Cano J.M., García, H.E. 1998. Estimating the population density of Galemys pyrenaicus in four Spanish rivers. J. Zool. London 246 454-457

Nores, C., Ruano, A., Ojeda, F., Villate, I., García, H.E., Cano J.M., González, J. 1993. Pyrenean Desman survey of Spain: firs results. Proceedings of the Meeting on the Pyrenean Desman. Lisboa. Sept. 1992

Peyre, A. 1956. Ecologie et biogéographie du Desman (Galemys pyrenaicus) dans les Pyrénées françaises. Mammalia 20: 405-418.

Peyre, A. 1961. Recherches sur l'intersexualité spécifique chez Galemys pyrenaicus. Thèse. Université de Toulousse. Toulouse.

Poduschka, W., Richard, B. 1985. Hair types in the fur of the Pyrenean desman (Galemys pyrenaicus), Geoffroy, 1811 (Insectivora: Talpidae: Desmaninae). Sitzungsberichte. Akad. Wiss. Wien 194: 39-44.

Quaresma, C.M. 1995. Habitat use by the Desman, Galemys pyrenaicus, in Montesinho Natural Park (NE Portugal). Seminar on the biology and conservation of european desmans and water shrews (Galemys pyrenaicus, Desmana moschata, Neomys spp.). Ordesa, Espagne. 7-11 June 1995. T-PVS (95) 32 Conseil de l'Europe.

Queiroz, B. 1985. Le desman des Pyrénées, un mammifère inconnu à découvrir. Ed. Le Rocher. Mónaco.

Queiroz, A.I., Alves, M.H., Almada V. 1993. The small hydroplants: predicted impacts on the Pyrenean desman populations. Proceedings of the meeting on the Pyrenean Desman. Lisboa. 28 September-1 October 1992

Queiroz, A.l., Bertrand, A., Khakhin, G. 1996. Status and conservation of Desmaninae in Europe. Nature and Environement 76. Council of Europe.

Queiroz, A.I., Quaresma, C.M., Santos, C.P., Barbosa, A.J., Carvalho, H.M. 1998. Bases para a Conservaçao da Toupeira-deÁgua, Galemys pyrenaicus. Estudos Biol. Conservaçao Nat. 27 116-118

Richard, B. 1976. Extension en France du Desman des Pyrénées (Galemys pyrenaicus) et son environnement. Bull. d'Ecologie 7: 327-334.

Santamarina, J. 1993. Trophic resources of Galemys pyrenaicus (Geoffroy, 1811) in relation with water quality. Proceedings of the Meeting on the Pyrenean Desman. Lisboa. sept. 1992: 27-32.

Stone, R. D. 1985. Home range movements of the Pyrenean Desman (Galemys pyrenaicus) (Insectivora, Talpidae). Angew. Zool. 1-2: 25-36. 
Stone, R. D. 1987a. The social ecology of the pyrenean desman (Galemys pyrenaicus) as revealed by radiotelemetry. J. Zool. London 212: 117-129.

Stone, R. D. 1987b. The activity pattern of the Pyrenean Desman (Galemys pyrenaicus) (Insectivora, Talpidae), as determined under natural condition. J. Zool. London 213: 95-106.

Trutat, M. E. 1891. Essai sur l'histoire naturelle du Desman des Pyrénées. Imprimerie. Douladoure. Toulouse.

UICN 2001. IUCN Red List Categories and Criteria: Version 3.1. IUCN Species Survival Comission. Gland-Cambridge. 